\title{
Maintenance Approaches and Practices in Selected Foreign Nuclear Power Programs and Other U.S. Industries: Review and Lessons Learned
}

Final Report

Manuscript Completed: January 1990

Date Published: April 1990

M. Dey, NRC Project Manager

Division of Regulatory Applications Office of Nuclear Regulatory Research U.S. Nuclear Regulatory Commission Washington, DC 20555

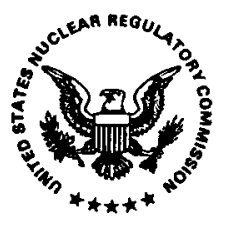




\section{DISCLAIMER}

This report was prepared as an account of work sponsored by an agency of the United States Government. Neither the United States Government nor any agency Thereof, nor any of their employees, makes any warranty, express or implied, or assumes any legal liability or responsibility for the accuracy, completeness, or usefulness of any information, apparatus, product, or process disclosed, or represents that its use would not infringe privately owned rights. Reference herein to any specific commercial product, process, or service by trade name, trademark, manufacturer, or otherwise does not necessarily constitute or imply its endorsement, recommendation, or favoring by the United States Government or any agency thereof. The views and opinions of authors expressed herein do not necessarily state or reflect those of the United States Government or any agency thereof. 


\section{DISCLAIMER}

Portions of this document may be illegible in electronic image products. Images are produced from the best available original document. 



\begin{abstract}
The Commission published a Notice of Proposed Rulemaking on Maintenance of Nuclear Power Plants on November 28, 1988, spelling out NRC's expectations in maintenance. In preparing the proposed rule, the NRC reviewed maintenance practices in other countries and considered maintenance approaches in other industries in
\end{abstract}

ABSTRACT

this country. As a result of the review of maintenance practices, it was concluded that certain practices in the following areas have been found to contribute significantly to effective maintenance: (1) systems approach; (2) effectiveness monitoring; (3) technician qualifications and motivation; and (4) maintenance organization. 



\section{CONTENTS}

Page

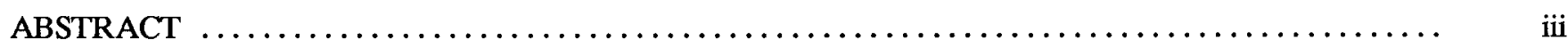

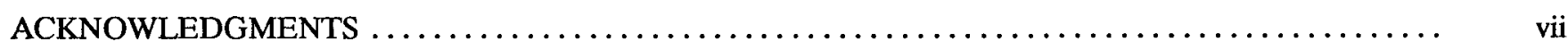

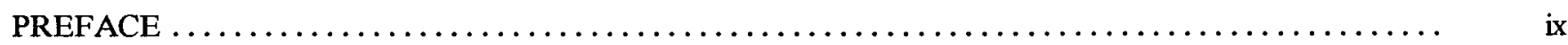

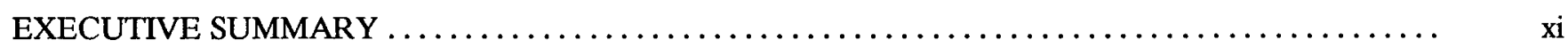

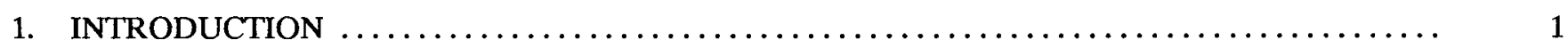

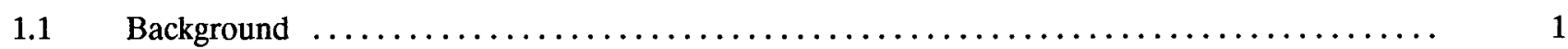

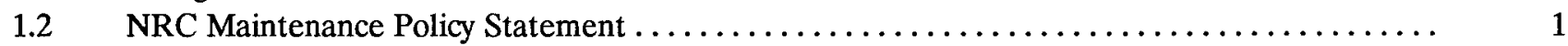

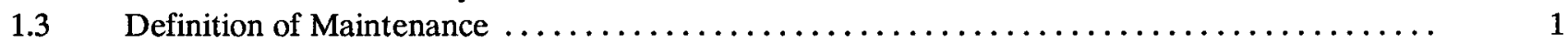

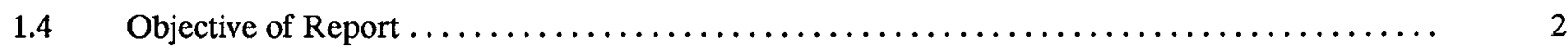

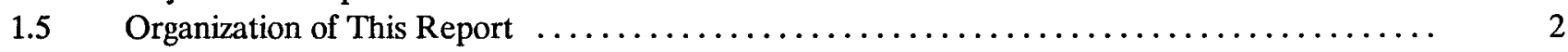

2. JAPANESE COMMERCIAL NUCLEAR INDUSTRY $\ldots \ldots \ldots \ldots \ldots \ldots \ldots \ldots \ldots \ldots \ldots \ldots \ldots$

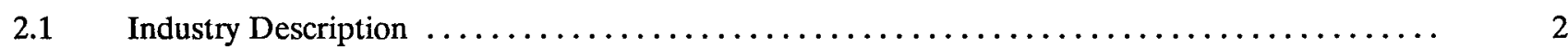

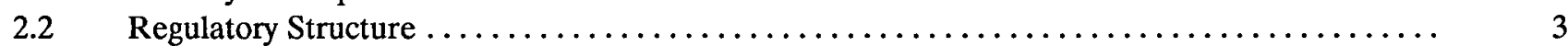

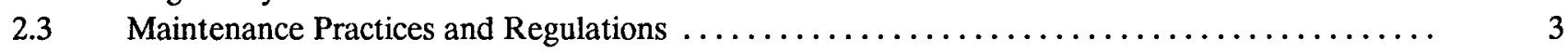

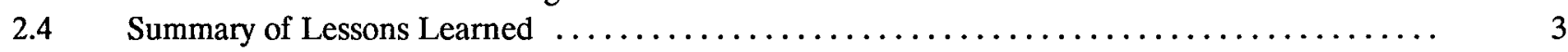

3. EUROPEAN COMMERCIAL NUCLEAR INDUSTRY $\ldots \ldots \ldots \ldots \ldots \ldots \ldots \ldots \ldots \ldots \ldots \ldots \ldots$

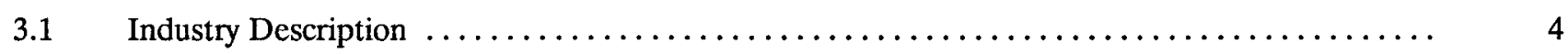

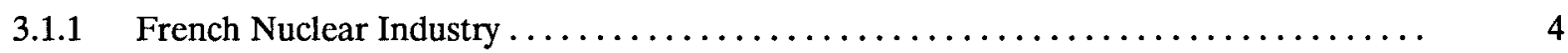

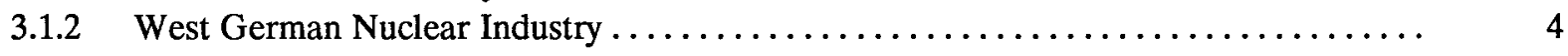

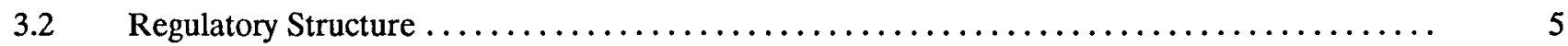

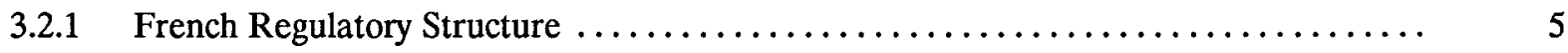

3.2.2 West German Regulatory Structure $\ldots \ldots \ldots \ldots \ldots \ldots \ldots \ldots \ldots \ldots \ldots \ldots \ldots \ldots \ldots \ldots \ldots \ldots \ldots$

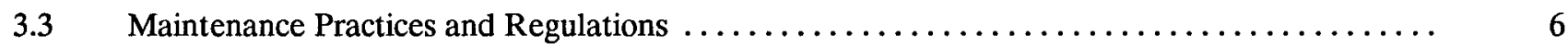

3.3.1 French Maintenance Practices and Regulations $\ldots \ldots \ldots \ldots \ldots \ldots \ldots \ldots \ldots \ldots \ldots$

3.3.2 West German Maintenance Practices and Regulations $\ldots \ldots \ldots \ldots \ldots \ldots \ldots \ldots \ldots \quad 8$

$3.4 \quad$ Summary of Lessons Learned $\ldots \ldots \ldots \ldots \ldots \ldots \ldots \ldots \ldots \ldots \ldots \ldots \ldots \ldots \ldots \ldots \ldots \ldots \ldots \ldots$

4. U.S. COMMERCIAL AVIATION INDUSTRY $\ldots \ldots \ldots \ldots \ldots \ldots \ldots \ldots \ldots \ldots \ldots \ldots \ldots \ldots \ldots \ldots \ldots \ldots \ldots$

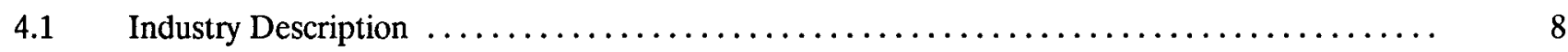

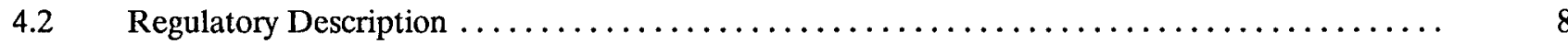

4.3 Maintenance Practices and Regulations $\ldots \ldots \ldots \ldots \ldots \ldots \ldots \ldots \ldots \ldots \ldots \ldots \ldots \ldots \ldots \ldots \ldots$

4.3.1 Maintenance Steering Group Process $\ldots \ldots \ldots \ldots \ldots \ldots \ldots \ldots \ldots \ldots \ldots \ldots \ldots \ldots$

4.3.2 Designated Engineering Representatives $\ldots \ldots \ldots \ldots \ldots \ldots \ldots \ldots \ldots \ldots \ldots \ldots \ldots \ldots$

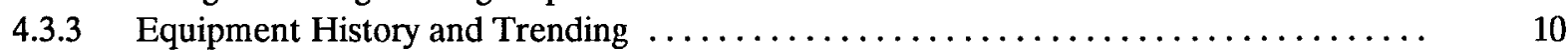

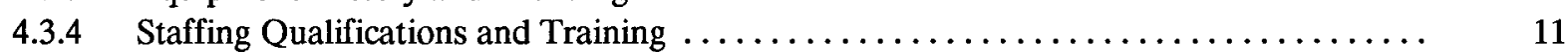

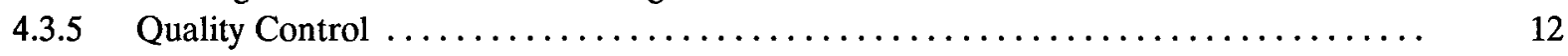




\section{CONTENTS (Continued)}

Page
P.

Summary of Lessons Learned $\ldots \ldots \ldots \ldots \ldots \ldots \ldots \ldots \ldots \ldots \ldots \ldots \ldots \ldots \ldots \ldots \ldots \ldots \ldots \ldots \ldots$

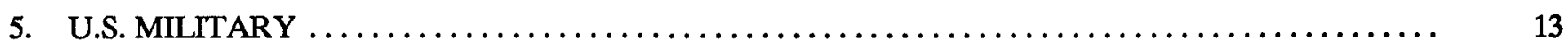

5.1 Maintenance Regulations and Practices in the U.S. Air Force $\ldots \ldots \ldots \ldots \ldots \ldots \ldots \ldots \ldots . \ldots \ldots$

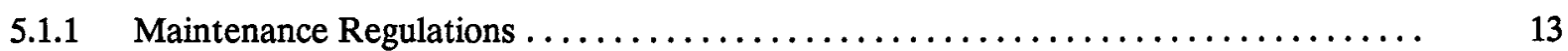

5.1.2 Preventive and Corrective Programs . . . . . . . . . . . . . . . . . . . . . . . 13

5.1.3 Performance Measures ........................................ 14

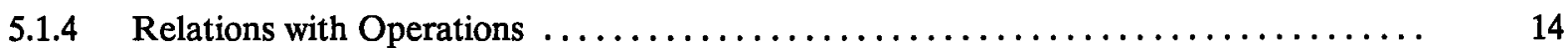

5.1.5 Quality Control and Quality Assurance $\ldots \ldots \ldots \ldots \ldots \ldots \ldots \ldots \ldots \ldots \ldots \ldots \ldots$

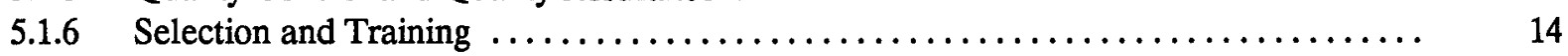

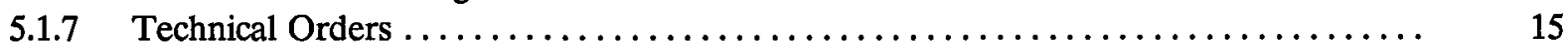

$5.2 \quad$ Maintenance Regulations and Practices in the U.S. Navy $\ldots \ldots \ldots \ldots \ldots \ldots \ldots \ldots \ldots \ldots \ldots$

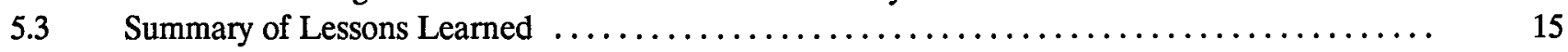

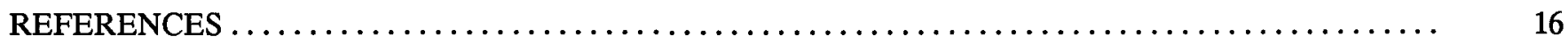

APPENDIX A: JAPANESE MAINTENANCE PRACTICES $\ldots \ldots \ldots \ldots \ldots \ldots \ldots \ldots \ldots \ldots \ldots \ldots$ A-1

APPENDIX B: EUROPEAN MAINTENANCE PRACTICES $\ldots \ldots \ldots \ldots \ldots \ldots \ldots \ldots \ldots \ldots \ldots \ldots \ldots \ldots \ldots$

APPENDIX C: U.S. COMMERCIAL AVIATION INDUSTRY $\ldots \ldots \ldots \ldots \ldots \ldots \ldots \ldots \ldots \ldots \ldots$ C-1 


\section{ACKNOWLEDGMENTS}

This study is the result of the effort of a number of NRC and contractor personnel. The primary contributors to this report are M. Dey, NRC Task Manager; A.D. Chockie, J. Olson, J.A. Thurber, M.H. Morgenstern, J.T. Hauth, C.L. Geisendorfer, E.S. Terrill, and P.R. Yost, Battelle Human Affairs Research Centers; and W.B. Scott, Battelle Pacific Northwest Laboratory. K. Inaba,
XYZYX Information Corporation, provided observations and suggestions that have been incorporated in the recommendations of the report. T.L. King, R. Frahm, and J. Jankovich, NRC, provided peer review and comments on the report. This document was edited by L. Gallagher, NRC. 



\section{PREFACE}

The Commission published a Notice of Proposed Rulemaking on Maintenance of Nuclear Power Plants on November 28, 1988, spelling out NRC's expectations on maintenance. Subsequently, on August 17, 1989, a draft regulatory guide was published to provide guidance on the implementation of the rule. In preparing the proposed rule, the NRC considered maintenance approaches in other countries and reviewed practices in other industries in this country in which equipment reliability and maintenance play an important role in safe operations. The regulatory activities associated with these maintenance practices were also examined to assess their effectiveness and applicability to the NRC. A draft report for comment was published in November 1988 in which the review and findings of the study were presented.

The study examined the nuclear maintenance regulations and practices in Japan, France, and the Federal Republic of Germany. Also assessed was the Federal Aviation Administration's (FAA) role in the maintenance of U.S. commercial aircraft and the U.S. Navy and Air Force maintenance programs.

As a result of the review of maintenance practices, it was concluded in the draft report that the following have been found to contribute significantly to effective maintenance:

1. Focus on long-term maintenance objectives; establishment of a proactive maintenance program as opposed to reactive maintenance;

2. Use of a reliability-centered approach to maintenance, including consideration of the man-machine interface;

3. Collection and engineering evaluation of failure data (root cause analysis);
4. Use of an integrated information system for collecting data and monitoring the effectiveness of a maintenance program;

5. Use of maintenance technician training/certification programs;

6. Derivation of planning and scheduling from overall program objectives;

7. Enhancement of environment/motivation of maintenance technicians (e.g., through cross-training, "crew chief" concept); and

8. Clear definition of interfaces between maintenance and other activities (engineering support, operations $\mathrm{QA}, \mathrm{QC}$, corporate offices, safety review).

The proposed rulemaking on maintenance listed and identified the above practices as items to be considered in the development of any maintenance standard providing guidance on the implementation of the rule.

On December 8, 1989, the Commission published a Revised Policy Statement for Maintenance of Nuclear Power Plants to hold rulemaking in abeyance for an 18-month period in order to monitor industry initiatives and progress, to assess alternative regulatory approaches and options, and to develop a maintenance standard.

No comments were received on the draft report for comment version of this document. Therefore, this final report is issued with only minor editorial changes.

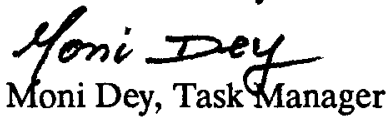

Office of Nuclear Regulatory Research

U.S. Nuclear Regulatory Commission

Washington, D.C. 20555 



\section{EXECUTIVE SUMMARY}

On March 23, 1988, the Commission published a final Policy Statement on Maintenance of Nuclear Power Plants (53 FR 9430), providing a general framework for a proposed rule. On November 28, 1988, the Commission published a Notice of Proposed Rulemaking on Maintenance of Nuclear Power Plants, spelling out NRC's expectations on maintenance. Subsequently, on August 17, 1989, a draft regulatory guide was published to provide guidance on the implementation of the rule.

The study on which this document reports was initiated as part of NRC's program to develop a rule on the maintenance of nuclear power plants. The objective of the study was to review and benefit from an examination of maintenance approaches and practices in foreign nuclear power programs and domestic industrial activities. Specifically the aim of the study was to:

1. Review various regulatory approaches and determine their applicability to the proposed rulemaking on maintenance; and

2. Determine foreign and domestic maintenance practices found to contribute significantly to effective maintenance.

This report examines Japanese, French, and German (FRG) nuclear maintenance regulations and practices and the Federal Aviation Administration (FAA) regulatory approach to the maintenance of U.S. commercial aircraft. Also addressed in this report are the U.S. Navy and Air Force maintenance programs.

The results of the study indicate that an NRC rulemaking approach that includes industry participation in the preparation of standards and implementation of the rule would be effective. It is felt that this approach promotes industry responsibility, leadership, and interaction within the industry for the development of effective maintenance programs, for the sharing of effective maintenance practices, and for the continual improvement and enhancement of maintenance technology.

This approach is similar to that adopted by the FAA for the airline industry. The study also presents activities, from the review of maintenance practices, that are the key to the effectiveness of a maintenance program. The regulatory approach and expectations for a maintenance standard outlined in NRC's proposed rule were developed in part from the conclusions of this study.

On December 8, 1989, the Commission published a Revised Policy Statement for Maintenance of Nuclear Power Plants to hold rulemaking in abeyance for an 18-month period in order to monitor industry initiatives and progress, to further assess alternative regulatory approaches and options, and to develop a final maintenance standard.

\section{REGULATORY APPROACHES TO MAINTENANCE}

The following is a summary of the regulatory approaches adopted by the FAA for the U.S. airline industry and the approach to maintenance in the nuclear programs of Japan and France. The review of these approaches provides insight into the influence of such factors as regulatory environment and the nature of industry and culture on the conduct and effectiveness of a regulatory approach to maintenance, as well as an identification of those factors considered to be the key to the success of these maintenance programs.

\section{Federal Aviation Administration}

The regulatory basis for approval of airline maintenance programs is contained in Federal Aviation Regulations (FAR), Part 121 (CFR, 1988, 14:121 and 14:43) stemming from the Federal Aviation Act of 1958 (Title VI). The regulations describe general rules governing the certification and operation of air carrier maintenance programs and cover the applicable general areas listed in the Commission's Policy Statements on Maintenance of Nuclear Power Plants. The regulations do not specify an approach for maintenance program development. Instead, airlines may develop a maintenance program that best suits their operational and maintenance requirements. Generic maintenance program development guides are issued by industry groups (e.g., Airline Transportation Association) and are used to develop the specific airline maintenance programs.

The FAA makes a substantial effort to accommodate the economic and operational requirements of airlines in light of maintenance requirements at all stages of the aircraft's life cycle. As new aircraft are used and experience is gained, the FAA-approved scheduled maintenance requirements are subject to change. These changes can come from the manufacturer, the FAA, or the airlines as technological advances in airframe, engine, and equipment design occur and information is gained on preventive maintenance and reliability methods.

The relationship between the manufacturer and the airline is an important aspect of the continued surveillance and improvement of aircraft maintenance. Manufacturers have product support departments that monitor the use of their equipment and provide assistance through onsite representatives. They assist the airline with engineering and maintenance advice, provide training 
when necessary, serve as a point of contact with the manufacturer, and report to their parent company on matters of technical significance.

The FAA approach to regulating airline maintenance programs, in which industry takes the lead role in the development of standards, provides for the necessary interaction within industry to account for advances in systems design and for feedback from operational experience. This approach, based on general maintenance regulations, allows flexibility in the conduct of plant maintenance programs and in the modification of programs as experience is gained.

\section{Japan}

The Ministry of International Trade and Industry (MITI) traces its regulatory jurisdiction of maintenance at commercial nuclear power plants to the Electric Utility Industry Law and the Law for the Regulation of Nuclear Source Materials, Fuel Materials, and Reactors.

The Electric Utility Industry Law stipulates the technical standards for the installation, operation, and maintenance of electrical structures. This law contains the primary requirement for maintenance-the mandatory periodic inspection, which occurs during a scheduled outage for inspection and maintenance.

Japanese reactors experience significantly fewer trips than U.S. reactors. The differences between Japanese and U.S. plant performance were found not to be due to differences in trip setpoints or technical specifications since the requirements in Japan are very similar or identical to those in the U.S. These differences in performance appear to stem from the structured, industrywide Japanese program of extensive preventive maintenance, consisting of statutory annual inspections, voluntary internal inspections, special work, and routine inspection. Additionally, the Japanese regulatory authority, MITI, is closely involved in the maintenance process and witnesses most maintenance activities during each annual outage.

MITI regulations require that a plant be shut down for an annual inspection at least every 13 months. During the outage, approximately 70 items in the plant are disassembled or functionally inspected. Various components of the steam turbine are inspected every other outage. The duration of the outages is decreasing because of efficient inspection practices, technical improvements in maintenance and repair, and extensive education and training programs.

Preventive maintenance is performed during the outage and is so effective that plants are seldom required to shut down at unscheduled times to perform maintenance. If the plants must shut down or reduce power to perform maintenance, the repairs must be reported to MITI and an analysis is required in order to determine the cause of the problem. Extensive post-maintenance tests are also required before the plant may be restarted. MITI collects and analyzes data on equipment performance domestically and overseas. These analyses lead to maintenance and inspection modifications.

Although the periodic inspection program is cooperatively modified through experience gained and data collected, it is a mandatory program. The U.S. nuclear industry consists of a large number of utilities, some with successful maintenance programs. A requirement for a mandatory periodic inspection during a scheduled outage would require drastic modification of some already effective maintenance programs, with little gain in benefits. The Japanese approach does not seem to be practically implementable in the U.S. nuclear industry. However, other aspects of the Japanese maintenance programs can be incorporated in the U.S. nuclear industry and are discussed later.

\section{France}

In France, the nuclear power industry is much more centralized than is its U.S. counterpart. France has a single, large nuclear utility, the Electricite de France (EDF), which is an agency within the national government. Another important characteristic of the French industry is standardization that limits the number of basic designs.

There are no regulations specifically for plant maintenance programs other than those for technical specifications and inservice inspection, as is the case presently in the U.S. However, the regulatory authority in France (CEA) has endorsed a standardized maintenance program plan developed by EDF. This plan is implemented in each EDF facility, incorporating site-specific needs. Operational data from all plants and the standardized program are reviewed annually by EDF and the regulatory authority to determine the effectiveness of the program and to determine the need for any modifications.

The regulatory approach adopted in France is not easily transferable to the U.S. nuclear industry as a result of the differences in the structure of government agencies, safety regulatory authorities, and utilities. However, the use of a standardized program plan and the centralized feedback of operational data have benefits and are discussed later.

\section{MAINTENANCE PRACTICES}

The review of foreign country and other U.S. industry maintenance programs showed that certain practices are emphasized in these programs and have been found to contribute significantly to effective maintenance. These are discussed below. 


\section{Systems Approach}

A systems approach may be described as containing the following elements:

- Systematic evaluation of the functions and objectives of plant systems, components, and structures to determine maintenance activities and requirements;

- Afocus on long-term maintenance objectives, establishing a proactive maintenance program as opposed to reactive maintenance;

- Use of a reliability-centered approach to maintenance, including consideration of the man-machine interface; and

- The deriving of planning and scheduling from overall program objectives.

The systems approach to developing maintenance program requirements is emphasized in the U.S. airline industry and in the nuclear programs of Japan and France.

In the commercial aviation industry, the MSG-3 process (based on Reliability Centered Maintenance) is used to address long-range maintenance goals through the identification of a set of scheduled maintenance requirements to accompany each aircraft type. This is achieved by identifying the systems and components within the airframe or power plant likely to affect safety, economic, and hidden consequences of failure.

The Japanese inservice inspection program provides a systematic review of systems and components for maintenance attention. Beginning with the regulatory requirements for annual maintenance inspections, the utilities prepare a long-range (10-year) maintenance plan. Following each inspection outage, the results of the inspection are carefully reviewed for adequacy of inspection scope and frequency. The Japanese utilities' primary goal is the prevention of corrective maintenance between annual outages.

The French have developed a plant model that has its roots in the reliability-centered maintenance approach that identifies the safety significance and the availability significance of plant systems and components. Using these two points of significance, the French determine the appropriate maintenance tasks to be performed, establish the priority for conducting these tasks, and allocate resources to conduct the tasks.

German maintenance programs emphasize planning and scheduling of maintenance tasks. Large, dedicated organizations are established to coordinate the activities of maintenance with engineering, operations, health physics, etc. These organizations work closely with the outage planning and scheduling groups, which are also well staffed.

The maintenance programs reviewed are experiencing improvements in component reliability that are attributed to reliability improvement programs in place for several years (some up to a decade). It was clear in the reviews that these reliability improvements did not begin with a reliability improvement program; rather, as the program improved the condition of equipment through proper predictive and preventive maintenance, component reliability began to slowly improve.

\section{Effectiveness Monitoring}

The programs reviewed had major efforts for the monitoring of maintenance effectiveness, which included:

- The collection and engineering evaluation of failure data (root cause analysis); and

- The use of an integrated information system for collecting data and monitoring the effectiveness of a maintenance program.

Both Japan and France have established extensive data bases on component failures and root causes. In Japan, the Nuclear Power Engineering Test Center (NUPEC) established in 1985 the Nuclear Power Safety Information Research Center for analysis of operational data. This center evaluates failure data down to the train level. This program feeds information into the annual inspection outage planning cycle and factors the results of failures and preventive maintenance results into the inspections. It also specifies component or system design changes where appropriate. In France, among other things, the root cause analysis program provides data that are used to modify the maintenance program through changes to policies, procedures, training, and preventive maintenance schedules. Root cause analysis programs that are comprehensive in scope and are applied to the entire maintenance process are capable of providing feedback on program effectiveness, as well as the traditional data on component or system failure causes.

In the commercial aviation industry, the FAA requires a system for continuous analysis and surveillance of performance and effectiveness of maintenance programs. The structure of aviation maintenance practices allows the FAA, the airline, and the manufacturer to make changes in maintenance programs based on individual operator experience or fleetwide service experience.

\section{Technician Qualifications and Motivation}

The programs reviewed placed emphasis on the role of the maintenance technician and his ability to perform assigned duties. The programs were oriented to: 
- The use of maintenance technician training/certification programs; and

- Enhancement of the environment/motivation of maintenance technicians.

Japan has recently created National Maintenance Training Centers that include equipment for hands-on training for maintenance personnel. Japan's training program is quite extensive and goes beyond the training and certification of technicians by including the maintenance engineering staff. The training program established in Japan for its maintenance staff encompasses virtually the entire career of the worker, beginning with the basics of quality maintenance and proceeding through most plant functions (e.g., quality assurance, licensing requirements) for the professional staff.

Since the key element in the proper maintenance of an aircraft is considered to be the individual who is responsible for the maintenance, the FAA requires that each aviation mechanic have a valid certificate from the agency with the appropriate ratings. The FAA also certifies the mechanic schools and instructors who teach in the institutions. Currently, there are over 280,000 certified mechanics in the U.S.

An important point with respect to the French utility program is that maintenance in French plants is recognized to be at least as important as operations. Maintenance is considered to be the principal route for management development. The result is that the majority of plant and utility managers in France have maintenance backgrounds. This emphasis on maintenance has been considered to be of value both in securing resources and support necessary to ensure safety and productivity and in the motivation of personnel to enter the maintenance field.

In the U.S. Navy, where a piece of equipment has a home base, a crew chief is assigned to the equipment. He is responsible for the performance and reliability of the equipment and finds personal satisfaction and peer respect in reliable equipment performance.

\section{Maintenance Organization}

A key element of the foreign programs was a clear definition of interfaces between maintenance and other activities (e.g., engineering support, operations, quality assurance, quality control, corporate offices, safety review).
An important aspect of the interface is the adequate and timely engineering support that includes the evaluation of failure data. The French components reliability improvement program has benefited from strong engineering support and involvement that includes laboratory analysis of most all components and rigorous root cause analysis of failures. Engineering is also involved in component redesign, when necessary, and procedure revisions.

In Japan, the strong commitment to avoid repeat failures is met primarily by extensive analysis of all events, including those occurring at the plant, in the Japanese industry, and in the foreign community. Additionally, the Japanese nuclear industry has established close relationships with domestic equipment vendors who value the nuclear component of their business and work closely with the Japanese utilities to solve equipment-related problems.

Each U.S. airline monitors the performance of aircraft systems and components and makes modifications to maintenance programs when warranted. Engineering support is also provided by the manufacturer through onsite representatives and in-house engineering analysis of system and component operational performance. The mainframe manufacturers maintain a high level of interest in airline operational data so as to provide recommendations to the operators and to modify and enhance their designs. Mainframe manufacturers consider low failure rates of their products to be the key to their success.

Interfaces and communications in Germany are handled by a formal signoff process on all important paperwork and plans. Also, in German plants, a quality assurance unit keeps a list of maintenance rework, specifying the maintenance work for a particular component and the time intervals. Teams are assigned to individual systems requiring rework to develop updated maintenance procedures.

A somewhat different approach is employed by the Japanese utilities. They use a group decisionmaking process, augmented by job rotations and information dissemination. Within each utility, regular meetings are held to review maintenance schedules. The meetings are designed to provide information on the conditions and activities of the various organizational units to ensure that problems are avoided and the most appropriate maintenance approach is developed. Also, the quality assurance activities in Japanese plants are directed at working with the manufacturers on the design and quality of the production of components and equipment. 


\section{INTRODUCTION}

\subsection{Background}

On March 23, 1988, the Commission published a final Policy Statement on Maintenance of Nuclear Power Plants (53 FR 9430). In the policy statement, the Commission stated that it expected to publish a Notice of Proposed Rulemaking in the near future and provided the general framework for the proposed rule. This chapter reviews the NRC Maintenance Policy Statement, defines nuclear power plant maintenance and its components, and outlines the objective and organization of this report.

On November 28, 1988 , the Commission published the Notice of Proposed Rulemaking on Maintenance of $\mathrm{Nu}$ clear Power Plants, spelling out NRC's expectations on maintenance. Subsequently, on December 8, 1989, the Commission published a Revised Policy Statement for Maintenance of Nuclear Power Plants to hold rulemaking in abeyance for an 18-month period in order to monitor industry initiatives and progress, to assess alternative regulatory approaches and options, and to develop a maintenance standard.

\subsection{NRC Maintenance Policy Statement}

The NRC Maintenance Policy Statement of March 23, 1988, reads as follows:

The Commission has a program to continually evaluate the operational performance of nuclear power plants. Analysis of operational events has shown that, in some cases, nuclear power plant equipment is not being maintained at a level which ensures, with a high degree of reliability, that the equipment will perform its intended function when required. A limited NRC examination of nuclear power plant maintenance programs has found a wide variation in the effectiveness of these programs. Inadequate maintenance at some plants has been a significant contributor to plant reliability problems and, hence, is of safety concern. The Commission believes safety can be enhanced by improving the effectiveness of maintenance programs throughout the nuclear industry. The Commission is proceeding with rulemaking consistent with this belief. This Policy Statement is being issued to provide guidance to the industry while the rulemaking proceeds.

It is the objective of the Commission that all components, systems, and structures of nuclear power plants be maintained so that plant equipment will perform its intended function when required. To ac- complish this objective, each licensee should develop and implement a maintenance program which provides for the periodic evaluation, and prompt repair of plant components, systems, and structures to ensure their availability.

The NRC Policy Statement further states that all commercial nuclear power plants:

...should develop and implement a well-defined and effective program to assure that maintenance activities are conducted to preserve or restore the availability, performance and reliability of plant structures, systems, and components. The program should clearly define the components and activities included, as well as the management systems used to control those activities. Further, the program should include feedback of specific results to ensure corrective actions, provisions for overall program evaluation, and the identification of possible component or system design problems.

\subsection{Definition of Maintenance}

In its Policy Statement (53 FR 9430), the Commission defines nuclear power plant maintenance as:

...the aggregate of those functions required to preserve or restore safety, reliability, and availability of plant structures, systems, and components. Maintenance includes not only activities traditionally associated with identifying and correcting actual or potential degraded conditions, i.e.,repair, surveillance, diagnostic examinations, and preventive measures; but extends to all supporting functions for the conduct of these activities.

The Policy Statement lists 15 activities that form the basis of an adequate maintenance program:

- Technology in the areas of

- Corrective maintenance,

- Preventive maintenance,

- Predictive maintenance,

- Surveillance;

- Engineering support and plant modifications;

- Quality assurance and quality control;

- Equipment history and trending;

- Maintenance records;

- Management of parts, tools, and facilities; 
- $\quad$ Procedures;

- Post-maintenance testing and return-to-service activities;

- Measures of overall program effectiveness;

- Maintenance management and organization in the areas of

- Planning,

- Scheduling,

- Staffing,

- Shift coverage,

- Resource allocation;

- Control of contracted maintenance services;

- Radiological exposure control (ALARA);

- Personnel qualification and training;

- Internal communications between the maintenance organization and plant operations and support groups; and

- Communications between plant and corporate management and the maintenance organization.

The definition in the Policy Statement is consistent with the earlier definition of nuclear power plant maintenance in Phase I of the NRC Maintenance and Surveillance Program (MSP) report NUREG-1212 (Vol. 1, p. 7, 1986):

Maintenance is defined as a process with the objective of preserving the reliability and safety of nuclear power plant structures, systems, and components or restoring that reliability when it is degraded. As defined in the MSPP and for the purposes of this report, NPP maintenance and surveillance includes (a) diagnostic or periodic testing, surveillance and inspection to determine the condition of structures, systems, and components; (b) preventive and corrective actions such as repair, replacement, lubrication, adjustments, or overhaul; and (c) proper equipment isolation, restoration to service, and post-maintenance testing to assure adequacy of corrective action. Maintenance and surveillance are performed during all modes of NPP operation by plant staff, vendors, or contractors. The scope of this definition of maintenance and surveillance is consistent with the International Atomic Energy Agency's Safety Guide on Maintenance of Nuclear Power Plants (No. 50-SC-07, IAEA, 1982).
In the Revised Maintenance Policy Statement, the Commission reemphasizes and clarifies its previous views (outlined above) with respect to elements of an effective maintenance program. A regulatory guide was published on August 17, 1989, to provide guidance on the implementation of the proposed rule.

\subsection{Objective of Report}

The purpose of this report is to describe the maintenance practices and programs in the commercial nuclear industries in Japan, France, and the Federal Republic of Germany; in the U.S. aviation industry; and in selected branches of the U.S. military. The objective of this work is to identify selected successful maintenance practices and regulations and maintenance "lessons learned" that would be used toward the formulation of a proposed rule on maintenance.

\subsection{Organization of This Report}

This report includes summaries of maintenance regulations and practices in the various industries and organizations reviewed and recommendations on the endorsement of various maintenance practices that are consistent with the NRC Policy Statement on Maintenance of Nuclear Power Plants. The balance of this report is organized into five sections and three appendices. Section 2 summarizes maintenance initiatives and programs in the Japanese commercial nuclear power industry. Section 3 summarizes maintenance practices in France and West Germany. The maintenance practices in the U.S. commercial aviation industry are described in Section 4. Section 5 provides an overview of the maintenance programs in the U.S. Air Force and U.S. Navy. Appendices A through $\mathrm{C}$ contain extensive descriptions of maintenance practices for commercial nuclear power plants in Japan and Europe and an overview of the FAA's role in civil aviation maintenance programs.

\section{JAPANESE COMMERCIAL NUCLEAR INDUSTRY}

This section discusses the Japanese approach to commercial nuclear power plant maintenance and maintenance regulation. It begins with an overview of the industry. This is followed by a general description of the regulatory context. Next, Japanese practices and regulations are described for the areas listed in the NRC's policy statement on maintenance. A summary of lessons learned is provided. Appendix A contains more detailed information on Japanese maintenance practices.

\subsection{Industry Description}

Nuclear power is an important source of energy in Japan. At the end of 1986, nuclear energy provided $28 \%$ of the 
power consumed in Japan. Because of Japan's limited natural resources, the Japanese will depend more heavily on reliable nuclear power in the future. Japanese nuclear plants operate very efficiently, at a capacity of $76.2 \%$ in 1986 (Sumi, 1987). There are 10 utilities that operate 36 commercial reactors. The Japanese public places a great deal of emphasis on safety in the nuclear industry and on the minimization of radiation exposure to workers at plants and to the public.

\subsection{Regulatory Structure}

The regulatory environment in Japan depends heavily on cooperation among utilities, manufacturers, and regulators. The Japanese Fundamental Act of 1955, as amended in 1978, delegated the responsibility of regulating nuclear reactors to three government agencies according to the type of reactor. The Ministry of International Trade and Industry (MITI) became the regulatory authority over all aspects of commercial nuclear power, while the Science and Technology Agency, under the Prime Ministry, became the regulator for research reactors. The Ministry of Transportation has jurisdiction over nuclear reactors on ships. Two other government agencies active in the nuclear arena are the Nuclear Safety Commission and the Atomic Energy Commission. These are advisory agencies to the Prime Minister that were established in the reformation of 1978 to, respectively, unify the advancement and safety aspects of nuclear power.

MITI traces its regulatory jurisdiction of maintenance at commercial nuclear power plants to the Electric Utility Industry Law and the Law for the Regulation of Nuclear Source Materials, Fuel Materials, and Reactors.

The Electric Utility Industry Law stipulates the technical standards for the installation, operation, and maintenance of electrical structures. This law contains the primary requirement for maintenance-the mandatory periodic inspection, which occurs during a scheduled outage for inspection and maintenance.

\subsection{Maintenance Practices and Regulations}

Japanese reactors experience significantly fewer trips than U.S. reactors. The differences between Japanese and U.S. plant performance were found not to be due to differences in trip setpoints or technical specifications since the requirements in Japan are very similar or identical to those in the U.S. (Boegel et al., 1985). These differences in performance appear to stem from the structured, industrywide Japanese program of extensive preventive maintenance, consisting of statutory annual inspections, voluntary internal inspections, special work, and routine inspection. Additionally, the Japanese regulatory author- ity, MITI, is closely involved in the maintenance process and witnesses most maintenance activities during each annual outage.

MITI regulations require that a plant be shut down for an annual inspection at least every 13 months (Uebayashi and Miyake, 1985). During the outage, approximately 70 items in the plant are disassembled or functionally inspected. Various components of the steam turbine are inspected every other outage, although MITI is currently reviewing whether this is an appropriate interval (Atoms in Japan, 1987). The duration of the outages is decreasing because of efficient inspection practices, technical improvements in maintenance and repair, and extensive education and training programs.

Preventive maintenance is performed during the outage and is so effective that plants are seldom required to shut down at unscheduled times to perform maintenance. If the plant must shut down or reduce power to perform maintenance, the repairs must be reported to MITI and an analysis is required in order to determine the cause of the problem. Extensive post-maintenance tests are also required before the plant may be restarted. MITI collects and analyzes data on equipment performance domestically and overseas. These analyses lead to maintenance and inspection modifications.

MITI also requires that a resident inspector be stationed at each plant and must approve any modifications to or repair of safety-related equipment (O'Shima, 1986).

\subsection{Summary of Lessons Learned}

The following observations can be made regarding maintenance in the Japanese nuclear industry:

- The Japanese place heavy emphasis on a systematic, preventive maintenance program.

- The periodic inspection program is cooperatively modified through experience gained and data collected.

- The Japanese maintenance program depends on a long-term outlook and relationships of trust among the utilities, vendors, and government.

\section{EUROPEAN COMMERCIAL NUCLEAR INDUSTRY}

This section discusses the French and the West German (Federal Republic of Germany) approach to commercial nuclear power plant maintenance and maintenance regulation. These two countries were selected for this assessment effort for several reasons. One of the major reasons is that both countries have highly successful nuclear 
power programs, as indicated by such factors as the high levels of plant availability and the continued growth of the industries. Also, as in the U.S., the nuclear power programs in these countries are based on light-water-reactor technologies.

The first area addressed is a description of the nuclear power industry in both France and West Germany. General descriptions of the regulatory structure and maintenance practices for both countries are then provided. The final section is a summary of lessons learned. Appendix B contains more detailed information on the French and the West German maintenance practices.

\subsection{Industry Description}

The following provides an overview of the nuclear power industry in France and the Federal Republic of Germany.

\subsubsection{French Nuclear Industry}

The nuclear power industry in France is a large and growing industry. It is highly centralized, stable, and standardized. It currently provides over two-thirds of the electric power needs and over half of the total power needs for France. The proportion of electric power production from nuclear power plants is expected to increase to over $75 \%$ in the near future. Thus, nuclear power plays not only an important, but actually a central, role in the production of power in France (Vendryes, 1986).

The French nuclear power industry is much more centralized than is its U.S. counterpart (EDF, 1982). France has a single, large nuclear utility, the Electricite de France (EDF). The EDF is an agency within the national government, reporting to the Ministry of Industry. EDF maintains a monopoly on electrical power production in France, operating fossil and hydro plants in addition to the large number of nuclear plants. EDF also is responsible for around $80 \%$ of the distribution of the electrical power system in France. EDF not only operates the plants but also serves as architect/engineer. In addition to EDF, the nuclear steam supply system supplier for PWRs in France is FRAMATOME, which is $30 \%$ owned by the Commissariat a l'Energie Atomique (CEA), a government agency. Thus, the French nuclear industry is highly concentrated, and because of this, well integrated and stable.

Another important characteristic of the industry is standardization. In 1973, EDF made the decision to pursue rapid expansion of its nuclear component, but to limit the number of basic designs. The first generation plants following this decision were 900 MWe PWRs. More recently, a fleet of 1300 MWe PWRs has been added, using much the same design. A third generation of $1450 \mathrm{MWe}$ PWRs is also planned. EDF has also standardized its se- lection of vendors for the secondary side; one firm, Alsthom Atlantique, supplies the generator-turbine configuration.

The advantages to standardization have been numerous and large (Bemer, 1986; Mercier, 1987; Degot and Lebreton, 1985; Bitsch, 1985). Because of standardization, EDF has been able to develop stable working relationships with a few key vendors. This has allowed for feedback and improvement in design, as well as shared responsibility for maintenance. Licensing and construction costs and schedules have been minimized since each plant is not a custom design. EDF has been able to invest in centralized facilities since they can serve numerous plants at a considerable cost saving. These facilities have allowed for centralized training, the development of industrial robots for maintenance, the maintenance of an effective equipment performance and evaluation data base, and more effective warehousing of spare parts. More importantly, however, standardization has allowed for easier learning from operating experience than seems to be the case in the U.S. The lessons learned at one plant have been easily transferred to the other plants. The result is a high level of availability, in excess of $80 \%$, and reasonable capacity and scram statistics given the load-following philosophy applied by EDF to its nuclear plants.

\subsubsection{West German Nuclear Industry}

As of 1987, there were 19 nuclear power plants operating in West Germany and approximately seven in the planning or construction phase. Total net output at this time was in excess of $13,791 \mathrm{MWe}$. The majority of plants in West Germany are PWRs. However, there are several BWRs and high temperature reactors. In addition, a Liquid Metal Fast Breeder Reactor (LMFBR) is scheduled for operation sometime in 1988. The plants are divided among 18 state and privately owned utilities. Kraftwerk Union AG (KWU) provides reactors for PWRs and the turbine/generator for most plants (Nuclear News, 1988). Nuclear power plants in West Germany are fully owned by public and private utilities, and construction is carried out by private industrial firms, with indirect guidance from the government.

Nuclear power production, although gradually expanding, is not the sole source of electricity in West Germany and continues to be a controversial issue. West Germany is experiencing a relative degree of success recently in constructing plants and placing them on line, following a series of legal and licensing complications. In 1985, somewhat more than one-third of the electrical power production in West Germany was from nuclear power. This increased success in constructing plants is thought to be related to a standardized licensing procedure started in 1980, referred to as the "convoy" procedure (Rippon, 1986). The convoy procedure is hoped to spur several new projects; however, low projections of growth in the de- 
mand for electricity may prevent the projects from coming to fruition. In addition, much like in the United States, there is ongoing public debate in West Germany regarding nuclear power expansion. The accident in Brunsbuttel in 1978 raised awareness of the risks of nuclear energy production and caused changes in personnel issues and regulations. Nuclear energy production is clearly not the central focus, in contrast to France, as government programs are additionally in support of conservation and other means of energy production. More recently, the Transnuclear incident and the accident at Chernobyl have helped stimulate opposition to nuclear power.

The nuclear power capacity in West Germany, nevertheless, has expanded over the past few years. In 1986, the 16 commercial nuclear power plants in operation at the time had an average capacity of approximately $85 \%$ and nuclear electricity production rose from 93 billion $\mathrm{kWh}$ in 1984 to 126 billion $\mathrm{kWh}$ in 1985 (Rippon, 1986).

West Germany has a complex, yet effective, approach toward regulating the nuclear power industry. The decentralized system allows for a degree of variation among states, in that each state is responsible for regulating and licensing plants in their territory. A framework of minimum requirements or standards is supplied by the Federal Ministry of the Interior, however, to maintain quality and some homogeneity in approach across the states. The safety standards incorporate input from a large body of experts, pooling information from a great many sources. The system, based on the exchange of information across many areas of technical expertise, reduces the chance of overlooking important safety-related details.

\subsection{Regulatory Structure}

The nuclear power-related regulatory structure in France and West Germany is presented in this section.

\subsubsection{French Regulatory Structure}

Several government ministries are concerned with aspects of nuclear power production. For example, the Ministry of Health has responsibility for radiation exposure regulations. However, the ministry with the major responsibility for nuclear power is the Ministry of Industry. Within the Ministry of Industry is found responsibility for nuclear power promotion (CEA), production (EDF), and safety regulation (CEA and the Central Safety Department for Nuclear Facilities).

Until the 1970s, the CEA had primary responsibility for the regulation of nuclear power. Similar to the situation with the Atomic Energy Commission in the U.S., however, concern grew over its joint mission of energy promotion and safety regulation. While the CEA continues to regulate fuel cycle activities and to provide some support to the regulation of nuclear power plants, a separate group reporting to the Ministry of Industry has taken over much of the regulatory role for commercial nuclear power. This organization, the Central Safety Department for Nuclear Facilities (SCSIN), develops safety rules and regulations and oversees their application. In addition, the SCSIN develops organization, staffing, and general policies. The SCSIN makes decisions involving safety regulations and typically receives advice from the Institute of Protection and Nuclear Safety (IPSN) on safety issues.

IPSN, a unit in the CEA, is comprised of two departments-the Department of Nuclear Safety (DNS) and the Department of Protection(DP)-and determines the adequacy of applications submitted by the electrical utility. The DNS evaluates structural, mechanical, and electrical systems while the DP provides technical assistance to the Ministry of Industry regarding the discharge of radioactive waste.

The French nuclear program is a part of French national economic policy. There is a higher level of public support for nuclear power in France than in many other countries (Vendryes, 1986). This is the result, in part, of the comparative cost saving from nuclear power but must also be attributed to the high safery and efficiency of operation experienced to date. As in Japan, there is more industry and government cooperation than in the U.S. This cooperation can be seen in joint planning, governmentsponsored research and development, and the nonprescriptive approach taken to regulation of the EDF by other government agencies.

\subsubsection{West German Regulatory Structure}

The West German regulatory system for nuclear power is highly complex due to the federalist structure of the nation. There are 11 separate state governments in West Germany that license and regulate nuclear power plant operations within their jurisdictions. The Federal Ministry of the Interior (BMI) supervises each of the 11 state ministries and exercises control in a direct fashion, using standardized minimum requirements.

The BMI supplies administrative guidelines or regulations that must be followed by the state licensing authorities. The BMI relies, in particular, on two appointed advisory committees for technical and scientific information that the BMI incorporates in its guidelines: (1) the Reactor Safety Commission (Reaktor-Sicherheitskommission, or RSK) and (2) the Radiological Protection Commission (Strahlenschutz Kommission, or SSK).

The Reactor Safety Commission advises the BMI on safety issues. The Radiological Protection Commission, also involved in research and development, provides technical information to the BMI. The guidelines set by the 
BMI must be fulfilled and verified before a license will be issued.

The Nuclear Safety Standards Commission (Kerntechnischer Ausschub, or KTA) is responsible for developing safety standards or steps to illustrate whether the guidelines have been fulfilled and to see to their application. The KTA is made up of members from such groups as manufacturers, constructors, owners, and operators, plus 10 other members from technically oriented organizations.

The German Standards Institute (Deutsches Institut fur Normung, or DIN) plays a similar role to the KTA, but, instead of developing safety standards, focuses on the development of technical standards. The DIN has a more simplified approach to developing the standards, avoiding the use of task groups. The Technical Committee on Nuclear Engineering (Normenausschub Kerntechnik, or $\mathrm{NKe}$ ) is also involved in developing technical standards.

The licensing authorities must ensure that the safety and technical standards have been met and therefore consult the BMI, Technical Inspection Agencies (Technische Uberwachungs Vereine, or TUV), and the Reactor Safety Company (Gesellschaft fur Reaktorsicherheit, or GRS) for additional information regarding safety issues.

The TUV is a group of nonprofit organizations supervised by the government that inspect safety measures for industries. These agencies are important for maintenance activities as they determine the quality of the safety tests in use. There are 11 TUVs, of which seven have special nuclear departments. Since each TUV is independent, a group was formed that would allow for uniformity in decisionmaking. The Nuclear Steering Committee of the Technical Inspection Agencies (TUV-Leitstelle Kerntechnik) is comprised of members from those TUVs with the nuclear departments and members from the GRS. The Nuclear Steering Committee of the TUVs is responsible for ensuring homogeneous examination, assessing similar technical contents, controlling task groups, and coordinating certain Committee members (e.g., KTA and NKe).

The GRS, an advisory body to the government, is financed by the federal government and conducts studies on the safety of nuclear facilities and of radiological protection by order of the BMI.

Each state licensing authority is responsible for coordinating public advisory groups, state and regional agencies, and authorizing the licensure of plants (Franzen, 1982).

\subsection{Maintenance Practices and Regulations}

The following provides an overview of maintenance practices and regulations in France and the Federal Republic of Germany.

\subsubsection{French Maintenance Practices and Regulations}

The organization and management of maintenance within EDF pertains to both centralized functions within the utility and to activities at the plant level (Mercier, 1987). For the utility as a whole, maintenance is the responsibility of the Equipment Division. Three major centralized support organizations for maintenance exist within EDF. The first, a centralized maintenance department, is responsible for collecting equipment design specifications, analyzing significant events and failures, maintaining information on equipment life, helping plants with major maintenance, implementing plant modifications, designing and implementing preventive maintenance programs, relating operating experience to vendors, and providing general interface with vendors for maintenance issues.

A second support organization, the Groupe des Laboratories, provides centralized research support concerning knowledge of equipment condition and failure mechanisms and for establishing material and chemical specifications.

A third organization, the Technical Support Group (UTO), a subsidiary of EDF, is responsible for assisting plants in the development of maintenance procedures; the development of robots, mockups, and specialized tools; the maintenance of a centralized, spare-parts store; and the promotion and dissemination of planning assistance systems.

In addition to these support organizations, the EDF also provides for centralized maintenance training schools, including a maintenance training simulator, and for regional "hotshops" for the performance of maintenance outside the plant.

Within the maintenance department at the plant, there are four major groups: analogic controls (low-current instrumentation), I\&C/electrical maintenance, mechanical maintenance, and planning and scheduling. Together these groups are responsible for daily maintenance activities.

Nonroutine maintenance is planned and executed by the Technical Support Subdivision (SUT), reporting directly to the site manager and to the Construction Branch at EDF. This group provides special maintenance support for all the units at the site, including maintenance during outages and outage planning. 
Quality assurance/quality control (QA/QC) is part of the Nuclear Safety Department reporting to the Deputy Site Manager and is responsible for independent verification of maintenance work and for the review of maintenance work packages. Plant operations also reviews work packages and oversees post-maintenance testing.

At the plant level, considerable emphasis is placed on coordinating the activities of operations, maintenance, and other plant functions. This is reflected in a pattern of review and oversight of one function's activities by another and in the emphasis on planning and scheduling of all activities.

EDF maintenance workers are not subject to externally imposed standards for staffing, personnel qualifications, and training. A typical plant may have around 270 workers assigned to it with another 300 to 400 workers providing support to the several plants at the site. Approximately 120 maintenance workers are assigned to each plant. Several hundred more are available from the site's Technical Support Subdivision, and about 200 traveling maintenance workers are available for scheduled outages from the central EDF maintenance department. Vendors and other subcontractors are also used during scheduled maintenance.

Career paths appear to stress promotion from within (Rippon, 1985). Emphasis is placed on long-term employment and the provision of in-house training to allow workers to take advantage of job openings within EDF. One inference that can be drawn from this policy is that the overall experience level is higher (controlling for the expansion of the industry) in EDF than in some U.S. utilities. Another inference is that an EDF employee may be likely to perform several different jobs over the course of his career as opposed to simply one. This pattern may be reinforced by the fact that labor, while unionized, is not unionized along the lines of job specialty (craft). Instead, there is a single, EDF-wide union. Taken together, these employment and personnel practices may encourage rotation of staff within EDF and associated benefits in plant knowledge on the part of workers.

According to one source, entering maintenance workers typically have completed public school through age 16, plus 2 years of technical school. This is followed by either a university education in engineering, or a 2-year program at a technical university (see also IAEA, 1980). EDF conducts a substantial in-house training program for maintenance workers, including a centralized maintenance training center, a maintenance simulator, and various mockups (e.g., steam generator and primary circuit system).
The French approach is to minimize both corrective maintenance and unnecessary preventive maintenance (Mercier, 1987). Corrective maintenance must be minimized because it puts the maintenance program in a reactive mode. It is difficult to plan for and contributes disproportionately to unavailability. Unnecessary preventive maintenance must be avoided because it is costly; it may actually increase the failure probabilities for some types of equipment, and it, too, contributes to unavailability.

The French strategy for minimizing corrective and preventive maintenance focuses on the use of predictive maintenance within a general risk model of the plant (Mercier, 1987). The analysis failure data are used to determine what are the reasonable expectations for failure for each component. Safety and economic consequences are considered, and priorities for preventive maintenance are established.

A second aspect of predictive maintenance, of course, concerns testing to identify degradation in performance of components. For nonredundant systems (e.g., reactor containment and reactor coolant system), a high level of monitoring is suggested even though failures may be extremely rare. For redundant systems where failure does not jeopardize either safety or availability, little or no preventive maintenance may be performed.

In the attempt to maximize availability, the French approach is to minimize the length of scheduled outages to the length required by refueling and fuel handling. A heavy emphasis is placed on outage planning and adequate staffing for outages so that preventive maintenance and plant modifications do not become the critical path during the scheduled outage.

The strategy of being proactive rather than reactive depends substantially on feedback from operating experience. By analyzing failure information in detail (including causes), EDF constantly changes its maintenance procedures and training so that avoidable failures are not repeated. The heavy emphasis on outage planning also allows the maintenance program to avoid surprises and unreasonable backlogs of work requests.

Quality assurance is provided in a manner very similar to that in the U.S. There is a separate QA/QC department that reports to the plant manager. This department is responsible for reviewing work packages and verifying completed work.

A key to the success of the French nuclear program is feedback from operating experience, including activities relevant to maintenance. The EDF maintains an extensive data file on equipment history and maintenance practices that allows for continual adjustment of procedures and maintenance strategy. 


\subsubsection{West German Maintenance Practices and Regulations}

West Germany recognizes the importance of good maintenance procedures. The Biblis plant, for example, spends $50 \%$ of maintenance time on corrective activities and $50 \%$ on preventive measures. Periodic inspections are conducted of plant systems and components. A cata$\log$ of inspections is developed in cooperation with the manufacturer (KWU), the operator of the plant, and the official expert. In addition, there are a number of preventive maintenance measures that are used to aid plant availability. The following are used in particular by the Gemeinschaftskernkraftwerk (GKN), a nuclear power plant in West Germany: (1) recurrent tests; (2) special tests; (3) upkeep; and (4) repair, modification, and deviation (Hoensch and Kolditz, 1985).

Recurrent tests are used to ensure that the instrument is functioning properly to perform its job. The frequency of this type of test depends on the needs of the whole plant, the requirements of the system, and the component and licensing standards. In addition, systems, components, and system parts are typically tested during recurrent tests. The testing includes such things as visual inspection; surface, internal, and leakage tests; and chemical analysis and measurement. A QA unit keeps a list of recurrent maintenance specifying the maintenance work for a particular component and for a particular interval. Units are assigned to individual systems and must develop updated maintenance procedures. In addition, a test manual lists the tests, and a test schedule will provide the dates on which they should take place. Also, a test procedure manual is available that describes the details of the operation. These are all used for internal organizational documentation.

Contributing to successful maintenance is the process by which West Germany monitors spare parts. West Germany has a complex data processing system to keep track of inventory, referred to as the Kraftwerk-Kennzeichensystem (KKS) (Schegk, 1986). This system aids in maintenance practices since one may assess when parts need to be replaced.

\subsection{Summary of Lessons Learned}

It is important to recognize the significant differences in the organizational structure of the nuclear industry between France and the U.S. The EDF, as part of the government, operates the plants and the SCSIN ensures that safety regulations are met. There is no current or anticipated regulation of maintenance in the same context as being considered in the U.S. Although more detailed assessments are required to determine the specific degree of applicability of the French regulatory/industrial ap- proach to maintenance to the U.S. situation, several lessons can be learned from the French approach:

- A highly prescriptive approach to maintenance or, more specifically, preventive maintenance is not necessarily prerequisite to an effective and safe maintenance program.

- Maintenance success depends on learning from operating experience.

- Maintenance success is greatly enhanced by having adequate resources to perfect procedures, training, specialized tools, and the like.

The serious approach taken toward maintenance and training, in addition to meeting quality safety standards, has contributed to West Germany's recent success. While additional information is needed, the review of the West German maintenance practices indicated that maintenance programs can be successful, even in decentralized industry and regulatory structures.

\section{U.S. COMMERCIAL AVIATION INDUSTRY}

This section discusses the U.S. commercial aviation industry's approach to maintenance and maintenance regulation. It begins with an overview of the industry. This is followed by general descriptions of the regulatory context and maintenance practices. A summary of lessons learned is provided. Appendix C contains more detailed information on maintenance practices in the U.S. aviation industry.

\subsection{Industry Description}

The aviation industry in the U.S. is among the largest in the world. There are currently over 223,000 active general aviation aircraft and 4,600 commercial aviation aircraft in the United States (FAA, 1987).

\subsection{Regulatory Description}

The Federal Aviation Administration (FAA) was established in 1958 from the Civil Aeronautics Board. In 1967, the FAA became part of the Department of Transportation. Over the years the principal mission of the FAA has been to both regulate and promote civil aviation to ensure its safe and orderly growth. To achieve these objectives, the FAA operates the air traffic control network, flight service stations, air traffic route control centers, and aids for navigation. The agency also issues and enforces rules, regulations, and standards for the production, operation, and maintenance of aircraft. All aircraft must be certified by the FAA as being airworthy. Both the original design 
and subsequent aircraft developed from the original design require FAA approval.

The regulatory basis for approval of airline maintenance programs is contained in Federal Aviation Regulations (FAR), Part 121 (CFR, 1988, 14:121 and 14:43) stemming from the Federal Aviation Act of 1958 (Title VI). The regulations describe general rules governing the certifications and operations of air carrier maintenance programs. The regulations do not specify an approach for maintenance program development. Instead, airlines may develop a maintenance program that best suits their operational and maintenance requirements.

The FAA uses onsite inspectors who are assigned to an airline or region. FAA inspectors generally work closely with the airlines to establish workable and viable solutions to problems related to manufacturing standards, flight certification, the development of a maintenance program, and flight standards.

The FAA makes a substantial effort to accommodate the economic and operational requirements of airlines in light of maintenance requirements at all stages of the aircraft's life cycle. As new aircraft are used and experience is gained, the FAA-approved scheduled maintenance requirements are subject to change. These changes can come from the manufacturer, the FAA, or the airlines as technological advances in airframe, engine, and equipment design occur and information is gained on preventive maintenance and reliability methods.

The relationship between the manufacturer and the airline is an important aspect of the continued surveillance and improvement of aircraft maintenance. Manufacturers have product support departments that monitor the use of their equipment and provide assistance through onsite representatives. They assist the airline with engineering and maintenance advice, provide training when necessary, serve as a point of contact with the manufacturer, and report to their parent company on matters of technical significance.

\subsection{Maintenance Practices and Regulations}

The FAA requires the airlines to perform corrective maintenance, preventive maintenance, inspections, and repairs. They also require the airlines to develop or adopt a continuous airworthiness maintenance program and tailor or adjust that program and related practices and procedures to best suit their needs (King, 1986). Certification of an airline's maintenance program requires FAA approval of the airline's maintenance manuals and materials.
In addition to the airline maintenance program itself, other related requirements are evaluated by the FAA prior to maintenance program certification, as outlined in FAR Part 121 (CFR, 1988, 14:121). The FAA evaluates an airline's operating philosophy, organizational structure, recordkeeping practices, statistical and data processing measures, and program for corrective action (FAA, 1978). FAR Part 121 also requires that each airline maintain an in-house reliability management program that audits and surveys its quality control through the use of internal and external reporting services and information systems (CFR, 1988, 14:121). The continuous flow of information between manufacturers, airlines, overhaul repair shops, and the FAA is used to maintain high reliability and safety standards industrywide.

The organization of maintenance within commercial airlines can take a variety of forms based on the size and regional distribution of the airline (King, 1986). The maintenance organization can be dispersed geographically with line maintenance (at the terminal), hanger maintenance (at selected airports), or centralized fleet maintenance (at one or more maintenance centers). More extensive maintenance and modifications may also involve the manufacturer.

Within the maintenance organization, there typically reside units responsible for aircraft and engine maintenance, maintenance planning, supply, training, ground support equipment, document control, and maintenance facilities (King, 1986). In some airlines, engineering is integrated into the maintenance department. In others, it constitutes a separate department. Quality control is a highly developed function and is organized separately from the actual conduct of maintenance.

\subsubsection{Maintenance Steering Group Process}

The Maintenance Steering Group (MSG) process has been developed and refined over the last two decades to assist the airlines and aircraft manufacturers in developing a preventive maintenance inspection schedule. Although not required by the FAA, the MSG process has been accepted as a method of complying with the FAA requirements. The current version of the MSG (MSG-3) is considered to represent the current state of the art in aircraft maintenance program design.

The underlying momentum and philosophy behind the development of current maintenance requirements within the aviation industry is Reliability Centered Maintenance (RCM). During initial design, a number of reliability tests are run to predict the expected life of a system or structure. These, in turn, help determine what maintenance requirements will be developed for the new aircraft.

The Maintenance Steering Committee (MSC) implements the MSG-3 process and develops the recom- 
mended maintenance requirements for the specific aircraft type. The maintenance program development activities are managed by the MSC, which is convened about the time the aircraft is prepared for its first flight (Matteson et al., 1984). Participants include representatives from the manufacturers of the airframe and power plant, the airlines purchasing the plane, the FAA, and foreign regulators. The FAA and foreign regulators attend the meetings as observers. The committee is chaired by one of the airline representatives and co-chaired by a manufacturer representative. This committee is then broken into five or six working groups-each addressing a major system, such as structures or avionics. There are approximately three or four FAA observers for each working group.

The Maintenance Review Board (MRB) is the committee of FAA personnel responsible for the approval of the proposed maintenance requirements submitted by the industry Maintenance Steering Committee. The MRB report for the specific aircraft type is developed by the FAA based on their review, analysis, and revision of the MSC Proposal Document. The MRB is chaired by an FAA Airworthiness Specialist in the controlling region. MRB members are FAA Principal Maintenance/Avionics Inspectors who are assigned to various airlines and thus have experience with maintenance regulations and requirements.

The document generated by the MRB, entitled "Maintenance Review Board Report: Requirements-Scheduled Maintenance Program," outlines the initial maintenance requirements as approved by the FAA for systems, power plant, structures, and zones for a specific type of aircraft operated by U.S.-certificated operators. The MRB report provides guidance to the air carrier in the preparation of the original Operations Specifications relating to maintenance and guidance to the FAA inspector in the approval of those Operations Specifications. Each operator may develop a complete maintenance program within the framework of these requirements that is compatible with its own basic maintenance philosophy. Each operator can negotiate with the FAA Certificating Region for any alteration of or deviation from the requirements in the MRB report. The FAA does not require any specific form of maintenance program. Since the FAA is involved in the preparation of the MSC report, they can partially review it as it is prepared and can object to a part of the maintenance plan early on, making the process more efficient. Final review of the report from the Maintenance Steering Committee by the FAA is reserved until it is completed.

In addition to the MRB, the aircraft operators also receive a Maintenance Planning Data (MPD) document from the manufacturer that includes the MRB requirements as well as other nonmandatory maintenance items. Recommendations on lubrication and other nonscheduled activities are also detailed in this document.

\subsubsection{Designated Engineering Representatives}

While the aircraft is still in the design phase, one of the key positions used by the FAA is that of the Designated Engineering Representative (DER). This position has resulted from the cooperative approach between the FAA and the manufacturer. The FAA uses a senior engineer, employed by the manufacturer, to certify that the new airline design meets FAA regulatory standards. The DERs are responsible for ensuring that all regulations applicable during the design of a new aircraft are satisfied (CFR, $1988,14: 25)$. For any new aircraft, the FAA uses a number of DERs, specializing in areas such as hydraulics and avionics. Individuals are nominated by the manufacturer but must be appointed by the FAA regional director based on their professional qualifications and experience.

The system has a number of obvious advantages for the FAA and the manufacturer. DERs have a state-of-the-art knowledge of the field and day-to-day familiarity with the particular systems that are unlikely to be found in the FAA. A major benefit to the manufacturer is the flexibility the DER provides in reviewing the designs as the schedule requires.

\subsubsection{Equipment History and Trending}

Once an aircraft is in use, the airlines, the manufacturer, and the FAA track equipment performance to justify any appropriate changes to their current maintenance program. The airline industry uses several methods to track aircraft fleet reliability (Robertson, 1986):

- $\quad$ Service history and operating experience based on information provided from the airlines and repair shops to the manufacturer and the FAA.

- Onsite presence of manufacturer field representatives and FAA inspectors.

- Use of reliability statistics, such as shop visit, removal, and in-flight shutdown rates.

- Engineering analyses of parts used in service.

Most airline maintenance information systems separate the reporting of critical events from the reporting of routine statistics. Analysis of data collected on a frequent, industrywide basis, such as daily airline Maintenance Reliability Reports and Maintenance Interruption Summaries, contributes to quick responsiveness within the industry (NAS, 1980).

Airlines are required to submit reliability and significantevent reports to the FAA on a regular basis. Reporting requirements of the FAA-approved maintenance reliability program include daily Mechanical Reliability Reports (MRRs), which are sent to their assigned FAA 
maintenance inspectors. These reports cover 16 types of aircraft failure, malfunction, or defect (NAS, 1980). Airlines are also required to submit Mechanical Interruption Summaries (MISs), listing the causes of all mechanical difficulties that result in flight delay or cancellation (NAS, 1980).

Information systems within the airlines and the manufacturers are fairly comprehensive. This is attributed to reliability and maintenance data collection methods developed primarily during the last 25 years, FAR criteria for maintenance program development, and the transfer of information between manufacturers and airlines.

The FAA is currently developing an automated information-gathering and data base system. This would include access to airline and manufacturer records (Voelcker, 1986). Under this system industrywide safety statistics based on reliability and maintenance review could serve as a basis for rulemaking and enforcement. Indices of safety based on statistical measures aid effective rule formulation by identifying specific trouble areas where safety due to maintenance can be improved. This includes analysis of maintenance procedures or maintenance performance indicators.

Several processes are used to notify the airlines and take corrective action when problems are encountered in service by the above-mentioned reliability tracking methods:

- All-operator correspondence-advisories and recommendations. Telegrams, facsimile, telephone, or letters are used to alert operators to the problem area. These communications are then followed with recommended action.

- Service Bulletins-specific recommendations by the manufacturer on maintenance procedures or hardware improvements. For example, if there is a service problem that requires a new periodic inspection technique, the service bulletin will tell the operator when and how to do it.

- Airworthiness Directives (ADs)-mandatory changes issued by the FAA on maintenance procedures or hardware improvements. These are usually based on service bulletins as service difficulties develop, or they are based on accidents or incidents that pose fleetwide safety implications.

- Revisions to manuals - the manufacturer will regularly send updated pages to add to their official maintenance manuals.

- Industry meetings-convened to address specific problems and update procedures.

\subsubsection{Staffing Qualifications and Training}

Responsibility for training resides with the airline. Airline maintenance personnel usually complete courses at certificated aviation maintenance technician schools. Training is equally divided between classroom and hands-on instruction. Training programs can vary substantially. United Airlines, for example, has a comprehensive training program commensurate with its fleet size and diversity of operations. Training programs within the industry are derived from specific operations specifications and maintenance requirements within each airline. However, every airline maintenance training program must adhere to training and certification requirements outlined in FAR, Part 65 (CFR, 1988, 14:65).

Personnel may also become certified by providing satisfactory evidence of practical experience in the construction, maintenance, or alteration of aircraft or power plants. Oral and practical skill tests are administered to determine the applicant's suitability based on experience (Richardson and Rodwell, 1985).

There are three types of maintenance personnel: mechanics, inspectors, and repairmen. The FAA grants either airframe or power plant licenses in each of these categories after the individual has passed written, oral, and practical tests for the appropriate area and rating.

Mechanics currently obtain ratings and remain perpetually licensed regardless of subsequent work experience, training, or changes in their qualifications (NAS, 1980). In general, a certified aircraft mechanic must satisfy the following FAA requirements:

- Perform work with demonstrated proficiency or accomplish the work under supervision of a certified mechanic.

- Understand current instructions of the manufacturer and the maintenance manuals for specific operations.

- Have experience within the previous 24 months that demonstrates task proficiency, or demonstrate within the previous 6 months that the mechanic has supervised in an executive capacity the maintenance or alteration of aircraft.

Inspection authorizations are issued to aviation mechanics who demonstrate experience and responsibility for approving finished work. The following requirements, cited in FAR Part 65.91, must be satisfied by an applicant in order to gain an inspection certification rating (CFR, 1988, 14:65.91):

- Hold current mechanic certificate with both an airframe and a power plant (A\&P) rating, effective for at least 3 years. 
- Have been actively engaged for at least 2 years before application in maintaining certificated aircraft.

- Have a fixed base of operations, not necessarily located where inspections will be conducted.

- Have necessary equipment, facilities, and inspection data to inspect airframes, power plants, propellers, or related parts and appliances.

- Pass a written test on ability to inspect according to safety standards for returning aircraft to service after major repairs, alterations, annual inspections, and progressive inspections.

All maintenance work must be signed by an individual with an appropriate license. Inspection authorizations are renewed annually. They are renewed when the inspector demonstrates that during each 90 days of his term at least one annual aircraft inspection was performed; that inspections were performed of major repairs or alterations; and that the inspector performed or supervised and approved at least one progressive inspection in accordance with prescribed standards (Richardson and Rodwell, 1985).

Airline maintenance mechanics and inspectors are assisted by certified repairmen. Certified repairmen perform or supervise the maintenance, preventive maintenance, or alterations of aircraft and aircraft components appropriate to their qualifications and certification rating. Eligibility for certification requires employer recommendation, formal training, and 18 months of practical experience. Certified repairmen may perform condition inspections in accordance with the operating limitations of the aircraft.

\subsubsection{Quality Control}

Inservice reliability management is mandated by FAR Part 121 and requires that each airline maintenance program develop an in-house reliability management program that audits and surveys its quality control. Inservice reliability management permits each airline to develop and operate a program suited to its particular needs. The program is monitored by the FAA (CFR, 1988, 14:121). This regulatory flexibility facilitates unique operational requirements while maintaining industry standards.

\subsection{Summary of Lessons Learned}

Based on analyses of the FAA's role in civil aviation maintenance programs, the following six points were considered as potentially useful factors.

- Maintenance Steering Group (MSG) Process. The MSG process may represent a potentially viable method for the nuclear industry in the development of scheduled maintenance inspection requirements. The MSG is a process that lends itself to a variety of tasks. For example, in the airline industry, it has been used to develop maintenance requirements for both plane structures and engines and has been used by a number of different manufacturers.

- Maintenance Review Board (MRB). A board similar to the FAA MRB provides a method for a regulatory agency to become involved in the creation of scheduled maintenance requirements early in the process. The board is composed of FAA inspectors who are involved as observers in the MSG process where initial maintenance requirements are drafted. The MRB has final approval of the scheduled maintenance requirements. The board promotes early interaction with industry working groups leading to more timely decisions with input from all affected parties.

- Designated Engineering Representative (DER). The DERs are senior engineers employed by the manufacturer who report to the FAA. Their primary duty is to certify that manufacturing designs for the airframe, power plant, and avionics meet FAA regulatory standards. DERs make possible the timely review of documents, and they have increased the FAA's ability to monitor day-to-day operations during new aircraft design.

- Maintenance Program Modifications. Airline maintenance programs are continually being reviewed and modified. The initial maintenance requirements for an aircraft are subject to change as new reliability data, fleetwide maintenance trends, and information from specific incidents become available.

- Engineering Support Shared Responsibilities. Modifications to maintenance programs involve interaction among the airlines, FAA, and manufacturers. The FAA accommodates unique airline maintenance program development based on specific operational requirements. The airlines work closely with the aircraft and parts manufacturers to provide reliability data on existing equipment. In turn, the manufacturers continue to make improvements in the equipment and the maintenance program, subject to FAA approval.

- Maintenance Performance Information Systems. Data on fleetwide reliability, equipment maintenance techniques, and specific problems are well developed in the commercial aviation industry. Airlines, manufacturers, and the FAA use a variety of inhouse and industrywide data analysis and reporting systems to enhance aircraft system reliability and safety through maintenance. 


\section{U.S. MILITARY}

This section discusses approaches to maintenance in the U.S. Air Force and the U.S. Navy.

\subsection{Maintenance Regulations and Practices in the U.S. Air Force 1}

The Military Airlift Command's (MAC's) major operating unit is the Military Airlift Wing (MAW). Within the Wing, the maintenance organization is comprised of three squadrons that support the different maintenance organizations:

- The Organizational Maintenance Squadron (OMS)-The OMS is responsible for on-flight-line maintenance and performs both scheduled and unscheduled maintenance.

- Avionics Maintenance Squadron (AMS)-The AMS is responsible for maintenance of electronic equipment such as radios, radars, and in-flight computers. Maintenance is normally performed in the shops but may be done on the aircraft, especially if it is a "remove and replace" task.

- The Field Maintenance Squadron (FMS)-The FMS performs the overhauls in the shop for components, subsystems, and systems. In those cases where the Wing does not have the equipment, personnel, or facilities to perform a certain type of maintenance, the aircraft would be sent to a depot specializing in that type of work.

\subsubsection{Maintenance Regulations}

The organization of the regulations is structured like a pyramid in the sense that the primary regulation is very general and is supported with varying levels of the Air Force by supplemental regulations. The degree of specificity increases the closer one gets to the organization that is actually doing the work. The primary regulation is Air Force Regulation (AFR) 66-1. AFR 66-1 requires that there be a maintenance program for every organization in the Air Force. AFR 66-1 is then supplemented at the next lower level of organization, which is the Major Air Command. The Major Air Commands such as the Strategic Air Command (SAC) and the Military Airlift Command (MAC) each develop and implement their regulation such as MAC Regulation 66-1. Each Wing within a major air command, in turn, has regulations, plus manuals

\footnotetext{
This section is based on an in-person interview with the Deputy Commander for Maintenance and his Assistant of the 63rd Military Airlift Wing at McCord AFB on May 23, 1988. The Deputy Commander for Maintenance is responsible to the Wing Commander for all maintenance performed on $\mathrm{C}-141, \mathrm{C}-130$, and transient aircraft such as the C-5.
}

and technical orders, that provide the detailed direction and information needed to perform the actual maintenance.

\subsubsection{Preventive and Corrective Programs}

This Wing group has both a preventive and a corrective (what they referred to as "restorative") program.

The preventive maintenance program consists of a series of scheduled inspection cycles based on the number of calendar days between inspections. Home Station Checks are scheduled every 50 days or 105 days, depending on the type of aircraft. These preventive and corrective maintenance activities during these Home Station Checks alternate between a major inspection (up to 7 days) with a minor inspection ( 2 or so days). The overall cycle of inspections is about 400 days with some overlap of inspections and preventive maintenance activities because of aircraft scheduling requirements. Every 5 years, an aircraft is flown to the depot designated for that type of aircraft for extensive overhaul, modification, or both.

The preventive maintenance program requirements are based on performance, reliability, and failure data generated during design, testing, and the operational life of the aircraft. MAC has a standard program for collecting data on every component of the aircraft. This information is derived from statistical and engineering analyses performed on data generated by the manufacturer and the user. These data include reliability data and failure analyses from the various MAC Wings that have this type of aircraft, plus destructive and nondestructive tests performed on aircraft systems. These data are reported to and analyzed at a centralized organization called the Air Logistics Center (ALC). Access to the data is provided through the on-line Maintenance Data Collection System. The scheduled inspections are based on the above objective criteria derived from the ALC's assessment and testing of components as well as from the experience reported by the various Wings. It is important to note that there is a feedback mechanism in this system. The Deputy Commander can notify the ALC about problems or insights detected from experience and that affect the regulations regarding a specific component or technical order.

The corrective maintenance program is based on a Mission Essential Submission List (MESL). The MESL is a list of the critical components necessary for safe operation. This list is checked in a pre-flight inspection and in a post-flight inspection. If one of these components is inoperable, then a decision is made whether the component must be repaired before the aircraft can operate or if it can be deferred until its next scheduled inspection (there are a number of redundant safety systems built in the aircraft so that it can operate safely with some degradation of mission capability). The regulation that covers the "go/ 
no-go decision points" or the status reporting for operative use is AFR 65-110.

Use of contract maintenance is limited. On occasion, the Wing may contract for support in very special cases, but this must first be approved at higher headquarters.

\subsubsection{Performance Measures}

The Deputy Commander for Maintenance has a variety of objective data available to him that he described using as "management indicators." These indicators are used to assess the effectiveness of the maintenance program.

A monthly quality assurance report provides the following objective measures:

- $\quad$ Percentage of maintenance activities observed that complied with technical orders

- Percentage of maintenance work spot-checked that complied with technical orders

- High-failure items

- Man-hours expended

- Departure reliability

- Abort rates

The Deputy Commander for Maintenance holds regularly scheduled staff meetings three times a week. Each meeting is approximately 40 minutes long. During these meetings, he obtains information that he uses to make a more subjective assessment of day-to-day performance as well as trends in the overall effectiveness of the maintenance program. Examples of this type of information are:

- Occurrence of a series of discrepancies or recurrences of system failures

- Takeoffs barely within the tolerance limits for an ontime takeoff

- Amount of overtime expended and the extension of duty hours

An additional, subjective source mentioned was the number of phone calls that he receives indicating problems that cannot be easily resolved.

Additional sources of objective data that he uses are:

- Incident reports from the Maintenance Data Collection System
- Quality and Material Deficiency reports generated in the Wing

- Amount of unscheduled maintenance required

It is important to note that the incident reports can be generated by anybody. There is also very little delay between when a report is submitted and when it becomes available on the system. The quality and material deficiency reports generated in the Wing are also reported to the Air Logistics Center.

\subsubsection{Relations with Operations}

The Deputy Commander of Maintenance meets once a week with the Deputy Commander of Operations. They have a systematic planning approach whereby they project monthly, then schedule weekly (a 10-day cycle), and refine daily. As the Commander of Maintenance rarely operates at $100 \%$ (where the entire fleet of aircraft are operable), he will typically give the Commander of Operations a percentage of his fleet that he can guarantee will be operable and reliable. In this way he can work around the scheduled maintenance inspections.

\subsubsection{Quality Control and Quality Assurance}

The Commander of Maintenance described the quality control function to be directed at ensuring the quality of items received from the vendor. The vendor provides the required quality and the Air Force's quality control organization checks on the vendor and deals with vendor reliability problems. If there should be a problem with a component's performance, the vendor is fined, loses the contract, or replaces the defective component.

The quality assurance program is designed to ensure that the maintenance performed by the Air Force meets quality standards. Ideally, they would prefer that the individual crew chief for each aircraft be responsible for quality assurance. This happens in organizations such as a fighter Wing, where the aircraft normally return to their home base after each mission. The crew chief system has been successful for many years because the crew chiefs have a real feeling of ownership and pride in the aircraft. The MAC Wing has a problem in implementing a full-blown crew chief system since their aircraft frequently "stage" to other bases around the world and are gone for extended periods. Therefore, it is not always possible to schedule the crew chief as the only supervisor of the maintenance performed on a particular aircraft. However, even with a modified crew chief system, the concept that the individual(s) doing the maintenance are responsible for quality has been successfully implemented.

\subsubsection{Selection and Training}

Enlisted maintenance personnel are initially selected on the basis of aptitude tests and commitments made at the 
time of enlistment. After basic training, the individual attends a technical training school operated by the Air Training Command. An electronics technician may attend a year-long school. A mechanical maintenance technician may attend a 6-to 8-week school. Upon graduation, the individual would be assigned, in our example, to a Military Airlift Wing. At the time, the individual would have an entry level (three-level number as part of his Air Force Specialty Code) designation. The person would then receive further training specific to the requirements of the Wing. This training would often be a combination of classroom and on-the-job training. After gaining this training and experience, the individual may earn a fivelevel designation. This designation allows the individual to perform more critical tasks and is also a requirement for promotion. With additional training, experience, and good performance, the individual may attain a seven-level designation, which may place him in a supervisory role, so that he is able to sign off work performed by others. The highest designation, a nine-level, means that the individual will assume a management position. Throughout this process, the individual may be given specialized training ranging from courses taught by the Air Training Command or manufacturer's technical representative on highly technical matters related to a new piece of equipment to courses in leadership and management.

\subsubsection{Technical Orders}

One of the fundamental requirements of the Air Force maintenance system is that maintenance must be performed using Technical Orders (TOs). TOs provide technical information, detailed procedures, and other job performance aids for specific maintenance activities. The TOs are developed by the contractor during the system acquisition program to be in compliance with specific requirements spelled out in Military Standards and Specifications. The TOs are continuously updated throughout the life of the system. A special type of TO is the Time Compliance Technical Order (TCTO). As the name implies, the TCTO is a directive with which compliance is required within a specific time limit. For example, if a corrosion problem is discovered in one aircraft in the fleet, it may be considered serious enough so that a TCTO is issued to every organization with that type of aircraft requiring that an inspection be performed within 48 hours and before the aircraft flies again. In some cases, the TCTO will not only give the details of how the inspection is to be performed, but will also provide the corrective action if this type of corrosion is discovered. If this inspection becomes a normal part of the aircraft preventive maintenance program, the regular TO is updated to include the requirements of the TCTO and the TCTO is cancelled.

\subsection{Maintenance Regulations and Practices in the U.S. Navy?}

Preventive maintenance in the U.S. Navy centers on two concepts: Reliability Centered Maintenance (RCM), which is the system used to determine what preventive maintenance needs to be performed, and the Planned Maintenance System (PMS), which describes who will perform the maintenance and how it will be performed. The system is very prescriptive and is aimed at minimizing maintenance and reducing the maintenance man-hours required on board a ship.

RCM is a logical discipline for developing a scheduled maintenance program that determines the inherent reliability levels of complex equipment. RCM provides an orderly record of the facts that initiated a maintenance task (Reliability Centered Maintenance Handbook, 1983). The RCM concept partitions equipment into systems and subsystems. A ship is divided into seven systems: hull structure, propulsion plant, electric plant, command and surveillance, auxiliary group, outfit and furnishings, and armament. These systems are further divided into subsystems. Systems and subsystems are then analyzed to determine the appropriate maintenance requirements.

PMS is a means for scheduling, planning, controlling, performing, and auditing the preventive maintenance determined by RCM. The system has been in use for 20 years. PMS is governed by OPANIST $4790.9 A$ of 27 August, 1984, Ships 3-M System Manual. This document gives the responsibility for PMS to the Commander, Naval Sea Systems Command. He is supported by the Systems Command and the Naval Medical Command. A specific PMS program is developed for each type of ship according to MIL-P-245348A (Navy), PMS Documentation Specification 2 weeks before a ship is being commissioned or converted.

Under the PMS program, maintenance is conducted according to a series of prescriptive documents. These documents specify, at a "nuts-and-bolts level," the actions that must be taken when maintenance is performed. A formal process exists to improve maintenance procedures through feedback based on operational experience.

\subsection{Summary of Lessons Learned}

The following points characterize maintenance in the U.S. Military:

- The Air Force and Navy have developed a systematic, prescriptive approach to maintenance. Such an

\footnotetext{
2The information in this section was compiled from the following major maintenance documents: NAVSEA Instruction 4790.8A, 6 June 1985; NAVSEA Instruction 4790.3B, 6 June 1985; and MIL-P-2453A (Navy), 7 May 1985. These documents were made available to the NRC by the U.S. Navy for this report.
} 
approach is essential because of the high turnover of personnel.

- The approaches to maintenance used in the Air Force and Navy are based on the assumption that readiness must be maintained and that sufficient resources will be provided to ensure that readiness.

- The Air Force makes use of an extensive, centralized data collection system.

- The crew chief concept, in which one person is responsible for-and takes pride in - the maintenance of a single aircraft, is of great benefit to the Air Force. A similar concept exists for ship-based systems in the U.S. Navy.

\section{REFERENCES}

Atoms in Japan. 1987. "Miti to Review Periodic Inspection System of Turbines of Nuclear Plants," May 1987.

Bemer, J. P. 1986. "Maintenance Success in Availability Trends," Nuclear Power Plant Maintenance, Proceedings from an International Meeting, March 23-27, 1986, Utah.

Bitsch, D. 1985. “Continuous Improvement of Operation and Maintenance Conditions of French PWR Nuclear Islands," Nuclear Power Plant Availability, Maintenance and Operation, International Atomic Energy Agency (IAEA), Vienna, pp. 209-216.

Boegel, A. J., et al. 1985. "Analysis of Japanese-U.S. Nuclear Power Plant Maintenance," NUREG/CR-3883, June 1985.

Code of Federal Regulations (CFR). 1987. Appendix B, "Quality Assurance Criteria for Nuclear Power Plants and Fuel Reprocessing Plants," 10 CFR Part 50.

Code of Federal Regulations (CFR). 1988. 14:121.

Code of Federal Regulations (CFR). 1988. 14:65.

Code of Federal Regulations (CFR). 1988. 14:25.

Degot, D., and G. Lebreton. 1985. "Standardization of Nuclear Power Plants," American Nuclear Society Transactions, May 19-23, 1985, 49:103-112.

Electricite de France, (EDF), Construction Division. 1982. The French Nuclear Electricity Programme, France.

Electric Power Research Institute. 1987. "EPRI Operations and Maintenance Source Book," EPRI NP-4986-SR.
Electric Power Research Institute. 1987. "Standard, Limitorque SMB Operators," Draft Technical Repair Standard.

Federal Aviation Administration (FAA). 1978. "Aircraft Maintenance Handbook," Advisory Circular 121-1A, Washington, D.C.: U.S. Department of Transportation.

FAA. 1987. This is the FAA, Washington, D.C.: U.S. Department of Transportation.

Federal Register (FR). 1988. 53:56.

Federal Register (FR). 1988. 53:9430.

Franzen, L. F. 1982. "The Nuclear Licensing and Supervisory Procedures for Nuclear Facilities in the Federal Republic of Germany," GRS-43, February 1982.

Hoensch, V., and J. Kolditz. 1985. "Organizational Measures for Maintenance of a Nuclear Power Plant," Nuclear Power Plant Availability, Maintenance and Operation, IAEA, Vienna, pp. 201-208.

IAEA. 1980. "France," Manpower Development for Nuclear Power, Technical Report Series No. 200, Vienna.

King, F. H. 1986. Aviation Maintenance Management, Southern Illinois University Press.

Matteson, T.D., J. F. McDonald, and A. M. Smith. 1984. "Commercial Aviation Experience of Value to the Nuclear Industry," Prepared by Los Alamos Technical Associates, Inc., for Electric Power Research Institute, NP-3364, Final Report, January 1984.

Mercier, J. P. 1987. "Nuclear Power Plant Maintenance the EDF Way," Presented at the International Executive Conference for NPP Maintenance, December 1987, Orlando.

National Academy of Sciences (NAS). 1980. Improving Aircraft Safety-FAA Certification of Commercial Passenger Aircraft, Washington, D.C.: National Academy of Sciences.

Nuclear News. 1988. 31(2):63-82.

O'Shima, E. 1986. "Maintenance Practice in Japanese LWRs," in International Meeting on Nuclear Power Plant Maintenance, Ed. R. J. Stouky, D. Majumdar, and M. Jones, Proceedings of the American Nuclear Society, March 23-27, 1986, pp. 4-27-4-38.

Reliability-Centered Maintenance Handbook. October 1983, Rev. Ed. Technical Report S9081-ABGIB-010/MAINT, published by Direction of Commander, Naval Sea Systems Command. 
Richardson, J. D., and J. F. Rodwell. 1985. Essentials of Aviation Management, Dubuque, IA: Kendall/Hunt.

Rippon, S. 1986. "The Nuclear Scene in Europe," Nuclear News, 29(7):86-100.

Rippon, S. 1985. "Training at Electricite de France," Nuclear News, 28(15):55-59.

Robertson, W. 1986. Statement of William G. Robertson, Pratt and Whitney, United Technologies Corp., in Aging Commercial Airline Fleet, Hearing before the Subcommittee on Aviation of the Committee on Commerce, Science and Transportation, U.S. Senate, April 15, 1986.

Schegk, J. R. R. 1986. "Maintenance Program, Organization, and Procedures," Presented at IAEA-Interregional Training Course, September 15-October 23, 1986, Essen.

Sumi, Y. 1987. "Good Performance in Japan is Proof of Continuing Safety and Reliability Improvement
Practice," Transactions of the American Nuclear Society, 54(suppl. 1):133.

Uebayashi, T., and Y. Miyake. 1985. "Pre-Service Inspection and In-Service Inspection in Japan," Transactions of the American Nuclear Society, 49 (suppl. 1):457-466.

U.S. Nuclear Regulatory Commission. 1986. "Status of Maintenance in the U.S. Nuclear Power Industry 1985: Findings and Conclusions,"NUREG-1212, Vol. 1, June 1986.

U.S. Nuclear Regulatory Commission. 1986. "Status of Maintenance in the U.S. Nuclear Power Industry 1985: Descriptions of Programs and Practices," NUREG-1212, Vol. 2, June 1986.

Vendryes, G. 1986. "Observations from France," LAEA Bulletin, Autumn, pp. 52-54.

Voelcker, J. 1986. “Gold-Plated Design," IEEE Spectrum, 23(11):56-66. 
APPENDIX A

JAPANESE MAINTENANCE PRACTICES 



\section{CONTENTS}

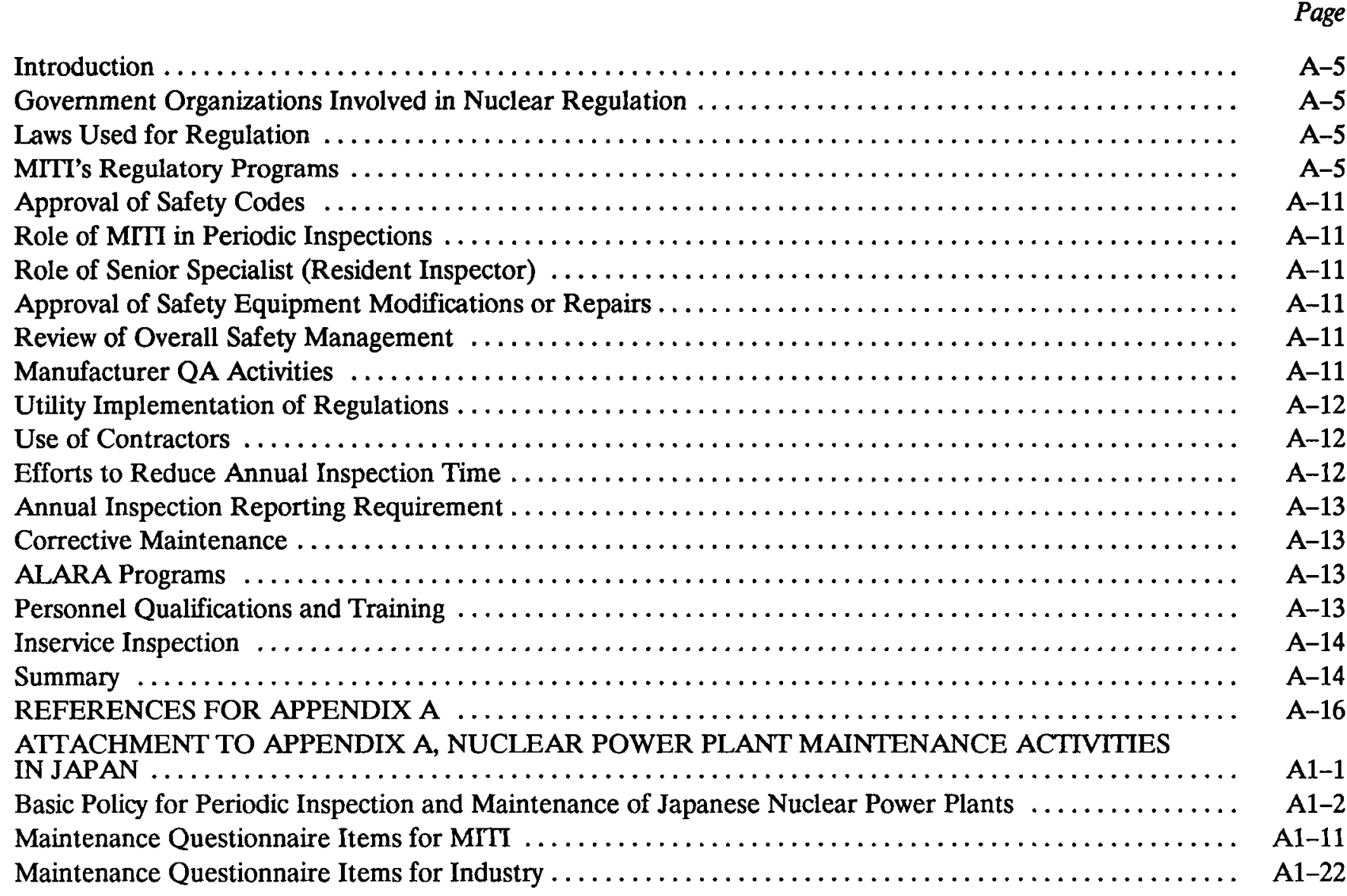

\section{FIGURES}

A.1. Government organizations involved in nuclear regulation $\ldots \ldots \ldots \ldots \ldots \ldots \ldots \ldots \ldots \ldots \ldots$

A.2. Regulation system regarding periodic inspection

A.1.1 Location of Senior Specialists for Nuclear Power Operation $\ldots \ldots \ldots \ldots \ldots \ldots \ldots \ldots \ldots \ldots \ldots$ A1-10

\section{TABLES}

A.1. Systems inspected during periodic outage .

A.1.1 List of periodic inspection items by MTTI (example) $\ldots \ldots \ldots \ldots \ldots \ldots \ldots \ldots \ldots \ldots \ldots \ldots \ldots$ A1-12

A.1.2 Scheduled inspection items in technical specifications (example) $\ldots \ldots \ldots \ldots \ldots \ldots \ldots \ldots \ldots \ldots \ldots$ A1-13

A.1.3 Summary of practice in periodic inspection plan (example for PWR) $\ldots \ldots \ldots \ldots \ldots \ldots \ldots \ldots \ldots$ A1-13

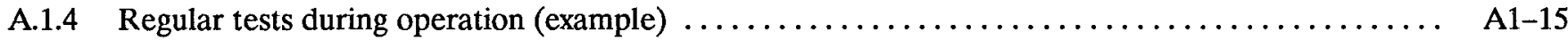

A.1.5 Practical example of PWR plant $\ldots \ldots \ldots \ldots \ldots \ldots \ldots \ldots \ldots \ldots \ldots \ldots \ldots \ldots \ldots \ldots \ldots \ldots \ldots \ldots$ 



\section{Introduction}

In 1985 , a study was conducted for the NRC to assess the degree to which differing approaches to the regulation and practice of nuclear power plant maintenance may explain the difference between U.S. and Japanese plants in the number of reactor trips and the availability of safety equipment (Boegel et al., 1985). The study found that the differences in performance measures appeared to stem from the structured, industrywide Japanese program of extensive preventive maintenance, consisting of statutory annual inspections, voluntary internal inspections, special work, and routine inspection.

The present review of Japanese maintenance practices and regulations is intended to update the 1985 study and to identify any new practices and regulations that may be beneficial in developing a proposed rule on maintenance. As part of this effort, discussions were held with representatives of both the Ministry of International Trade and Industry and the nuclear utilities regarding current maintenance regulations and practices. A copy of the information obtained during these discussions is presented in the attachment. The subject is complex and the temptation to generalize approaches to regulating U.S. nuclear power plant maintenance based on this limited report must be avoided. Although the nuclear power plants operated by the Japanese and the U.S. are very similar in design, there are complex differences that make direct comparisons difficult. Of particular importance are the great differences in the regulatory climate. The relatively nonadversarial climate in Japan results in the utilities not only complying with the requirements of the law but moving well beyond those requirements in order to maintain their plants in a highly reliable, cost-effective manner.

\section{Government Organizations Involved in Nuclear Regulation}

The Japanese Fundamental Act of 1955, as amended in 1978 , delegated the regulatory responsibility of nuclear reactors to three government agencies according to the type of reactor (MITI, n.d.). The Ministry of International Trade and Industry (MITI) became the regulatory authority over all aspects of commercial nuclear power. The Science and Technology Agency is the regulator for research reactors and the Ministry of Transportation regulates nuclear ships. Two other government agencies active in the nuclear arena are the Nuclear Safety Commission and the Atomic Energy Commission. These are advisory agencies to the Prime Minister that were established in the reformation of 1978 to unify the advancement and safety aspects of nuclear power. A diagram of the governmental regulatory agencies involved in nuclear reactor operations is presented in Figure A.1.

\section{Laws Used for Regulation}

MITI carries out its regulatory jurisdiction of maintenance conducted at commercial nuclear power plants through the Law for the Regulation of Nuclear Source Materials, Fuel Materials, and Reactors and through the Electric Utility Industry Law.

The Electric Utility Industry Law stipulates the technical standards for securing safety with regard to installation work, operation of electrical structures, and maintenance. It is this law that contains the primary requirement for maintenance-the mandatory periodic inspection (a scheduled outage for inspection and maintenance). The regulations associated with the periodic inspections are outlined in Figure A.2.

The regulation regarding the periodic inspection requires that "no plant is allowed to have continuous operation exceeding 13 months before it is required to shut down to perform periodic inspection" (Uebayashi and Miyake, 1985). Approximately 70 items of the nuclear reactor and related facilities are verified annually during the inspection. A list of specific items is shown in Table A.1. Various components of the steam turbine are inspected once every 2 years. MITI is currently reviewing operational information on steam turbines to determine if a change in inspection requirements will be necessary and at what level (Atoms in Japan, 1987). The level of inspection required for the various components is specified: "inspection by disassembling or opening, functional inspection, etc., shall be carried out according to the importance and conditions of use of the machines and instruments respectively in order to confirm their safety and soundness not being lost by the operation to the date and to judge whether there is any danger of such loss in the future" (MITI, n.d.).

\section{MITI's Regulatory Programs}

MITI administers several regulatory programs that are applied uniformly across all operating plants. Regulatory programs that directly or indirectly affect maintenance include:

- Annual inspections.

- Resident inspectors at all plants.

- Approval of plans prior to any modification or repair of safety-related components.

- Review overall safety management every 2 years or so. 


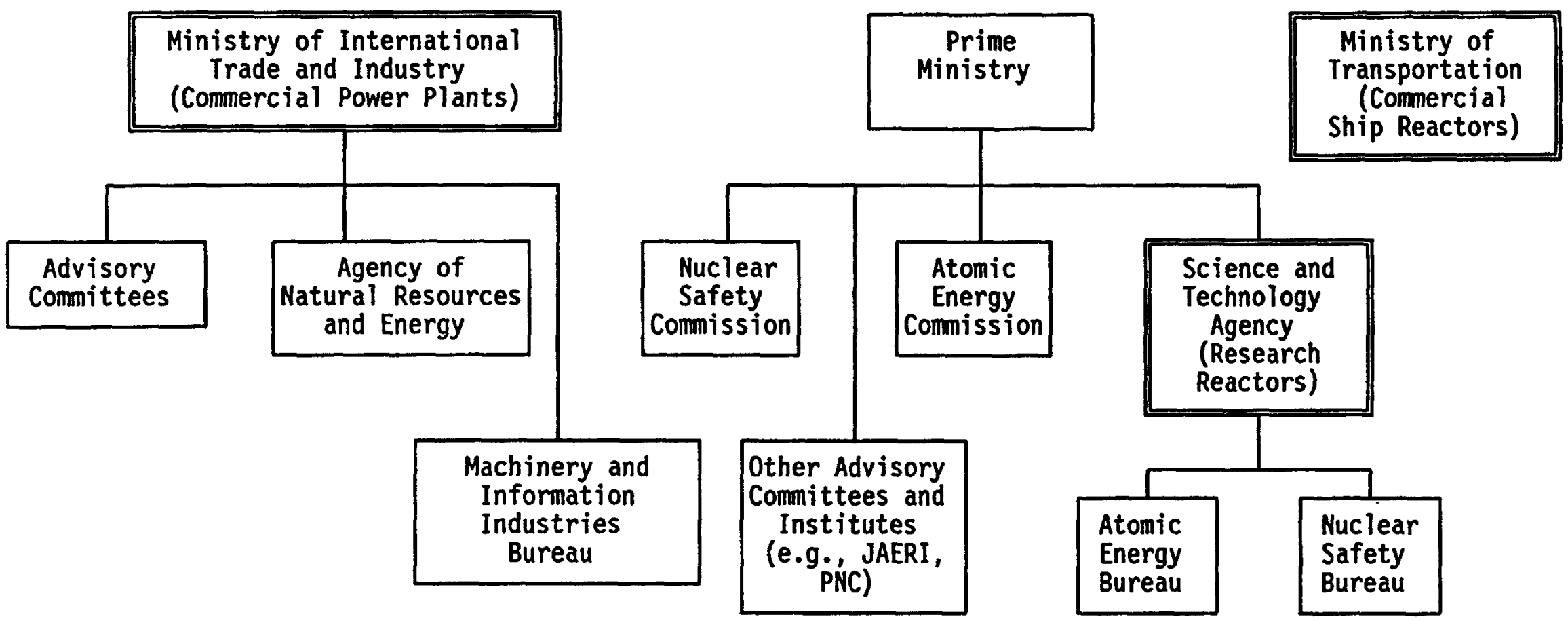

Figure A.1. Government organizations involved in nuclear regulation. 


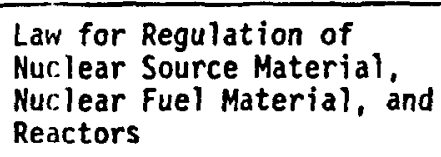

Article 35 Necessary measures__ Patrol of plant facilities

by the electric utility

- During operation

by the electric utility $L$ During inspection

Article 37 Approval of Safety

Safety Regulations

Regulations

Electric Utility Industry Law

Article 47 Periodic

Article 47 Periodic inspection
(perfomed by MITI) tandard rules (private rules)

Application for Periodic

inspection Inspection schedule

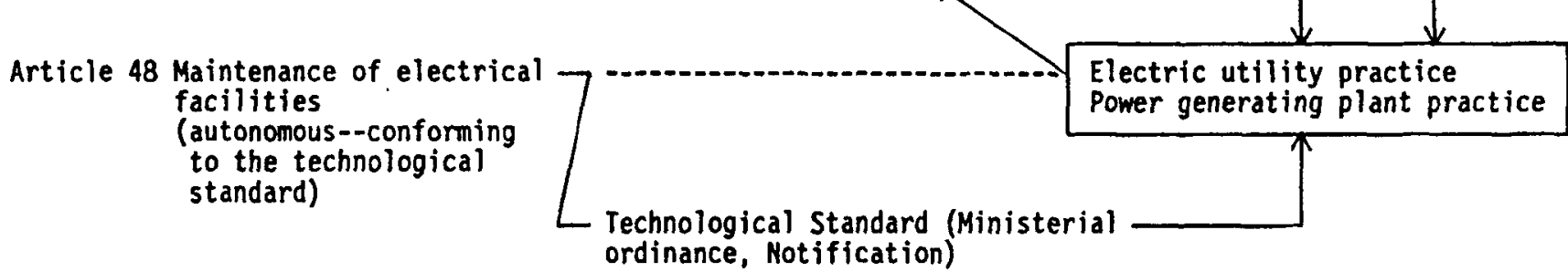


Table A.1. Systems inspected during periodic outage.

\begin{tabular}{|c|c|c|c|c|}
\hline \multirow[b]{2}{*}{ Electrie facility } & \multicolumn{2}{|c|}{$\operatorname{BWR}$} & \multicolumn{2}{|c|}{ PWR } \\
\hline & Name of facility & Contents of Inspection & Name of facilsty & Contente of Inspection \\
\hline \multirow{2}{*}{ Reactor asuesmbly } & $\begin{array}{l}\text { Reactor pressure } \\
\text { vessel }\end{array}$ & $\begin{array}{l}\text { Insorvice Inspection } \\
\text { (Non-destuctive } \\
\text { Inspection and } \\
\text { leak test) }\end{array}$ & pressure vessel & $\begin{array}{l}\text { Inservice Inspection } \\
\text { (Non-destructive } \\
\text { Inspection and } \\
\text { leak test) }\end{array}$ \\
\hline & Fuel assembly & $\begin{array}{l}\text { Slpping inspection, } \\
\text { visual inspection, } \\
\text { fuel shufking } \\
\text { inspection and } \\
\text { roactor shutown } \\
\text { margin inspection }\end{array}$ & Fuel assembly & $\begin{array}{l}\text { Sipping inspection, } \\
\text { pisual Inspection. } \\
\text { fuel shufiling } \\
\text { inspection and } \\
\text { reactor shutdown } \\
\text { margin inspection }\end{array}$ \\
\hline \multirow{7}{*}{$\begin{array}{l}\text { Reactor cooling } \\
\text { syetens }\end{array}$} & \multirow{2}{*}{$\begin{array}{l}\text { Main stear lines } \\
\text { safety valve } \\
\text { Relief valve } \\
\text { Isolating valve } \\
\\
\text { Turbine bypass valve }\end{array}$} & \multirow{2}{*}{$\begin{array}{l}\text { Disassembilng and In- } \\
\text { spection, functional } \\
\text { test } \\
\text { Ditto (Inelusive } \\
\text { of function of } \\
\text { automatic pressure } \\
\text { reducting system) } \\
\text { Leak rate test, } \\
\text { functional test, } \\
\text { functional tost }\end{array}$} & $\begin{array}{l}\text { steam genecator heat } \\
\text { exchanger tubes }\end{array}$ & Eddy current test \\
\hline & & & $\begin{array}{l}\text { Pressurizer } \\
\text { Safety valve } \\
\text { Rellef valve } \\
\text { Main rellet valve }\end{array}$ & $\begin{array}{l}\text { olsassembling and in } \\
\text { spection, leak test. } \\
\text { functional tast } \\
\text { Ditto } \\
\text { runctional test }\end{array}$ \\
\hline & $\begin{array}{l}\text { High pressure } \\
\text { injection systed } \\
\text { Low pressure } \\
\text { injection system } \\
\text { Core spray system }\end{array}$ & $\begin{array}{l}\text { Functional test, pump } \\
\text { disassembling ln- } \\
\text { spection linclusive of } \\
\text { auxiliacy steam } \\
\text { turbinel, main valve } \\
\text { disassembling and in- } \\
\text { spection }\end{array}$ & $\begin{array}{l}\text { main stean system } \\
\text { Safety valve } \\
\text { Relief valve } \\
\text { Isolating valva } \\
\text { Tucbine bypase } \\
\text { valve }\end{array}$ & $\begin{array}{l}\text { Leaktest, } \\
\text { functlonal test } \\
\text { oltto } \\
\text { runctlonal test } \\
\text { Dltto }\end{array}$ \\
\hline & $\begin{array}{l}\text { Cooling system for } \\
\text { isolated reactor } \\
\text { cooling system tor } \\
\text { auxiliary equipment } \\
\text { of the reactor } \\
\text { Hater supply pump }\end{array}$ & Functional test & $\begin{array}{l}\text { High pressure } \\
\text { injection system } \\
\text { Low pressure } \\
\text { injection system }\end{array}$ & $\begin{array}{l}\text { Punctional test, punp } \\
\text { disassembling and in- } \\
\text { spectlon, main valve } \\
\text { disassembling and } \\
\text { Inspection }\end{array}$ \\
\hline & \multirow[t]{3}{*}{$\begin{array}{l}\text { Vessels, plipings, } \\
\text { pumps and valves }\end{array}$} & \multirow[t]{3}{*}{ Inservice Inspection } & $\begin{array}{l}\text { hecumulator } \\
\text { Algh pressure, } \\
\text { injection syscen, } \\
\text { Reactor upper head } \\
\text { fnjection system }\end{array}$ & $\begin{array}{l}\text { Functlonal test, } \\
\text { maln valve dis- } \\
\text { assembling and } \\
\text { lnspection }\end{array}$ \\
\hline & & & $\begin{array}{l}\text { huxiliacy feedwater } \\
\text { fystem }\end{array}$ & $\begin{array}{l}\text { runctional test, punp } \\
\text { dissssembling and } \\
\text { inspection }\end{array}$ \\
\hline & & & $\begin{array}{l}\text { Neseel, plping, } \\
\text { pumps, valves }\end{array}$ & Inservice Inspection \\
\hline
\end{tabular}


Table A.1. (Continued)

\begin{tabular}{|c|c|c|c|c|}
\hline \multirow[b]{2}{*}{ Electric facillty } & \multicolumn{2}{|c|}{ BHR } & \multicolumn{2}{|c|}{ PWR } \\
\hline & Name of facility & Contents of Inspection & Name of tacility & Contents of Inspection \\
\hline \multirow{4}{*}{$\begin{array}{l}\text { Instrumentation } \\
\text { control system }\end{array}$} & $\begin{array}{l}\text { Instrument aic oystem } \\
\text { Boric acid injection } \\
\text { system }\end{array}$ & Functional inspection & $\begin{array}{l}\text { Control rod drlve } \\
\text { mechanleum } \\
\text { Instrument alc ayaten }\end{array}$ & runctlonal test \\
\hline & $\begin{array}{l}\text { Control rod drlving } \\
\text { system }\end{array}$ & $\begin{array}{l}\text { Functional test, } \\
\text { overhaul inspection of } \\
\text { the deive mechanism, } \\
\text { disassembling and in- } \\
\text { spection of the scrum } \\
\text { valve }\end{array}$ & \multirow[t]{3}{*}{$\begin{array}{l}\text { safety protection } \\
\text { syaten }\end{array}$} & \multirow[t]{3}{*}{ Callbration test } \\
\hline & $\begin{array}{l}\text { safety protection } \\
\text { syatem }\end{array}$ & $\begin{array}{l}\text { Inspection of safety } \\
\text { ordtection lement } \\
\text { (functional), } \\
\text { callbration test }\end{array}$ & & \\
\hline & $\begin{array}{l}\text { Wuclear Reactor } \\
\text { protection system }\end{array}$ & $\begin{array}{l}\text { Eunctional test of } \\
\text { plant interloek }\end{array}$ & & \\
\hline Fuel system & $\begin{array}{l}\text { Puel handing } \\
\text { system }\end{array}$ & Functional test & $\begin{array}{l}\text { Fuel handling } \\
\text { device }\end{array}$ & Functlonal test \\
\hline \multirow{2}{*}{$\begin{array}{l}\text { Radlation control } \\
\text { systen }\end{array}$} & $\begin{array}{l}\text { Fleld monitoring } \\
\text { area-monitoring } \\
\text { process monitoring }\end{array}$ & Punctional test & \multirow{2}{*}{\begin{tabular}{|l} 
Eleld monitoring \\
Area and process \\
monitoring \\
Annulus recicculation \\
exhaust syatem \\
Recirculation gystem \\
cot main control \\
coom
\end{tabular}} & \multirow{2}{*}{ Functional test } \\
\hline & $\begin{array}{l}\text { Emergency gas } \\
\text { treatment system } \\
\text { Reciruclation system } \\
\text { for main control }\end{array}$ & $\begin{array}{l}\text { Functional test, } \\
\text { filter performance teat }\end{array}$ & & \\
\hline \multirow[t]{2}{*}{$\begin{array}{l}\text { Waste disposal } \\
\text { system }\end{array}$} & $\begin{array}{l}\text { Gaseous waste } \\
\text { treatment system } \\
\text { Liquied waste } \\
\text { treatment system } \\
\text { leakage detector for } \\
\text { liquid radioctive } \\
\text { waste and warning } \\
\text { device }\end{array}$ & Functional test & $\begin{array}{l}\text { Gaseous waste } \\
\text { treatment system } \\
\text { Llquiled waste } \\
\text { treatment syatem } \\
\text { Solld waste } \\
\text { treatment systen } \\
\text { Leakage detector for } \\
\text { liquid radioactive } \\
\text { waste and warning } \\
\text { device }\end{array}$ & Eunctional test \\
\hline & Solld waste storage & $\begin{array}{l}\text { Inspection of control } \\
\text { condition }\end{array}$ & Solld waste storage & $\begin{array}{l}\text { Inspection of control } \\
\text { condition }\end{array}$ \\
\hline \multirow{4}{*}{$\begin{array}{l}\text { Reactor } \\
\text { Containment }\end{array}$} & $\begin{array}{l}\text { Reactor containment } \\
\text { Isolation valve } \\
\text { Vacuum breaker }\end{array}$ & $\begin{array}{l}\text { Leak rate test } \\
\text { Functional test, } \\
\text { Disassemiling and } \\
\text { inspection } \\
\text { Functional test }\end{array}$ & $\begin{array}{l}\text { Reactor containment } \\
\text { Isolation valve } \\
\text { Vacuum rellet valve }\end{array}$ & $\begin{array}{l}\text { Leak rate test } \\
\text { Functional test, } \\
\text { pisassembiling and } \\
\text { inspection } \\
\text { Punctional test }\end{array}$ \\
\hline & $\begin{array}{l}\text { Reactor containment } \\
\text { Spray system }\end{array}$ & $\begin{array}{l}\text { Eunctional test, pump } \\
\text { disassembling and } \\
\text { lnspection, main } \\
\text { valve disassembling } \\
\text { and inspection }\end{array}$ & $\left\{\begin{array}{l}\text { Reactor containment } \\
\text { Spray system }\end{array}\right.$ & $\begin{array}{l}\text { Functional test, pump } \\
\text { disassembling and } \\
\text { inspection maln } \\
\text { valve disassembling } \\
\text { and inspection }\end{array}$ \\
\hline & $\begin{array}{l}\text { Conbustible gas } \\
\text { concentration control } \\
\text { system }\end{array}$ & $\begin{array}{l}\text { Functional test, main } \\
\text { valve disassembiling and } \\
\text { Inspection }\end{array}$ & $\begin{array}{l}\text { Reactor containment } \\
\text { hydrogen recombiner }\end{array}$ & Functional test \\
\hline & Reactor building & Leak tost & Ice condensor & Functional test \\
\hline
\end{tabular}


Table A.1. (Continued)

\begin{tabular}{|c|c|c|c|c|}
\hline \multirow[b]{2}{*}{ zlecterle facillty } & \multicolumn{2}{|c|}{ BWR } & \multicolumn{2}{|c|}{ PWR } \\
\hline & Name of tacility & Contents of Inapection & Hame of eacillty & Contents of Inspection \\
\hline steam turbine & $\begin{array}{l}\text { Turbine and } \\
\text { accessories } \\
\text { (valves ote) }\end{array}$ & $\begin{array}{l}\text { Ovorhaul inspection, } \\
\text { Functional test } \\
\text { (values ete) }\end{array}$ & $\begin{array}{l}\text { rurbine and } \\
\text { accessories }\end{array}$ & $\begin{array}{l}\text { overhaul inspection, } \\
\text { runctional test }\end{array}$ \\
\hline Auxillary boller & $\begin{array}{l}\text { Auxillary boiler } \\
\text { and accessories } \\
\text { (values etc) }\end{array}$ & Overhaul inspection & Auxiliary botler & Functional test \\
\hline $\begin{array}{l}\text { Emergency power } \\
\text { generating system }\end{array}$ & $\begin{array}{l}\text { Emergency power } \\
\text { generating set }\end{array}$ & Functional test & $\begin{array}{l}\text { Emergency power } \\
\text { generating set }\end{array}$ & Functional test \\
\hline peher: & others & $\begin{array}{l}\text { Overall plant } \\
\text { performance teat }\end{array}$ & pehers & $\begin{array}{l}\text { overall plant } \\
\text { performance teat }\end{array}$ \\
\hline
\end{tabular}




\section{Approval of Safety Codes}

A utility must have its own safety procedures specifying the rules pertaining to various operations of the facility (Matsuda et al., 1984). Before starting operations, a utility must submit for approval a detailed plan of safety procedures to MITI. Included in this plan are the safety codes or procedures pertaining to routine and periodic inspections.

\section{Role of MITI in Periodic Inspections}

MITI enforces the legal requirements of the annual inspections by inspecting safety-related equipment as well as some balance-of-plant equipment. Inspectors representing MITI witness the inspection work at preestablished points and verify the inspection results. Prior to 1980 , all inspections were observed by MITI. Since then, the Nuclear Power Plant Inspection Center, under contract to MITI, has performed about two-thirds of the inspections (Boegel et al., 1985).

The utility is given the overall responsibility of preparing the equipment for the inspection, as well as the planning and scheduling of the inspection by MITI. Consequently, the actual examination/inspection by MITI does not require a large amount of manpower. Most utilities will have completed their own inspections and verified operability prior to the MITI inspection.

MTTI provides feedback immediately to the plant on the results of an inspection. In case of a failure or discrepancy, the inspector and the utility come to an agreement on the necessary corrective action (Boegel et al., 1985).

\section{Role of Senior Specialist (Resident Inspector)}

In response to the accident at Three Mile Island 2, MITI required that a senior specialist, similar to the NRC's resident inspector, be stationed at every operating site to supervise operations and ensure safe operation.

As described by Matsuda (1985), "the role of the resident inspector is to primarily monitor daily operations and to act as a contact point at the time of an accident." The specific duties of the resident inspector include:

- Monitoring the status of operations, including patrolling the facilities and checking compliance with safety procedures (reviewing inspection checksheets, visually confirming periodic self-inspections, confirming records transferred between shift supervisors, checking and confirming maintenance works, etc.).
- Routine reporting on the status of operations to MITI.

- Instructing licensee personnel in accordance with directions from MITI and acting as a contact point in case of an accident.

- Monitoring and instructing onsite safety education and training.

- Instructing and supervising utility personnel in relation to operation management.

\section{Approval of Safety Equipment Modifications or Repairs}

MITI requires that prior to any modification or repair of a component subject to the Electric Utility Industry Law, such as plugging of steam generator tubes or replacement of safety valves or major valves, a plan be submitted for approval. All work is then subject to inspection by MITT with the inspection to be carried out at pre-established points as specified in the applicable law. The equipment can then only be used after passing the inspection (O'Shima, 1986).

\section{Review of Overall Safety Management}

MITI offices conduct a safety review of each nuclear power plant every 2 years or so. The purpose of this review is to ensure that the voluntary safety management system performed by the utilities is improving the safety and reliability of nuclear power generation. Items reviewed can vary but usually include the following:

- The quality assurance and inspection system.

- The utility's management and audit system.

- Technology support and emergency operations system.

- The basic plan of management during operation combined with education and training, facility improvement, and the use of information from accidents, failures, etc.

- Radiation control and radwaste control.

\section{Manufacturer QA Activities}

When the Japanese refer to quality assurance or quality control, they are referring to activities undertaken to ensure the quality of vendor-supplied components. Thus, the primary responsibilities of a utility's quality control organization are working with the manufacturers on the design and quality of the manufacturing process of the 
components and equipment. Quality control is thus the primary responsibility and activity of the manufacturer.

One manufacturer emphasizes that the reliability and quality of their products depends upon the individual worker (Fujiwara et al., 1981). They have in place a "Qman check system." Under this system, one individual takes responsibility for his workshop, ensuring that no defective parts make their way to subsequent stages in the manufacturing process. This manufacturer believes that this increases the quality morale within the work group and, as a result, is more likely to ensure the quality of the products. This system is analogous to the crew-chief system implemented in the U.S. Air Force.

The utilities, manufacturers, and other support companies establish steady and cooperative interrelationships that have been identified as a key factor in integrating the various goals and activities necessary for a plant to achieve high reliability and safety (O'Shima, 1986). The teamwork approach among all active parties in the initial construction of a plant has been credited by Sumi (1987) with providing "an atmosphere of participatory awareness among the parties that will eventually be implemented into a groupwide quality control program after the plant is commissioned."

\section{Utility Implementation of Regulations}

There is a long-term aspect and a short-term aspect in the planning of periodic maintenance inspections. Utilities typically develop long-term (10-year) inspection schedules that provide the general framework for each annual inspection. The precise scope of the inspection is not detailed in the regulations; hence, the specific scope of the inspection is agreed upon by the utility and MITI prior to the pending inspection. Through discussions, such things as the facility's recent operational experience and other industry experience can be taken into consideration and the long-term schedule modified accordingly. Although there are pre-established inspection items to be covered in each inspection, inspections carried out during a scheduled outage are not limited to code requirements. Many other inspections that are mostly based on troubles experienced in both domestic and overseas plants can be included.

\section{Use of Contractors}

Most utilities have adopted the general contracting system for the work required in the annual inspection. Typically, more than 1,000 workers are required during the inspection. The utility retains responsibility and control for all the planning and scheduling and uses manufacturers or contractors to perform the specific work required. Many contractors might be used for various aspects of an inspection, so a utility will use one general contractor to supervise inspection and coordinate the work performed by the specialists that are supplied by the subcontractors. Usually, the manufacturers perform the inspection tasks of disassembling and assembling equipment for the reactor pressure vessel. Contractors will sometimes perform the work under the instruction and supervision of the manufacturer. There are certain types of work that some utilities prefer to do themselves; for example, work performed on the instrumentation and control system (O'Shima, 1986).

All procedures for the work to be performed are precisely specified beforehand (O'Shima, 1986). A checksheet that contains the information on the parts subject to replacement or inspection is used to verify that each step of the work has been performed correctly.

A superintendent is responsible for the designated major inspection work. The superintendent is first qualified by a technical qualification committee comprised of individuals representing the utility, plant manufacturers, and major contractors. A qualified superintendent has had training courses on the general and specialized skills that are required and has completed a written exam, an on-the-job examination, and an interview.

\section{Efforts to Reduce Annual Inspection Time}

The amount of time an inspection typically takes has been decreasing at Japanese nuclear power plants over the last few years. Several factors that the Japanese attribute to this trend include:

- The reduction in corrective maintenance as initial equipment problems have been resolved.

- Aggressive use of information collected on equipment performance.

- More efficiency in the orchestration and administration of inspections.

- Longstanding cooperation with manufacturers and other concerned parties.

- Overall technical improvements in maintenance and repair.

- Extensive education and training programs.

An inspection currently takes approximately 100 days. Because of this and the limited time a plant is allowed to operate continuously (no longer than 13 months), the maximum capacity that a good performing plant can achieve within the current regulations is $80 \%$ (MacLachlan, 1987). For these reasons, the nuclear industry is trying to find ways in which to decrease the amount of time it takes to perform an inspection and increase the amount of time a plant can operate between inspections. 
Ways in which utilities are anticipating reducing the time for annual inspections include:

- Improving detection techniques to provide more accurate and reliable inspection results to minimize inspection and evaluation time.

- Developing automated inspecting tools to minimize radiation exposure and inspection time.

- Alleviating "critical paths" in the work performed.

- Continuing evaluation of data collected on equipment performance and experience to identify inspections that can be done every 2 or 3 years instead of annually.

- Developing computer management systems for processing and evaluating the extensive amount of data collected.

One utility has submitted to MITI a request for authorization to extend the amount of time its facility is allowed to operate between scheduled outages from 13 months to 15 months. MITI will not make a decision for a few years to determine the effect on specific parameters such as scram rates in plants that are performing well and that currently have a 13-month operation and a 10-week inspection cycle. Utilities will also be required to demonstrate that major components can operate reliably for more than a year (MacLachlan, 1987).

\section{Annual Inspection Reporting Requirement}

The following items are included in the report that must be submitted to MITI upon completion of the inspection (Boegel et al., 1985):

- A general overview of the inspection.

- A list of items included in the inspection.

- A general itemized summary of the results of the inspection.

- A summary of the refueling operation.

- A list of the repair work and modification work accomplished.

- A summary of radiation control measures taken.

- A commitment to continue to conduct future inspections in accordance with the long-range plan.
- A list of actions taken in response to input provided by consultants.

- A list of actions taken in response to problems that have occurred within the Japanese industry.

- A summary of the pre-inspection performance history of the plant.

- The problems discovered during the course of the periodic inspection that would have caused a shutdown if the plant were at power (these are viewed as seriously as forced outages and are tracked accordingly by MITI).

Upon completion of the inspection outage, the Japanese facility performs a formal startup program culminating in a formal full-power inspection.

\section{Corrective Maintenance}

Most corrective maintenance in Japanese nuclear power plants is performed during the scheduled outage. Because of the effectiveness of their preventive maintenance program, there are few cases where the Japanese have to perform corrective maintenance between scheduled outages. Minor repairs may be made while the plant is operating. Corrective maintenance that would require the unit to reduce power or perform a controlled shutdown must be reported to MITI. An extensive analysis is performed to determine the cause of the problem. In those rare cases where the unit must reduce power or shut down for maintenance, there is an extensive postmaintenance test program to ensure that the problem has been fixed before the unit is restarted or restored to fullpower operation.

\section{ALARA Programs}

There is strong public pressure to minimize radiation exposure; consequently, this is a primary concern addressed and included in many of the policies implemented by MITI.

On the average, despite the longer and more detailed inspections conducted, the Japanese preventive maintenance program does not appear to result in a higher exposure rate than that experienced in the U.S. (Boegel et al., 1985). The Japanese, as mentioned earlier, are actively pursuing the use of robots for inspection work, not only to perform time-consuming tasks but to minimize radiation exposure.

\section{Personnel Qualifications and Training}

As contractors or vendors are used for most maintenance activities, the utility's maintenance personnel both plan 
and supervise the work performed by the contractors. The training program is thus geared toward an education in support of these areas.

A few utilities, such as Kansai Electric Power Co., have credited the "lifetime-employment" concept in Japan with enabling them to establish a systematic approach to education and training for the duration of an employee's career (IAEA, n.d.). Training is carried out at training centers and plant sites. One utility described the profile of their maintenance personnel as high school graduates who, upon entering the company, go through a year of basic engineering education provided by the company. The next year encompasses on-the-job training or an apprenticeship position. This particular utility also has a maintenance training facility that provides the formal training and education outlined for its maintenance employees across the span of their careers.

\section{Inservice Inspection}

The requirements for inservice inspection (ISI) are detailed in the regulation JEAC-4205-1980, "Inservice Inspection of Light Water Nuclear Power Plant Components." This requirement is similar in concept to the ASME Code Section XI. A task group formed by Japan Electric Association in 1975 has the primary responsibility of updating and revising the code approximately every 5 years.

Prior to ISI work, the utility prepares a detailed plan according to JEAC -4205 and submits it to MITI for review. The actual work is performed by the plant manufacturer or equipment supplier, who also prepare the detailed procedures. During the inspection, inspectors from Japan Power Plant Inspection Institute (JPPII) witness the work and verify the results. MITI will then confirm the results. If any discrepancies are discovered, any further actions must first be reviewed and approved by MITI (Uebayashi and Miyake, 1985).

New inspection techniques or automated inspection tools must first be qualified by a committee comprised of representatives from MITI, JPPII, the utility, the manufacturer, and other authorities. New inspection techniques must also be proved reliable. A program entitled "Proving Tests on the Effectiveness of Inservice Inspection" is undertaken by the ISI committee in the Nuclear Power Engineering Test Center (NUPEC) of Japan under the authority of MITI (Uebayashi and Miyake, 1985).

\section{Summary}

The following is a summary of the maintenance-related activities conducted by the Ministry of International Trade and Industry (MITI) and the Japanese nuclear industry. These have been organized to address the areas identified in the final Commission Policy Statement on Maintenance of Nuclear Power Plants (53 FR 9430) as being necessary parts of a nuclear plant maintenance program.

- Technology in the Areas of Corrective, Preventive, and Predictive Maintenance. The primary regulation for maintenance, the mandatory inspection, is specified in the Electric Utility Industry Law. This law states that a plant cannot operate for more than 13 months without shutting down for a periodic maintenance inspection. Approximately 70 items in the nuclear reactor and related facilities are inspected annually. Components in the steam turbine are inspected every 2 years. The level of inspections can involve such activities as disassembly and measurement of wear of individual components. The items to be inspected and the type of inspections are based in part on data collected from previous inspections (for example, wear data from teardown inspections).

- Technology in the Area of Surveillance. The routine inspection aspect of the Japanese preventive maintenance program is the analog of surveillance testing in the U.S. Specific testing requirements for a plant are listed in the facility's safety codes. Operational testing is generally de-emphasized and appears to be targeted at detecting passive failures. Verification of functional operability is apparently relegated to the mechanical inspections and functional tests performed during the inspection outage. Any inservice inspection activities are reviewed, approved, and verified under the authority of MITI.

- Quality Assurance and Quality Control. Quality assurance is primarily viewed as the responsibility of the manufacturer. The quality assurance divisions of a utility are primarily responsible for ensuring that a manufacturer's design and manufacturing process is of the latest technology and conducive to the highest quality of production.

- Equipment History and Trending. The Japanese collect extensive data on equipment performance with regard to domestic as well as overseas experience. In order to persuade MITI to allow extended operation periods and shorter inspection periods, utilities need to be able to demonstrate that components can operate reliably for more than a year. Equipment performance records have also enabled the Japanese to gradually update and improve on the problem equipment found in earlier power plant designs. These data are also used in planning the scheduled outage and in preparing the detailed plan for the outage that is submitted to MITI for approval.

- Maintenance Records. Because the Japanese have such an aggressive data collection and evaluation approach, computers are essential in processing and 
evaluating the large amounts of data. Several maintenance data systems are being used and developed by utilities in order to increase efficiency in the collection and evaluation process (Kishiwada et al., 1986).

- Management of Parts, Tools, and Facilities. This area is being addressed by the Japanese in trying to develop computerized and artificial intelligence maintenance systems that will be able to assist in the management of work procedures and job requirements.

- $\quad$ Procedures. MITI reviews summary procedures during an audit of an important modification or repair but typically leaves the specific procedures to the regulation of the utilities.

- Post-Maintenance Testing and Return-to-Service Activities. Included in post-maintenance testing are such items as pumps, valves, vessels, and electric parts and boards. MITI witnesses some functional tests prior to restart after a periodic outage. Before a plant can begin commercial operation, MTTI witnesses tests for overall plant performance. These tests include:

- Reactor shutdown margin test

- Functional test of high/low pressure injection systems

- Functional test of emergency generator

- $\quad$ Measures of Overall Program Effectiveness. Indicators that MITI uses to evaluate the effectiveness of maintenance activities are:

- Rate of unplanned outage

- Availability factor

- Rate of occurrence of incidents and failures regarding safety systems events that may lead to a failure incident/failure

- Total exposure dose of the plant personnel

- Amount of waste generated

Industry uses the same indicators as MITI to determine maintenance program effectiveness with the exception of rate of unplanned outages and various events that may lead to a failure incident/failure.

- Maintenance Management and Organization in the Areas of Planning, Scheduling, Staffing, and Shift Cover- age. For important modification and repair activities such as steam generator tube plugging or main piping replacement, MITI approval is required. For important safety items, MITI ensures that they are included in the periodic inspection. For other major items, MITI provides oversight to the plants through the audit of the operation, facilities, and periodic inspection plans.

- Control of Contracted Maintenance Services. For the annual inspections, utilities will typically have one general contractor who is responsible for supervising and coordinating the contracted work force that typically is comprised of more than 1,000 people representing more than 20 different companies. These companies generally specialize in performing maintenance on a specific system (e.g., the turbine). Utilities retain the overall responsibility for overseeing the scheduling of the work. The use of contractors during operations has been addressed in the questionnaire (see the attachment).

- Radiological Exposure Control (ALARA). The nuclear industry in Japan operates under very critical surveillance by the Japanese population. Consequently, significant measures are taken to minimize radiation exposure of its employees. Currently, the Japanese are turning toward the use of robots or other automated techniques in order to minimize the exposure of the workers to radiation.

- Personnel Qualification and Training. Most utilities abide by the lifetime employment system that enables them to outline a systematic approach to education and training across the span of their employees' careers. A typical program includes an initial year at a company's engineering school, formal training provided at maintenance training centers, an apprenticeship position that provides on-the-job training, followed by specific training classes as the employee begins to specialize.

- Internal Communications Between Maintenance Organization and Plant Operations and Support Groups. Within each utility, regular meetings are held to review safety measures and maintenance schedules. The objective is to provide information on the conditions and activities of the various organizational units to ensure that problems can be avoided and the most appropriate approach developed. 


\section{REFERENCES FOR APPENDIX A}

Atoms in Japan. 1987. "MITI to Review Periodic Inspection System of Turbines of Nuclear Plants," May 1987.

Boegel, A.J., et al. 1985. "Analysis of Japanese-U.S. Nuclear Power Plant Maintenance," NUREG/CR-3883, June 1985.

Fujiwara, K., A. Moriyama, and K. Okabe. 1981. "Quality Assurance Activities by the Companies in the Mitsubishi Group for Nuclear Power Plants in Japan," Quality Assurance for Nuclear Power Plants, Proceedings of an International Symposium on Quality Assurance for Nuclear Power Plants Organized by the International Atomic Energy Agency held in Paris, 11-15 May, 1981, IAEASM-253/9.

International Atomic Energy Agency (IAEA). n.d. "Education and Training of Personnel in Japan: Case in Kansai Electric Power Co.," Technical Report No. IAEACN-49/15.

Kishiwada, K., A. Muramatsu, and K. Isomura. 1986. "Maintenance Management System in the Fugen," in International Meeting on Nuclear Power Plant Maintenance, Ed. R. J. Stouky, D. Majumdar, and M. Jones, Proceedings of the American Nuclear Society, March 23-27, 1986, pp. 14-10-14-20.

MacLachlan, A. 1987. "Japan Moving Prudently Toward Shorter Inspections, Longer Cycles," Nucleonics Week, 28(44):11.
Matsuda, Y. 1985. "Experience in the Operation and Maintenance of Commercial Nuclear Power Plants in Japan," Transactions of the American Nuclear Society, 48:17-20.

Matsuda, Y., K. Suehiro, and S. Taniguchi. 1984. "The Japanese Approach to Nuclear Power Safety," Nuclear Safety, 25(4):451-471.

MITI. n.d. Outline of Safety Regulations Administration for Commercial Nuclear Power Plants in Japan, Agency of Natural Resources and Energy, Ministry of International Trade and Industry, Tokyo, Japan.

O'Shima, E. 1986. "Maintenance Practice in Japanese LWRs," in International Meeting on Nuclear Power Plant Maintenance, Ed. R. J. Stouky, D. Majumdar, and M. Jones, Proceedings of the American Nuclear Society, March 23-27, 1986, pp. 4-27-4-38.

Sumi, Y. 1987. "Good Performance in Japan is Proof of Continuing Safety and Reliability Improvement Practice," Transactions of the American Nuclear Society, 54 (suppl. 1):133.

Uebayashi, T., and Y. Miyake. 1985. "Pre-Service Inspection and In-Service Inspection in Japan," Transactions of the American Nuclear Society, 49 (suppl. 1):457-466. 


\section{ATTACHMENT TO APPENDIX A NUCLEAR POWER PLANT MAINTENANCE ACTIVITIES IN JAPAN}

As part of the assessment of Japanese nuclear maintenance regulations and practices, two sets of approximately 20 questions each were developed covering the areas that the NRC had identified as being necessary for a proper maintenance program. One set of questions was directed at obtaining information from the Ministry of International Trade and Industry (MITI). The other set was developed for utility respondents. Both sets were pro- vided to MI'TI for their distribution.

The responses to the questions are provided in the following sections. Also included in this attachment is an overview of the management of periodic inspection activities, a table of the education and training requirements for maintenance personnel, and a review of the activities of electrical facility inspectors. 


\section{BASIC POLICY FOR PERIODIC INSPECTION AND MAINTENANCE OF JAPANESE NUCLEAR POWER PLANTS}

\section{Management of plant facilities after opera- tion of the nuclear power plant has started.}

\section{A. Management of plant facilities during operation}

Inspection after the start of the operation of the nuclear power plant facilities consists of periodic inspection performed regularly (while operation of the major equipment is suspended) and surveillance tests during operation to check the condition of the equipment.

\section{B. Periodic inspection}

Periodic inspection is required about every 12 months (at most 13 months) of operation and is performed with the plant shut down for 3 to 4 months. On that occasion, the equipment and systems are inspected, and their integrity is confirmed to prevent failures during operation, based on the philosophy of "preventive maintenance."

1. Regular autonomous inspection and maintenance performed voluntarily by the electric power company

In order to prevent component failures and degradation of performance as well as to maintain safety and integrity, inspection, maintenance, and replacement, as required, are systematically carried out on all equipment in the entire plant, including reactor facilities, turbine facilities, and electrical and instrumentation facilities, taking into account the history and operational status of each component and incorporating state-of-the-art technological information.

Basically, the following maintenance and inspections are carried out on the major facilities and equipment:

a. Overhauling (disassembling and inspection)-The integrity of the material, structure, and strength of the components is confirmed by visual or nondestructive inspection during disassembly.

b. Reassembling and functional test of the system components-Each component is reassembled, and its functions are tested.

c. Functional test and conditioning operation of the system-The function of the system is tested after the components and systems are reassembled and the operating condition of the plant is confirmed. Then the functional test of the plant is performed.

\section{Periodic inspection by government}

The government (MITI) performs inspections on important items (presently about 70) to enable continuance of stable operation of the nuclear power plant from the following viewpoints:

a. Disassembly, inspection, and functional test of such safety-related facilities and equipment as the reactor automatic shutdown system.

b. Nondestructive testing to confirm the integrity of the reactor pressure vessel, main piping, and valves.

c. Inspection of important components and facilities with reference to past experiences both at home and overseas.

d. Inspection at the final stage of commissioning operation to test the comprehensive function of the plant for safe and stable operation.

The main subjects for inspection are:

- Reactor and associated systems

- reactor

- reactor coolant system

- instrumentation system

- fuel assembly and fuel handling system

- radiation control system

- waste disposal system

- containment vessel

- auxiliary boiler

- emergency power generating system

- Steam turbine system

C. Inspections and checks during operation

The following inspections and checks are performed during operation.

1. Monitoring of operating conditions such as pressure, temperature, and water level.

2. Water chemistry.

3. Periodic tests during operation to confirm the function of safety protection systems and engineered safety features.

4. Observation and checks of the reactor facility to monitor the operating condition of the components and for early detection of abnormality (more than once per day). 


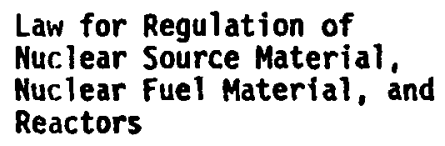

Article 35 Necessary measures

for safety assurance

Patrol of plant facilities

by the electric utility

Voluntary inspections

During operation

by the electric utility $L_{\text {During inspection }}$

Article 37 Approval of Safety Regulations

Safety Regulations

Electric Utility Industry Law

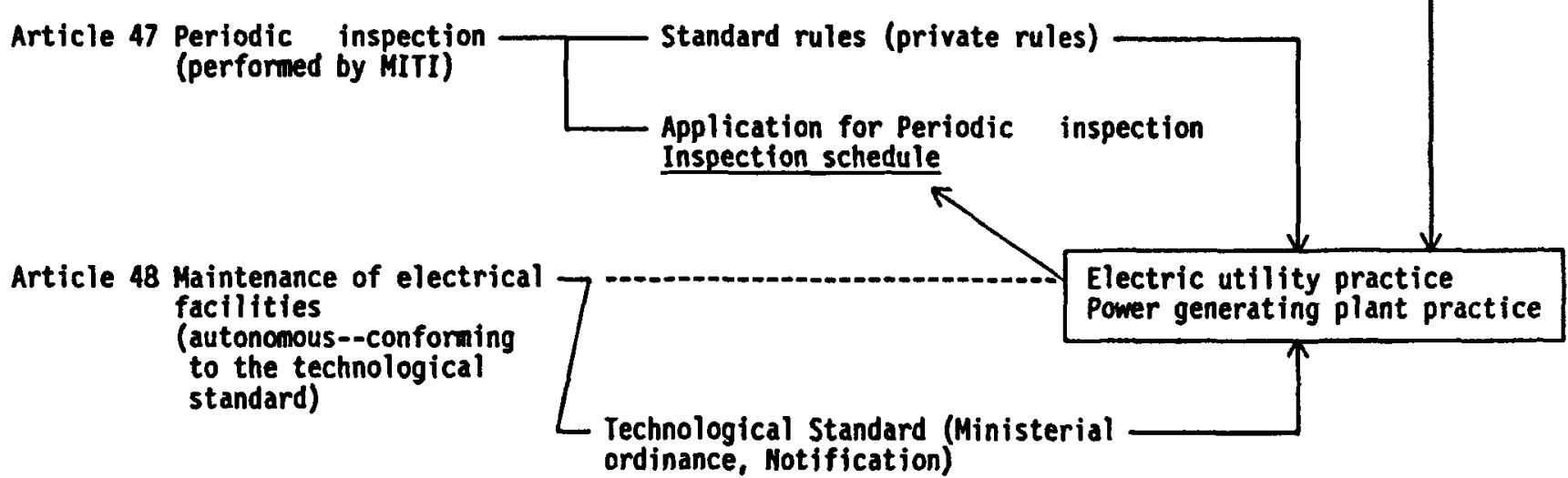




\section{Outline of periodic inspection.}

Periodic inspection of a nuclear power plant is required by the Electric Utility Industry Law. Examples of periodic inspection items are shown below.

Examples of facility and inspection.

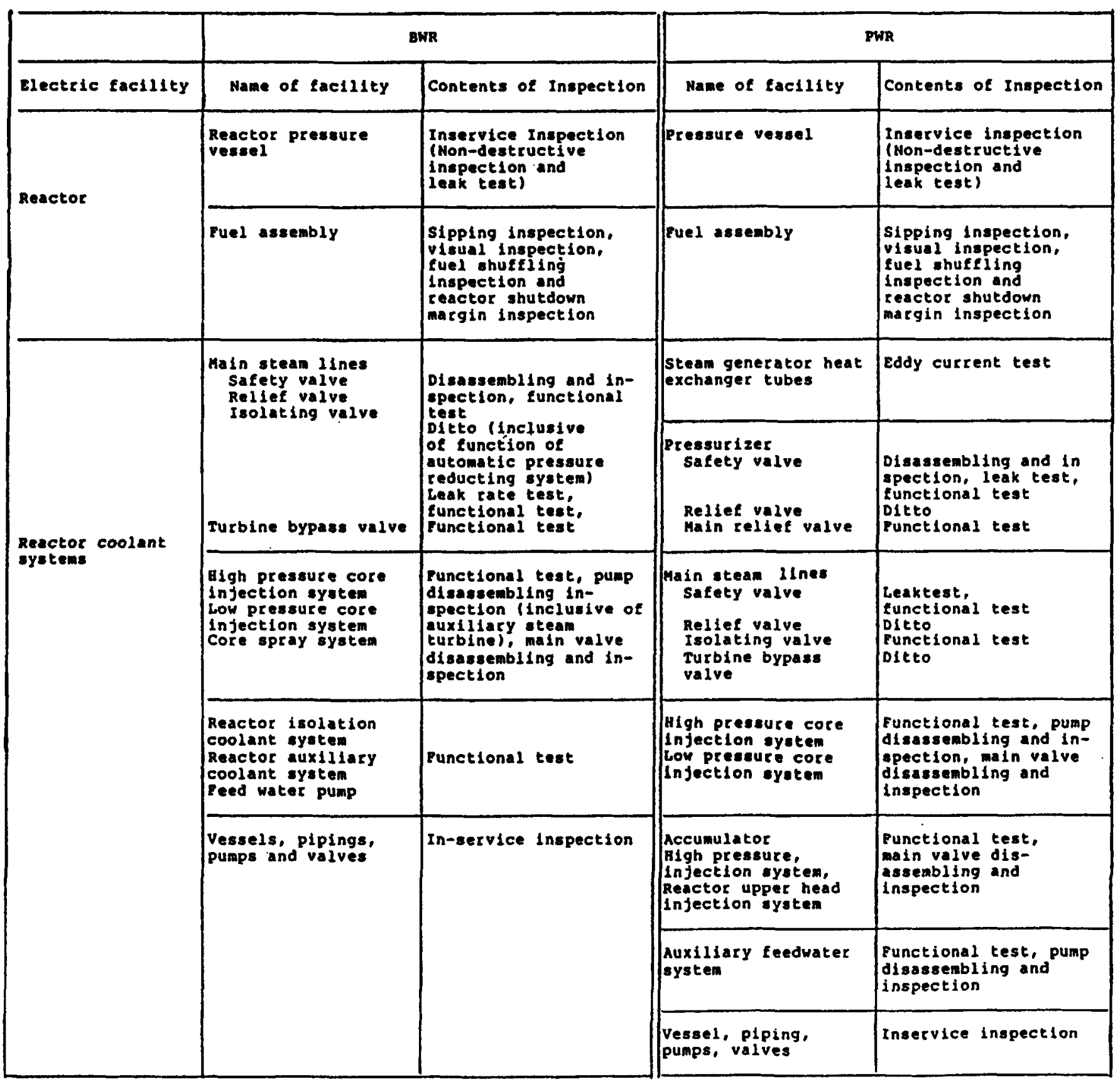




\begin{tabular}{|c|c|c|c|c|}
\hline \multirow[b]{2}{*}{ Electric Eacility } & \multicolumn{2}{|c|}{ BirR } & \multicolumn{2}{|c|}{ PWR } \\
\hline & Name of tacility & Contents of Inspection & Name of facility & Contents of Inspection \\
\hline \multirow{4}{*}{$\begin{array}{l}\text { Instrumentation } \\
\text { system }\end{array}$} & $\begin{array}{l}\text { Instrument alg system } \\
\text { boric deid injection } \\
\text { system }\end{array}$ & Functional inspection & $\begin{array}{l}\text { Control rod driving } \\
\text { ayotem } \\
\text { Ingtrument air syotem }\end{array}$ & Functlonal test \\
\hline & $\begin{array}{l}\text { Control rod driving } \\
\text { aysem }\end{array}$ & $\begin{array}{l}\text { Functional test, } \\
\text { overhauling inspection } \\
\text { of the drive mechanism. } \\
\text { disassembling and in- } \\
\text { spection of ene scrum } \\
\text { valve }\end{array}$ & \multirow[t]{3}{*}{$\begin{array}{l}\text { safety protection } \\
\text { ayatem }\end{array}$} & \multirow[t]{3}{*}{ Calibeation test } \\
\hline & $\begin{array}{l}\text { Safety protection } \\
\text { aystem }\end{array}$ & $\begin{array}{l}\text { Inspection of safety } \\
\text { oritection element } \\
\text { (Eunctlonal) } \\
\text { callbration test }\end{array}$ & & \\
\hline & $\begin{array}{l}\text { Nuclear Reactor } \\
\text { protection systen }\end{array}$ & $\begin{array}{l}\text { Functional teist of } \\
\text { plant interlock }\end{array}$ & & \\
\hline $\begin{array}{l}\text { Fuel assembly and } \\
\text { fuel handling } \\
\text { system }\end{array}$ & $\begin{array}{l}\text { Fuel handling } \\
\text { ayetem }\end{array}$ & Punctional teat & Fuel handiling & Functional test \\
\hline \multirow{2}{*}{$\begin{array}{l}\text { Radiation control } \\
\text { system }\end{array}$} & $\begin{array}{l}\text { Fleld monitoring } \\
\text { Area-monitoring } \\
\text { Process monitoring }\end{array}$ & Punctional test & \multirow{2}{*}{$\begin{array}{l}\text { Field monitoring } \\
\text { Area and process } \\
\text { mont toring } \\
\text { Annulus recirculation } \\
\text { exhaust system } \\
\text { Recirculation syatem } \\
\text { for main controi } \\
\text { room }\end{array}$} & \multirow{2}{*}{ Functional test } \\
\hline & $\begin{array}{l}\text { Emergency gas } \\
\text { treatment gystem } \\
\text { Reciruclation system } \\
\text { for main control }\end{array}$ & $\begin{array}{l}\text { Functional teat, } \\
\text { filter performance teat }\end{array}$ & & \\
\hline \multirow[t]{2}{*}{$\begin{array}{l}\text { Waste disposal } \\
\text { system }\end{array}$} & $\begin{array}{l}\text { Gaseous waste } \\
\text { treatment system } \\
\text { liquid waste } \\
\text { treatment system } \\
\text { Leakage detector for } \\
\text { liquid radioctive } \\
\text { waste and warning } \\
\text { device }\end{array}$ & Functional test & $\begin{array}{l}\text { Caseoua wate } \\
\text { treatment aystem } \\
\text { Liquid waste } \\
\text { treatment ystem } \\
\text { Solid waste } \\
\text { treatment aystem } \\
\text { Leakage detector for } \\
\text { liquid radioactive } \\
\text { waste and warning } \\
\text { device }\end{array}$ & Functional test \\
\hline & Solid waste storage & $\begin{array}{l}\text { Inspection of control } \\
\text { condition }\end{array}$ & solld wate storage & $\begin{array}{l}\text { Inspection of control } \\
\text { condition }\end{array}$ \\
\hline \multirow{4}{*}{$\begin{array}{l}\text { Containnent } \\
\text { vessel }\end{array}$} & $\begin{array}{l}\text { Containment vessel } \\
\text { Isolation valve } \\
\text { vacuum breaker }\end{array}$ & $\begin{array}{l}\text { Leak rate test } \\
\text { Punctional test, } \\
\text { Disaseemilng and } \\
\text { irspection } \\
\text { Eunctional test }\end{array}$ & $\begin{array}{l}\text { Containment vessel } \\
\text { Isolation valve } \\
\text { vacuum relief value }\end{array}$ & $\begin{array}{l}\text { Leak rate test } \\
\text { Runctional test, } \\
\text { Disaseembling and } \\
\text { Inspection } \\
\text { Functional test }\end{array}$ \\
\hline & $\begin{array}{l}\text { Containment vessel } \\
\text { Spray system }\end{array}$ & $\begin{array}{l}\text { Punctional test, pump } \\
\text { disassembling and } \\
\text { inspection, main } \\
\text { valve disassembling } \\
\text { and inspection }\end{array}$ & $\begin{array}{l}\text { Containment vessel } \\
\text { Spcay syster }\end{array}$ & $\begin{array}{l}\text { Eunctional test, pump } \\
\text { disassembling and } \\
\text { lnspection main } \\
\text { valve disasembling } \\
\text { and inspection }\end{array}$ \\
\hline & $\begin{array}{l}\text { Combuatible gas } \\
\text { concentration control } \\
\text { system }\end{array}$ & $\begin{array}{l}\text { Functional test, main } \\
\text { valve disassembiling and } \\
\text { inspection }\end{array}$ & $\begin{array}{l}\text { Containment vessel } \\
\text { hydrogen reconbiner }\end{array}$ & Functional test \\
\hline & Reactor bullding & Leak test & Ice condensor & Functional test \\
\hline
\end{tabular}




\begin{tabular}{|c|c|c|c|c|}
\hline Electric facility & Name of tacility & Contents of Inspection & Name of facility & Contents of Inspection \\
\hline $\begin{array}{l}\text { steam turbine } \\
\text { system }\end{array}$ & $\begin{array}{l}\text { Turbine and } \\
\text { accessories } \\
\text { (valves etc) }\end{array}$ & $\begin{array}{l}\text { Overhauling inspection, } \\
\text { Punctional test } \\
\text { (valves etc) }\end{array}$ & $\begin{array}{l}\text { Turbine and } \\
\text { accessories }\end{array}$ & $\begin{array}{l}\text { Overhauling inspection, } \\
\text { Functional test }\end{array}$ \\
\hline $\begin{array}{l}\text { Emergency power. } \\
\text { generating system }\end{array}$ & $\begin{array}{l}\text { Emergency power } \\
\text { generating set }\end{array}$ & Functional test & $\begin{array}{l}\text { Emergency power } \\
\text { generating set }\end{array}$ & Functional teat \\
\hline others & others & $\begin{array}{l}\text { Overa } 11 \text { plant } \\
\text { performance test }\end{array}$ & fothers & $\begin{array}{l}\text { overall plant } \\
\text { performance test }\end{array}$ \\
\hline
\end{tabular}




\section{Education and training for maintenance engineers.}

Education and training for maintenance engineers are provided according to the maintenance and training manual. Basically, included are classroom education, on-the-job training, and scheduled inspection, as shown on the next page. In the event that a firm incorporates an intercompany facility for training, engineers or officers in-house or belonging to outside manufacturing firms who have talent or expertise in related fields are hired as teachers or trainers for the trainees.

\section{Inspectors and senior specialists for nu- clear power operation (resident inspector).}

\section{A. Inspector of electric facilities}

Pursuant to the Electric Utility Industry Law (Article 104), the inspectors of electric facilities are designated by the Ministry of International Trade and Industry to inspect hydro, thermal, and nuclear power facilites.

Duties of the inspector of a nuclear power plant include:

1. Preservice inspection of electric facilities (Article 43),

2. Preservice inspection of the nuclear fuel assembly for nuclear power generation (Article 45),

3. Inspection of welding in the facilities and equipment (Article 46), and

4. Periodic inspection of electric facilities (Article 47).

Scope of the inspection for nuclear power plant

Ministry of International - Preservice inspection of nuclear facilities and equipment (excluding the

Trade and Industry responsibilities of the Local Bureau)

- Preservice inspection of fuel assembly

- Periodic inspection of nuclear facilities and equipment with a capacity of more than $600 \mathrm{MWe}$.

MITI's Local Bureau

- Preservice inspection of nuclear facilities and equipment relating to structure, strength, and leakage

- Inspection of welding (partially implemented by JAPEIC*)

- Periodic inspection of nuclear facilities and equipment with the capacity of less than $600 \mathrm{MWe}$.

*Japan Power Engineering and Inspection Corporation, one of the organizations affiliated with MITT.

\section{B. Permanent station of Senior Specialist for Nuclear Power Operation}

\section{Background}

Studies of the accident at Three Mile Island in the U.S. in March 1979 taught us that the causes of the accident were mainly negligence concerning safety rules and misoperation and misjudgment by the operator. The importance of quick and proper communication and notification in emergencies was confirmed. Because of the need to intensify the electric power company's supervision of operating management in order to diminish the insecurity of local residents concerning nuclear power generation and to respond to the strong demand of local governments for a resident administrator, MITI decided in April 1980 to dispatch a Senior Specialist for Nuclear Power Operation to each nuclear power plant to supervise the activities of operating management.

2. Duties of Senior Specialist for Nuclear Power Operation

The main duties of the senior specialist are to verify the daily operating management of a nuclear power plant and to communicate with MITI headquarters in case of incidents. More particularly: 


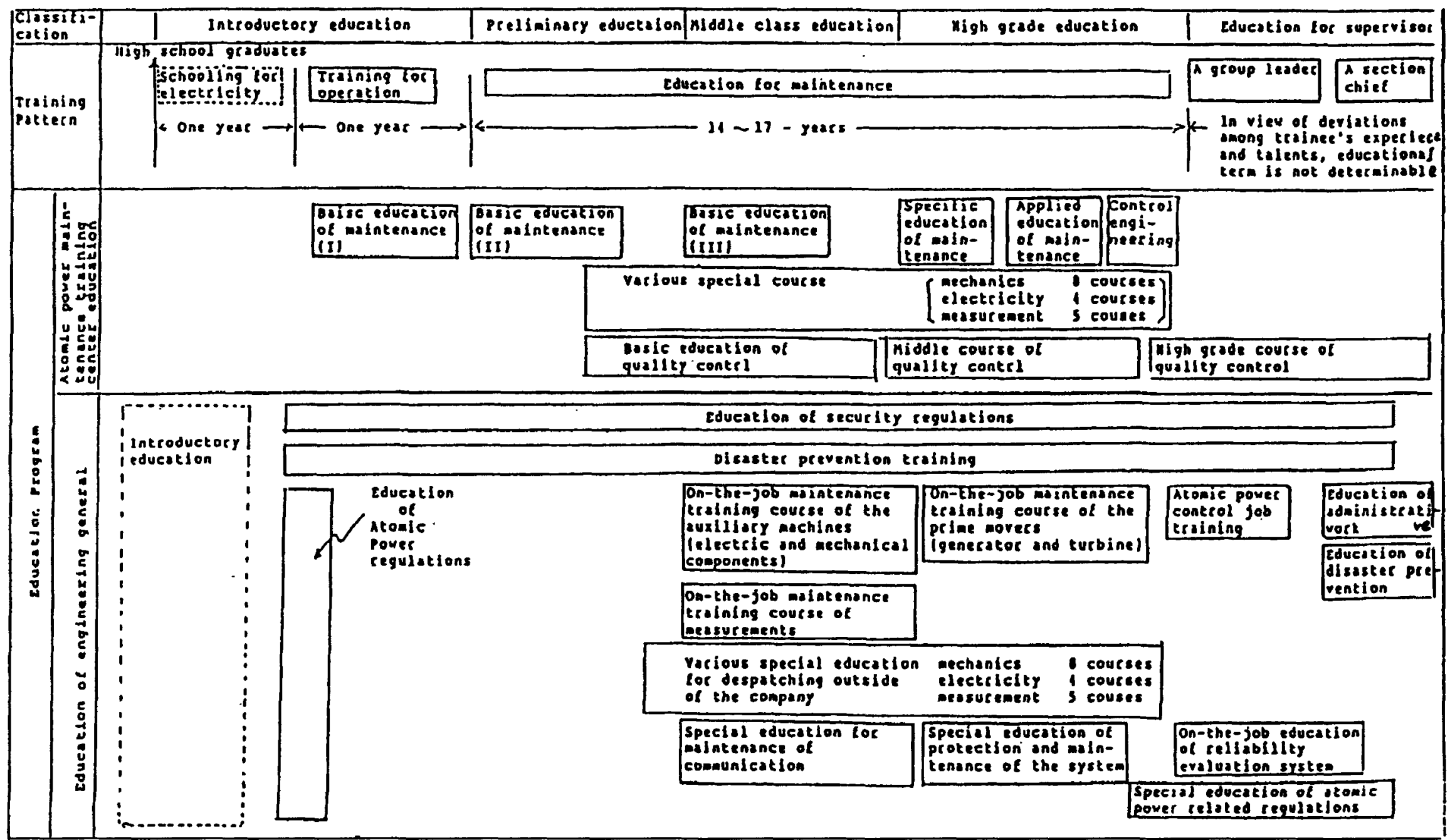


a. Identification of operating management activities.

Patrol reactor facilities and verify the utility's performance of its own safety regulations by checking patrol inspection sheets, witnessing voluntary periodic inspections by utilities, checking the records to be taken over between operating supervisors (shift supervisors), and checking repair activities.

b. Routine reports of operating status to MITI headquarters.

c. Communication with MITI headquarters in case of accident and emergency and guiding utilities based on directions from MITI headquarters.

d. Observation of performance of regular voluntary inspections and onsite training for accident response and providing guidance, as necessary.

e. Other advice to and supervision of the electric power company concerning operational management.

3. Placement of senior specialists

The placement of the senior specialists as of August 1988 is shown in Figure A.1.1. Senior specialists are located at 11 sites, and a total of 32 senior specialists are presently in service. 


Office For
Kashiwazaki-Kariwa N.P.S.
2 persons

Office for
Tsuruga-Mihama N.P.S.
4 persons

4 persons

\begin{tabular}{l}
\hline Office for \\
Ohi-Takahama N.P.S. \\
5 Persons
\end{tabular}

点
Tokyo E.P.Co.

Kashiwazaki-Kariwa

P.S.No. 2 (Operating)

Japan Atomic Power co.

Tsuruga P.5. No. 1,2

(Operating)

Kansai E.P.Co.

Mihama P.S. No. $1,2,3$ (Operating)

Kansai E.P.Co.

Ohi $P$ S NO $1,2,3,4$

loperating;

Kansai E.P.Co.
Takahama P.S.No. $1,2,3,4$ Takahama P;

E.P.Co.

Chugoku E.P.Co.
Shimane P.S.NO. 1

Shimane P.S

No. 2

(Test Operation)

office for Genkai N.P.S. 2 persons

Kyushu E.P.Co. Genkai P.S.No. 1,2 (Operating)

\section{Office for Sendai N.P.S.}

Kyushu E.P.Co

sendai P.S.No. 1,2

(operating)
Total 32 persons, as of August 1,1988 offices for senior specialist: 11 sites Power stations to which : 15 sites Senior specialists are dispatched

Figure A.1.1 Location of Senior Specialists for Nuclear Power Operation. 


\section{MAINTENANCE QUESTIONNAIRE ITEMS FOR MITI}

Q.1 In what form do the regulations and requirements for scheduled maintenance reach your industry? In other words, does MITI impose certain rules on the utilities, another set of rules on the power stations, and another set on individual units?

\section{PROBES - Is there a broad program of main- tenance requirements that are ad- ministered uniformly across the in- dustry? \\ - Do the individual utilities or units tailor these requirements and to what level of detail? \\ - Do individual power stations gen- erate their own plans that they send up to obtain approval from the regulators? \\ - Are the requirements unique to their operations? (What is the process?)}

A.1 The planned maintenance and inspection are divided into two categories as follows:

- Periodic inspection conducted by MITI on the basis of the Electric Utility Industry Law.

- Autonomous inspection and corrective maintenance conducted by the electric power company.

(1) The periodic inspections by MITI are defined by the Electric Utility Industry Law.

MITI has prepared the practical and detailed standard procedures as in-house regulations and informed the electric power companies (approximately 70 inspection items at present). This standard procedure has been individually prepared for PWR, BWR, and GCR. Individual power stations use the procedure for the specific reactor type and equipment and have generated more practical procedures (see Table A.1.1-List of periodic inspection items by MITI).

(2) For the autonomous periodic inspection by the electric power companies, MITI has provided the technical standards (equivalent to Sec. III of the ASME Code for structure, etc.) as Ministerial Ordinance and Notification on the basis of the Electric Utility Industry Law and requires the electric power company to maintain the facilities so as to conform to the technical standards under the Electric Utility Industry Law.

MITI does not give instructions on practical procedures for autonomous inspections to the electric power companies, etc., but individual utilities and power stations have prepared practical guidelines and procedures concerning the periodic inspections in order to maintain compatibility with the technical standards. For example, the repetition frequency and the detail of the inspection are specified with regard to individual components.

Also, the enforcement of the autonomous periodic inspections, such as inspection of the instrumentation control system calibration required for safety, is defined as the means of ensuring safety by the Law for Regulation of Nuclear Source Materials, Nuclear Fuel Materials, and Reactors. The electric power companies specify the inspection items shown in Table A.1.2, which are selected from the safety regulation approved by MITI. However, they are included in the periodic inspection conducted by MITI in accordance with the Electric Utility Industry Law.

(3) Individual power stations prepare a periodic test and inspection plan covering the above two inspections and audited by MITI before the commencement of every periodic inspection, then apply for the periodic inspection based on the Electric Utility Industry Law.

Upon audit of the above plan, MTT instructs and makes recommendations, as required, based on the contents of not only the inspection by MITI but also the autonomous inspection by the electric power companies.

An example is shown in Table A.1.3-Summary of practice in periodic inspection plan.

(4) In the above periodic inspection and maintenance, the MITI inspection items and the technical standards are the same for a given reactor type. However, there are sometimes specific requirements with regard to individual power plants to take into account the operating condition (for example, for fuel inspection in accordance with the radioactivity 
Table A.1.1 List of periodic inspection items by MITI (example).

\begin{tabular}{|c|c|c|}
\hline & No. & PWR \\
\hline 1. & & Inservice inspection for Class 1 component \\
\hline \multirow[t]{4}{*}{2.} & & Fuel assembly \\
\hline & $2-1$ & Fuel assembly slipping inspection \\
\hline & $2-2$ & Visual inspection, etc., for fuel assembly \\
\hline & $2-3$ & Fuel shuffling inspection \\
\hline 3. & & Reactor shutdown margin inspection \\
\hline 4. & & Inspection for clearance dimension at reactor baffle plate junction \\
\hline 5. & & Reactor coolant pump disassembling and inspection \\
\hline \multirow[t]{2}{*}{6.} & & Inservice inspection for Class 3 component \\
\hline & $6-2$ & Inservice inspection for Class 3 component (leak test) \\
\hline 7. & & Steam generator tube volumetric inspection \\
\hline \multirow[t]{4}{*}{8.} & & Pressurizer safety valve \\
\hline & $8-1$ & Pressurizer safety valve functional test \\
\hline & $8-2$ & Pressurizer safety valve leak test \\
\hline & $8-3$ & Pressurizer safety valve disassembling and inspection \\
\hline \multirow[t]{4}{*}{9.} & & Pressurizer relief valve \\
\hline & $9-1$ & Pressurizer relief valve functional test \\
\hline & $9-2$ & Pressurizer relief valve leak test \\
\hline & $9-3$ & Pressurizer relief valve disassembling and inspection \\
\hline 10. & & Main valve functional test for pressurizer relief valve \\
\hline 11. & & Reactor accessories cooling system functional test \\
\hline \multirow[t]{3}{*}{12.} & & High-pressure injection system \\
\hline & $12-1$ & High-pressure and low-pressure injection systems functional test \\
\hline & No. & BWR \\
\hline 1. & & Inservice inspection for Class 1 component \\
\hline \multirow[t]{4}{*}{2.} & & Fuel assembly \\
\hline & $2-1$ & Fuel assembly slipping inspection \\
\hline & $2-2$ & Visual inspection, etc., for fuel assembly \\
\hline & $2-3$ & Fuel shuffling inspection \\
\hline 3. & & Reactor shutdown margin inspection \\
\hline 4. & & Reactor recirculation pump disassembling and inspection \\
\hline \multirow[t]{2}{*}{5.} & & Inservice inspection for Class 3 component \\
\hline & $5-2$ & Inservice inspection for Class 3 component (leak test) \\
\hline \multirow[t]{3}{*}{6.} & & Main steam safety valve \\
\hline & $6-1$ & Main steam safety valve functional test \\
\hline & $6-2$ & Main steam safety valve disassembling and inspection \\
\hline \multirow[t]{4}{*}{7.} & & Main steam relief valve \\
\hline & $7-1$ & Main steam safety relief valve: safety valve functional test \\
\hline & $7-2$ & Main steam safety relief valve: relief valve functional test \\
\hline & $7-3$ & Main steam relief valve disassembling and inspection \\
\hline \multirow[t]{4}{*}{8.} & & Main steam isolation valve \\
\hline & $8-1$ & Main steam isolation valve functional test \\
\hline & $8-2$ & Main steam isolation valve leak rate test (after shutdown) \\
\hline & $8-3$ & Main steam isolation valve leak rate test (before start) \\
\hline 9. & & Turbine bypass functional test \\
\hline 10. & & Reactor auxiliary coolant system functional test \\
\hline 11. & & Emergency condenser system functional test \\
\hline 12. & & Reactor isolation coolant system functional test \\
\hline
\end{tabular}


Table A.1.2 Scheduled inspection items in technical specifications (example).

PWR

Warning device: set-valve confirmation.

Control rod drive mechanism functional test.

Safety-protection system: set-valve confirmation.

Safety-protection system functional test.

Pressurizer safety valve functional test.

Pressurizer relief valve functional test.

Main steam safety valve functional test.

Containment vessel leak rate test.

Annulus ventilation system filter performance inspection.

Etc.

\section{BWR}

Warning device: set-valve confirmation.

Control rod drive hydraulic system functional test.

Safety-protection system: set-valve confirmation.

Main steam safety valve functional test.

Main steam safety relief valve: safety valve functional test.

Main steam safety relief valve: relief valve functional test.

Main steam isolation valve functional test.

Containment vessel leak rate test.

Emergency gas treatment system filter performance inspection.

Etc.

Table A.1.3 Summary of practice in periodic inspection plan (example for PWR).

\begin{tabular}{|c|c|c|c|c|c|}
\hline & Facility & Quantity & Inspection Item & $\begin{array}{l}\text { Inspection } \\
\text { Period }\end{array}$ & Classification \\
\hline \multirow[t]{7}{*}{ I. } & Reactor & & & & \\
\hline & 1. Reactor Vessel & 1 unit & $\begin{array}{l}\text { Inservice inspection for } \\
\text { Class } 1 \text { component }\end{array}$ & Once a year & MITT \\
\hline & & & Opening inspection & Once a year & Autonomous \\
\hline & $\begin{array}{l}\text { 2. Reactor Core } \\
\text { Internal }\end{array}$ & 1 unit & General inspection & Once a year & Autonomous \\
\hline & 3. Fuel Assembly & $109 / 157$ & $\begin{array}{l}\text { Visual inspection, etc., for } \\
\text { fuel assemblies }\end{array}$ & Once a year & MITI \\
\hline & & $157 / 157$ & Fuel shuffling inspection & Once a year & MITI \\
\hline & & $157 / 157$ & $\begin{array}{l}\text { Fuel unloading/fuel insert } \\
\text { inspection and replacement }\end{array}$ & Once a year & Autonomous \\
\hline \multirow[t]{2}{*}{ II. } & $\begin{array}{l}\text { Reactor Coolant } \\
\text { System Facilities }\end{array}$ & & & & \\
\hline & $\begin{array}{l}\text { 1. Primary Coolant } \\
\text { Pump }\end{array}$ & $1 / 3$ & $\begin{array}{l}\text { Reactor coolant pump } \\
\text { disassembling and inspection }\end{array}$ & $\begin{array}{l}\text { Once every } \\
10 \text { years }\end{array}$ & MITI \\
\hline
\end{tabular}


level of the reactor water during operation) and results of previous inspections (for example, varying the inspection interval depending upon the aging).

Q.2 In what form do the regulations and requirements for unscheduled maintenance reach your industry? In other words, does MITI impose certain rules on the utilities, another set of rules on the power stations, and another set on individual units?

PROBES - Same as above.

A.2 (1) The Law for Regulation of Nuclear Source Materials, Nuclear Fuel Materials, and Reactors includes a rule that the electric power companies should have patrol inspections and control system inspections during operation as the means of determining the maintenance to be performed between the periodic inspections.

Based on the above, the electric power companies determine the inspection items to be conducted during operation in their own maintenance standard as specified in Table A.1.4. In addition, the Electric Utility Industry Law (EUIL) includes a rule that the electric power companies should maintain the nuclear power station to conform with the EUIL-based technical standards. In order to comply with such requirements, the electric power companies or the power stations must conduct a variety of daily inspections based on their own standards during operation.

(2) Utilities are trying to perform preventive maintenance in the scheduled maintenance program so as to avoid corrective maintenance during operation.

(3) Concerning unplanned maintenance caused by some incident or failure, the electric power companies must report such incident or failure to MITI. They must report not only that stipulated by law but also minor items specified under the MITI's administrative instruction.

In a case where it is required to send notification of such incident or failure to other plants, the MITI notifies other electric power companies of such events and instructs them to inspect the respective plants, if necessary, in addition to giving guidance. Recent examples are:

1. Inspection of the reactor coolant pump turning vane fitting bolts.

2. Investigation of wall thinning of piping caused by erosion/corrosion, etc.

Q.3 What determines the duration of a scheduled outage?

A.3 The duration of a planned outage is not specified by law. MITI requires that the electric power companies submit their operating plans at the beginning of every fiscal year and instructs them on the duration of the planned outage, taking into consideration the possibility of conducting any necessary inspection, along with their plan. The electric power companies establish the duration of the scheduled outage by adding the time required for special processes such as improvement work conducted during the outage to the duration of the standard outage, that is, the time required for refueling and the standard periodic inspection items.

Q.4 What types of plans and other information does MITI require units to submit prior to the planned outage?

A.4 Upon receiving the application for a periodic inspection, MITI receives information and gives instructions on the following items:

1. Basic policy of the periodic inspection

2. Main schedule

3. Summary of practice for a periodic inspection (see Table A.1.3)

4. Full list of periodic inspection items

5. Modification program conducted during the periodic inspection

6. Refueling plan

7. Inspection system during the periodic inspection

8. Safety control system during the periodic inspection

9. Radiation protection program during the periodic inspection 
Table A.1.4 Regular tests during operation (example).

(1) Example of regular tests during operation for BWR

\begin{tabular}{|c|c|c|}
\hline Test Item & $\begin{array}{l}\text { Repetition } \\
\text { Erequency }\end{array}$ & Test Details \\
\hline $\begin{array}{l}\text { Manual Sart of } \\
\text { Diesel Generator }\end{array}$ & $\begin{array}{l}\text { Once } \\
\text { a month }\end{array}$ & $\begin{array}{l}\text { Assurance of performance by manual } \\
\text { start at main control room. }\end{array}$ \\
\hline $\begin{array}{l}\text { Emergency Gas } \\
\text { Disposal system }\end{array}$ & $\begin{array}{l}\text { Once } \\
\text { a month }\end{array}$ & $\begin{array}{l}\text { Assurance of related automatic } \\
\text { valves' operation and system } \\
\text { performance by manual start. }\end{array}$ \\
\hline $\begin{array}{l}\text { Reactor Core } \\
\text { Spray System } \\
\text { (1) Pump Manual } \\
\text { Start } \\
\text { (2) Magnetic Valve } \\
\text { Operation }\end{array}$ & $\begin{array}{l}\text { Once } \\
\text { a month } \\
\text { Once } \\
\text { a month }\end{array}$ & $\begin{array}{l}\text { Assurance of performance by manual } \\
\text { start of pump at main control room. } \\
\text { Assurance of operation by manual } \\
\text { on-off switching of magnetic valve } \\
\text { at main control room. }\end{array}$ \\
\hline $\begin{array}{l}\text { Residual Heat } \\
\text { Removal system } \\
\text { (1) Pump Manual } \\
\text { Start } \\
\text { (2) Magnetic Valve } \\
\text { Operation }\end{array}$ & $\begin{array}{l}\text { Once } \\
\text { a month } \\
\text { Once } \\
\text { a month }\end{array}$ & $\begin{array}{l}\text { Assurance of performance by manual } \\
\text { start of pump at main control room. } \\
\text { Assurance of operation by manual } \\
\text { on-off switching of magnetic valve } \\
\text { at main control room. }\end{array}$ \\
\hline $\begin{array}{l}\text { High Pressure Core } \\
\text { Injection System } \\
\text { (1) Pump Manual } \\
\text { Start } \\
\text { (2) Magnetic Valve } \\
\text { Operation }\end{array}$ & $\begin{array}{l}\text { Once } \\
\text { a month } \\
\text { Once } \\
\text { a month }\end{array}$ & $\begin{array}{l}\text { Assurance of performance by manual } \\
\text { start of pump at main control room. } \\
\text { Assurance of operation by manual } \\
\text { on-off switching of magnetic valve } \\
\text { at main control room. }\end{array}$ \\
\hline
\end{tabular}


Table A.1.5 Practical example of PWR plant.

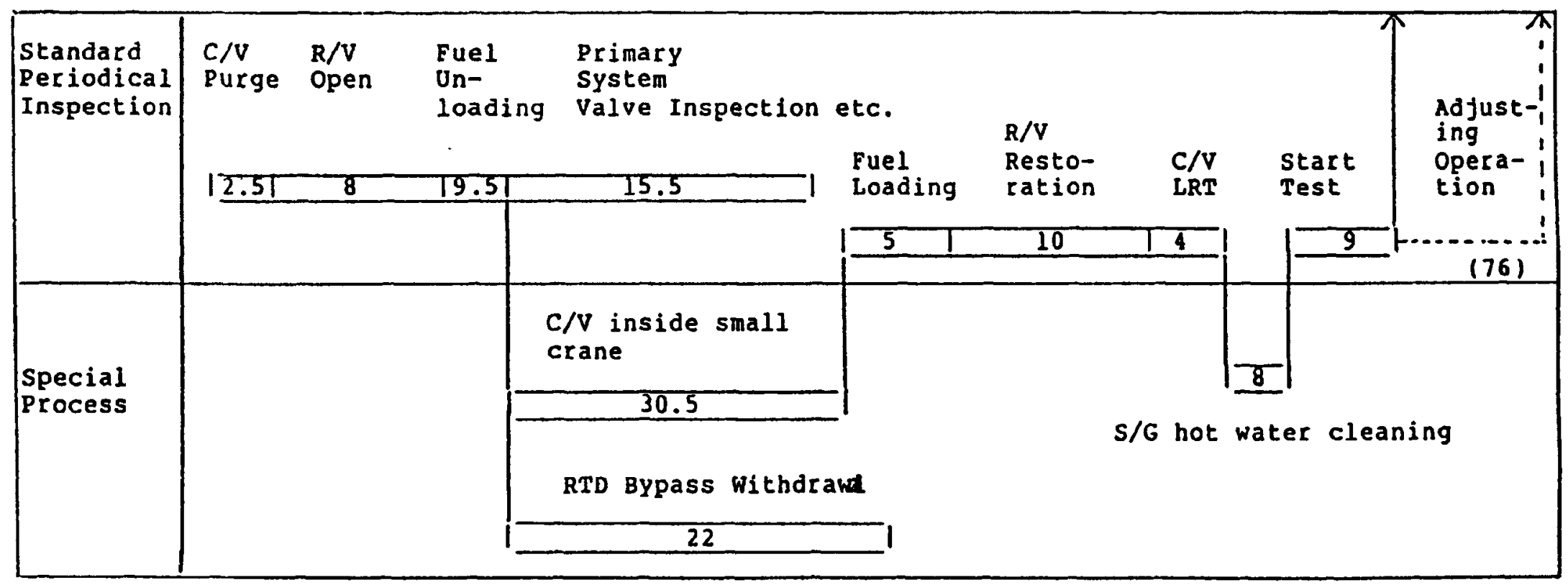


10. Quality assurance program during the periodic inspection

11. List of operational achievements

12. References to lessons learned from worldwide operational experiences, etc.

Q.5 What specific maintenance data does MTTI require units to submit for unscheduled corrective maintenance between outages?

A.5 (1) The surveillance tests specified by the safety regulation (technical specification) are conducted in the presence of the Senior Specialist for Nuclear Power Plant Operation and the results are confirmed. (For regular tests during operation, see Table A.1.4.) Also the daily operational parameters are reported to the Senior Specialist for Nuclear Power Operation.

(2) For corrective maintenance due to incidents or failures, MITI requires the electric power companies to submit the following data:

1. Investigation results on cause of incidents or failures, etc.

\section{Corrective measures}

MITI then gives instructions and recommendations on the advice of the MITI's Technical Advisory Committee on Nuclear Power Generation. In addition, the Senior Specialists for Nuclear Power Operation will conduct onsite confirmation on the results of maintenance.

The following are examples of recent unplanned outages.

1. Manual shutdown as a result of drain increase caused by the fatigue cracking on the small-diameter piping in the containment vessel.

2. Manual shutdown as a result of small leakage from pinholes caused by erosion/ corrosion on the drain piping of steam lines, etc.

In addition, for significant corrections, an examination will be performed at the time of application for approval or notification of the detailed design for corrections based on the Electric Utility Industry Law.
Q.6 Does MITI have people on site (or contracted inspectors representing MITI) during the scheduled outage?

PROBE - What are their roles?

A.6 MITI dispatches legally qualified inspectors to the plant site on the specified date during the planned outage to conduct the inspection. Their roles are:

Visual inspection during the disassembling and inspection, nondestructive test, leak test, functional test and performance test, and confirmation of test records, etc.

Q.7 Does MITI have people on site between outages?

PROBE - What are their roles?

A.7 The Senior Specialist for Nuclear Power Operation stays on standby duty at every power station.

The main roles of the senior specialist are confirmation of the daily operating management of the nuclear power plant and communication with MITI headquarters in case of incidents. More particularly:

1. Investigation of observance of safety regulation: Concerning the daily operating management activities at nuclear power stations, the senior specialist receives a report from the reactor chief engineer with regard to the records to be taken over between operating supervisors (shift supervisors), the records of the patrol inspection on the reactor facilities, and so on. He then verifies these records and, if necessary, makes an investigation.

2. Patrol in reactor facilities: Electric power companies with installed reactor facilities are required to make an autonomous patrol inspection. With respect to verification of the actual status of the patrol, the senior specialist makes a patrol of facilities such as the reactor and turbine facilities.

3. Witnessing the regular voluntary inspection: The senior specialist witnesses the regular voluntary inspection of the emergency cooling system and safety protection circuit, etc., and the simulation training for emergencies to be performed by the electric power companies.

4. Communication with headquarters in case of emergency: When the senior specialist is informed of accidents or failures at the nuclear power station or when he finds abnormality in 
the course of patrol in the reactor facilities, etc., he gives instructions to the nuclear power station while communicating with headquarters.

Q.8 Does MITI require predictive maintenance (for example, nondestructive evaluations or inspection of service records)?

A.8 The periodic inspection conducted by MITI at present consists of disassembling and inspection, nondestructive tests such as PT and UT, and functional tests. Almost all of them are intended for predictive maintenance. This is because repair and replacement on the spot is aimed at "preventive maintenance," avoiding troubles during operation by finding even a small defect at a very early stage. The electric power company's voluntary inspections are conducted in the same manner with their own standards under administrative guidance.

Q.9 What does MITI require with respect to a power station's quality assurance program?

A.9 (1) When the quality assurance guide, ranging from construction to operation of the nuclear power plant (among the autonomous private guides issued by the Japan Electricity Association), was established, MITI took part in its development from the beginning and subsequently gave necessary instruction and advice. Individual electric power companies develop an in-house quality assurance program based on the above guide, JEAG-4101, "Quality Assurance Guide to Nuclear Power Plants."

(2) For the quality assurance program of individual electric power companies or individual power stations, MITI reviews:

1. The electric power company's autonomous quality assurance program when the construction plan is approved before the start of construction or significant corrective maintenance.

2. The electric power company's autonomous quality assurance program in the periodic inspection at the application for the periodic inspection.

In addition, MITI reviews the implementation during the construction, operation, and periodic inspection of these quality assurance programs at the electric power companies by means of the Review of Overall Safety Management of Nuclear Power Plants, etc.
Q.10 Does MITI require units to maintain an inventory of spare parts?

A.10 The inventory of spare parts is, as a rule, maintained under the autonomous safety system of the electric power companies.

MITI receives a variety of information from the electric power companies concerning material control, etc., in a quality assurance program at the hearing on the periodic inspection program prepared by the electric power companies and then gives instruction and advice.

In addition, for the important corrective work, MITI conducts the preservice inspection to make sure that the materials and parts are free of defects.

\section{Q.11 Does MITI monitor a unit's ALARA program?}

A.11 MITI requires the electric power companies to control the radiation management program during periodic inspections so as to reduce the amount of external radiation exposure and to be free of internal radiation exposure.

MITI requires the electric power companies to submit an operating plan at the beginning of every fiscal year and receives information from them concerning the major measures for reducing radiation exposure of plant personnel.

MITI also requires the electric power companies to submit a radiation management program when applying for the periodic inspection and gives detailed instruction and advice concerning work where the exposure exceeds $100 \mathrm{mrem} /$ day.

MITI further requires the electric power companies to submit a report that includes the radiation protection activities and their exposure-reducing effects after the completion of the periodic inspection.

When the radiation exposure exceeds the expected amount in the program, the Senior Specialist for Nuclear Power Operation not only receives details on the extent of the radiation exposure, but also gives immediate advice.

The electric power company is required to submit a report in accordance with the law if the exposure exceeds the amount specified by the ordinance. Additionally, every power station is required to report quarterly the amount of radioactive waste and radiation exposure of plant personnel.

Q.12 Does MITI use the data provided by units to perform trend analysis or does MITI generate its own data? 
PROBE - How does MITI use trending information?

A.12 The corrective maintenance data are kept basically by the electric power companies or by each power station. MITI receives a variety of information from them as required, and this information is reflected in its operational administration.

As practical examples, MITI requires the electric power companies to review the limiting value for operation based on the data provided by units such as the amount of reactor vessel brittleness due to neutron irradiation and the iodine absorption efficiency of charcoal filters and to modify the inspection interval of the piping or to replace piping, both of which are decided based on the data on tube wall thinning.

Q.13 What performance measures does MITI use to determine the effectiveness of a unit's maintenance program?

A.13 The effect of the maintenance activities will be recognized directly by:

1. Rate of unplanned outage

2. Availability factor

3. Rate of occurrence of incidents and failures

Regarding the important part of the plant, judgment is also made on the possibility of any precursor event that may lead to the potential cause of a future incident or failure.

This effect appears indirectly by:

4. Total exposure dose of the plant personnel

5. Generated amount of waste disposal

Taking these into account, reviews of the inspection, replacement of components, etc., are conducted by individual units.

Q.14 Does MITI review technical data used when performing maintenance?

Q.15 Does MITI review work procedures or job performance aids used for maintenance?

A.14 and A.15

(1) For modification or repair work sufficiently important to need the approval of the detailed design, MITI reviews the technical data and work procedures through the examination of the detailed designs but leaves the de- tailed procedures and the technical data for minor work to the autonomous safety management by the electric power companies.

(2) In the periodic inspection, MITI bases its inspection on the technical standards and the standard procedures for the periodic inspection established by MITI. In the autonomous inspections by the electric power companies, the technical data are prepared in accordance with the requirements of the autonomous safety management of the electric power companies to meet the technical standards, and MITI also leaves the procedures to the electric power companies.

Q.16 Does MITI participate in the post-maintenance testing performed before returning a piece of equipment to service?

A.16 MITI witnesses some functional tests, primarily in the post-maintenance trial operation of periodic inspection items, depending upon their importance. Finally, before commercial operation, an overall plant performance test is conducted and MITI confirms the functions of the power plant by witness.

Examples of test items witnessed by MITI are:

- Reactor shutdown margin test

- High-pressure and low-pressure injection systems functional test

- Emergency diesel generator functional test

- Reactor protection system set value confirmation test

Q.17 Does MITI require units to submit for approval a maintenance management plan in regard to these areas: planning, scheduling, staffing, shift coverage, and resource allocation?

A.17 MITI leaves the details of the maintenance management to the electric power companies' own maintenance standards and procedures. However, as to the basic program, MITI requests the electric power companies to submit or report any information concerning the company's maintenance management and provides guidance as required.

Information is provided at the hearing on the company's plant installation plan and plant operation plan, both of which must be submitted to MITI at the beginning of every fiscal year; at the examination of detailed design and technical specifications, both of which must be approved by MITI; and at the review of the periodic inspection plan to be supplied to MITI. 
Q.18 To what extent is MITI involved in approving the maintenance plans and use of subcontractors?

A.18 The basic answer is the same as the answer to Q.17

\section{(1) Maintenance Plan}

1. For important modifications and repairs to the reactor facilities, the approval of MITI or notification to MITI of their detailed design is required.

\section{Example: - Plugging of steam gen- erator tubes. \\ - Replacement of main piping}

2. MITI leaves minor work to autonomous safety management of the electric power companies.

3. For both cases above, MITI inspects to verify the integrity of safety-important facilities or equipment that are modified or repaired during the periodic inspection.

4. In other cases, MITI gives instruction and advice to the electric power companies at the hearings for the plant operation plan, the plant installation plan, and the applied program for periodic inspection.

\section{(2) Use of Subcontractors}

MITI leaves the use of subcontractors to the autonomous safety management of the electric power companies.

Q.19 Does MITI have requirements regarding the selection and training of maintenance personnel?

A.19 An education and training plan must be prepared every fiscal year and the execution of the plan in the safety regulation (technical specification) must be approved by MITI. In addition, at the hearings on the plant operation plan and the plant installation plan, MITI gives necessary instruction and advice concerning the education and training of maintenance personnel. 


\section{MAINTENANCE QUESTIONNAIRE ITEMS FOR INDUSTRY}

Q.1 In what form do the regulations and requirements for scheduled maintenance reach your utility?

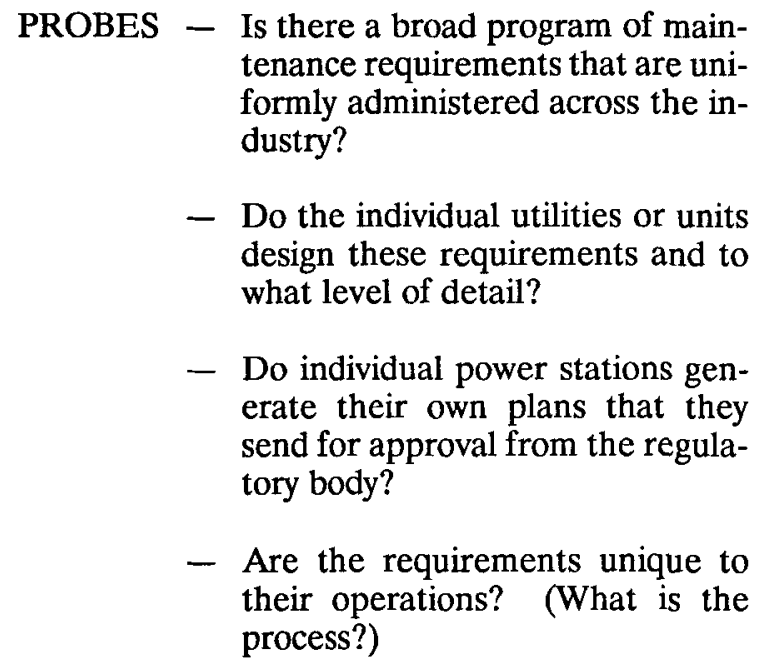

A.1 The regulations of our country require that the electric power companies shut down plant operation and perform periodic inspections of the overall facilities once approximately every 12 months of operation.

Regarding the details of the periodic inspections, which have been varied during the past 20 years, inspection of approximately 70 items are presently specified by MITI. The inspection items, procedures, and records of the inspections are standardized for each type of reactor.

\section{(1) Preparation of Autonomous Inspection Plan by} Electric Power Companies.

The electric power companies prepare the schedule of disassembling and inspection, nondestructive testing, and improvement of the facilities taking the following items into consideration:

1. Periodic inspection items according to the regulations,

2. Regular voluntary inspection plans for each piece of equipment,

3. Condition of the equipment during operation, and

4. Operating experience (accidents, failures, etc.) both domestically and overseas.
The periodic inspection plan is determined by integrating the above items and adjusting the time when it should be performed during the inspection. Therefore, the contents and timing of the autonomous periodic inspections depend upon each plant as to performance. Furthermore, the inspection procedures are prepared in detail (job procedures, checksheets, etc.) so that all the maintenance personnel can understand the inspection details and not make any mistakes.

\section{(2) Application to MITI for a Periodic Inspection}

When applying to MITI for the periodic inspection, the following explanatory documents are prepared on the basis of the massive data for each facility, as discussed above, and a hearing is held by MITI:

1. Basic policy of the periodic inspection

2. Main schedule

3. Summary of practice for a periodic inspection

4. Full list of periodic inspection items

5. Modification program conducted during the periodic inspection

6. Refueling plan

7. Inspection system during the periodic inspection

8. Safety control system during the periodic inspection

9. Radiation protection program during the periodic inspection

10. Quality assurance program during the periodic inspection

11. List of operational achievements

12. References to lessons learned from worldwide operating experience, etc.

Q.2 In what form do the regulations and requirements for unscheduled maintenance reach your utility?

PROBES - Same as above. 
A.2 Unplanned maintenance performed simultaneously with the periodic inspection is planned and carried out in accordance with the answer to Q.1.

The operation of the plant is shut down on the occurrence of a failure or an incident to perform an unplanned inspection. In this case, the causes are investigated and countermeasures taken. The failure or incident must be immediately reported to MITI, and the plant is shut down. The method of clarifying the causes, the results, and the countermeasures must proceed step by step through close communication with MITI.

Q.3 What determines the duration of a scheduled outage?

A.3 The plan of the period of a scheduled outage is reported by the electric power companies to MITI based on the electric power companies' consideration of the work period required so as to perform the required maintenance within a reasonable time.

Q.4 During the planned outage, what data does MITI require when making decisions regarding the type of maintenance task to perform during the outage, including the type of inspections required on individual components.

A.4 In preparing an operation plan for a nuclear power station, the electric power companies in Japan are required by MTTI to:

(1) Maintain the capacity of electric supply to meet the electric power demand (the operation schedule of the overall power generation facilities of the utilities is required).

(2) Perform inspections for ensuring the safety of the facilities in the nuclear power station.

Accordingly, with the responsibility of the electric power companies to supply electric power, it is necessary to prepare the plant operation plan, plant installation plan (supply/demand schedule) of the electric power companies as a whole, and the periodic inspection plan to be performed during the nuclear power plant shutdown.

Regarding the inspection of each piece of equipment, explanatory materials for the application of the periodic inspection are required as described in the answer to Q.1, which is the result of our experience over approximately 20 years. In the initial stage, the preparation of inspection procedures for each piece of equipment was required, but now the inspection procedures are standardized for each reactor type.

Q.5 What is your experience with unscheduled corrective maintenance between outages?

A.5 We have recently experienced a plant shutdown that resulted from the following failures and incidents:

1. Leak of the small tubing of the steam generator

2. Thermal fatigue crack of the piping

3. Leak of piping caused by erosion, corrosion, and so on.

Q.6 How much inservice inspection occurs between outages?

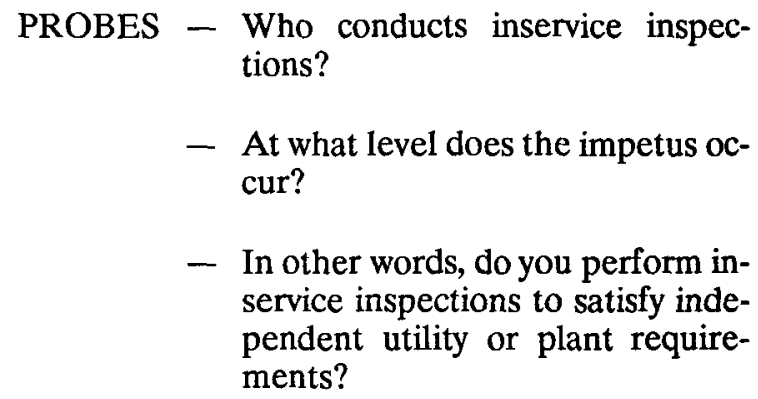

A.6 As for the inservice inspection (ISI) during operation, the logic test of the safety protection system is performed under the autonomous inspection standards of the electric power companies.

The ISI during the periodic inspection is performed on the basis of the autonomous inspection standards approved by MITI according to Section XI of the ASME Code.

Inspection contents are explained at the time of the application for periodic inspection to MITI from whom we receive instructions. Regarding the inspection, MITI will witness our inspection or verify the records.

A consistent followup is indispensable because the execution of ISI closely relates to the design, manufacture, and installation of the plant. Therefore, although the electric power companies place an order for the actual inservice inspection work with the vendors, we ourselves design the work plan and witness the work.

Q.7 What role do the maintenance teams perform in deciding what maintenance is necessary? 
A.7 The autonomous regular inspection by the electric power companies is performed under the following system:

\section{(1) Electric Power Company}

Each specialist group (organized in sections) listed below originates its own maintenance work plan on the basis of the operation status, inspection experience, etc., of each facility. (The entire plan of the power station is prepared by the engineering coordination group after integrated coordination has been performed.)

(Specialist group)

- Engineering coordination group

- Equipment group (mechanical, electrical, and instrumentation groups)

- Radiation control group

- Operation group
- Quality control and safety group

\section{(2) Prime Contractor}

The prime contractor, based on the plan prepared by the electric power companies as in (1) above, organizes a work group led by skilled engineers on each facility, classifying a working field under respective title of work, and performs maintenance and inspection work.

Q.8 What type of predictive maintenance (for example, nondestructive evaluation or inspection of service records) do you do?

A.8 Disassembling and inspection of the equipment and nondestructive testing (UT, PT, etc.) are conducted with the aim of performing corrective maintenance by finding slight defects in advance so as to prevent failures in service.

Examples:
- Reactor pressure vessels

- Major piping

- Fine tubing of steam generator examination of irradiated specimens

UT, PT testing

eddy current testing
We make best use of the results of predictive maintenance in establishing reasonable setups of the frequencies and locations of inspections (including the setup of replacement times for the parts, etc.).

Q.9 To what extent is the engineering division at a power station involved in the maintenance activities?

\section{A.9 (l) Division in Charge of Operation}

This division is in charge of the work relating to management of the operation. This division well understands the operating status of the individual facilities and equipment through its daily duties of surveillance and patrol inspection. They take countermeasure action such as changing over to a spare facility on the occurrence of a failure or its symptoms to minimize the influence on the plant operation, and, at the same time, they communicate such failures or events to the division in charge of maintenance. They are also in charge of isolating the components before the work and the reassembling after the work and test operation.

\section{(2) Division in Charge of Maintenance}

This division is in charge of radiation control. It takes charge, in cooperation with the maintenance division, regarding reduction of the radiation exposure rate during the maintenance work and prevention of the dispersion of contamination, of determining the working area before commencing the work, and the surveillance before and after the work.

\section{(3) Division in Charge of Engineering}

This division studies plant failures, incidents, etc., experienced both at home and overseas and discusses with the maintenance division the countermeasures for preventing recurrence and for preventive maintenance. Furthermore, the division coordinates the maintenance activities of the entire power station 
through an overall meeting involving divisions in charge of operation, security, and maintenance.

Q.10 What type of quality control checks do you perform on equipment being maintained? (How do you verify that maintenance activities have been correctly performed?)

A.10 The electric power companies have a specific quality control program covering the range from construction to operation of a nuclear power station on the basis of the "Quality Assurance Guide," which has been autonomously established. Under this program, the electric power companies practice the quality assurance activities and report the status to the government in each stage of construction and periodic inspection, as required.

Q.11 What is your philosophy about spare parts inventory?

A.11 With regard to spare parts, the electric power companies maintain a reasonable quality and quantity that are autonomously specified and keep appropriate management.

Our basic philosophy is shown as follows:

(1) We intend not to duplicate the spare parts of the same specification. If there is an available spare component or system, spare parts are not stored. In view of the nature of spare parts, a general commodity and disposables are not defined as spare parts.

(2) Spare parts should include the machines (or their components) that significantly influence the output power in the case of failures.

(3) Spare parts should include the imported machines (or their components) that are not available as equivalent domestic products.

(4) Spare parts should include the imported machines (or their components) for which a substantial period prior to receipt is required.

(5) Spare parts should include products that cannot be appropriated to other uses.

In addition, spare parts should be available for use by nearby nuclear power stations owned by the same electric power company.

Furthermore, regarding important maintenance work, the government performs preservice inspections to verify the quality of the parts to be used.
Q.12 What are you doing as part of your maintenance program to achieve your ALARA goals?

A.12 For radiation control in the periodic inspection, we are trying to reduce the radiation exposure by improving the working environment, the working procedures, and the equipment.

The plant operation plan is submitted to the government at the beginning of every fiscal year. This includes a report on the measures for reducing the radiation exposure of plant personnel. In addition, the electric power companies explain the radiation control program at the time of the application for the periodic inspection and submit a report upon the completion of the inspection. Thus, we are trying to improve the management with proper guidance and advice from the government.

Additionally, with regard to waste disposal, we are trying to improve material, structure, and treatment of the waste for the enhancement of the integrity of the facilities and equipment on the waste disposal system, and we are making every effort to ensure no effect on the surrounding public area.

Q.13 Do you try to do trending analysis of individual components, subsystems, or systems?

$$
\begin{gathered}
\text { PROBES - What data do you use to do this? } \\
- \text { What is the benefit to the individ- } \\
\text { ual unit or the utility in doing } \\
\text { trending analysis? }
\end{gathered}
$$

A.13 Specific examples of maintenance data are:

- Embrittlement rate by neutron irradiation of the reactor pressure vessel

- Eddy current test data for small tubing of the steam generator

- Tube wall thinning caused by erosion or corrosion

- Degradation of the consumables (mechanical seals of the pump, packing materials, oil, etc.)

Trending analysis on these parts ensures performance evaluation of the equipment and also ensures proper planning of the maintenance schedule as well as verifying the integrity of the equipment. In addition, the improvement of the availability factor can be expected by effective inspection and replacement.

Q.14 What performance measures do maintenance managers use to determine the effectiveness of their maintenance programs? 
A.14 The effectiveness of the maintenance activities will be recognized directly by:

(1) Availability factor.

(2) Rate of occurrence of incidents and failures. Regarding the important part of the plant, judgment is also made concerning the possibility of any precursory event that may lead to the potential cause of future incident or failure.

(3) Total exposure dose of the plant personnel.

(4) Generated amount of waste disposal.

These are the measures we use in determining the effectiveness of our maintenance program.

Q.15 What technical data (for example, clearance, torque values, or hydraulic diagrams) do maintenance people use?

PROBE - How are the technical data obtained or generated?

A.15 Typical technical data used by the maintenance personnel are:

(1) Clearance

(2) Dimensional measurement at various points

(3) Runout measurement at various points

(4) Torque values

(5) Set values on the instrumentation

(6) Indication characteristics

(7) Insulation resistance value

(8) Various data taken at test operation (oil pressure, inlet/outlet pressures, measurements relating to vibration and temperature, etc.)

These data are collected and recorded by the maintenance personnel at the time of disassembling and inspection and test operation.

Q.16 Do you have detailed work procedures or job performance aids that are used by an individual to perform maintenance tasks?

$$
\begin{gathered}
\text { PROBES - Who writes and updates these pro- } \\
\text { cedures? } \\
- \text { Do maintenance workers use them } \\
\text { as a step-by-step guide in perform- } \\
\text { ing work? }
\end{gathered}
$$

A.16 With regard to the regular maintenance tasks, the division in charge of maintenance at each nuclear power station prepares the detailed work procedures for use as a guide for performing the duties.

Additionally, regarding an important modification or repair for which government approval is required, we explain to the government the conformance with technical standards and detailed work procedures, etc.

Q.17 What type of post-maintenance testing do you perform before returning a piece of equipment to service?

A.17 Examples of post-maintenance testing are:

(1) Pumps

- unit test of pump motor

- $\quad$ vibration test of pump

- $\quad$ interlock test

(2) Valves

- open/close test

- interlock test

(3) Vessels

- leak test

(4) Electric parts and boards

- interlock test

(5) System functional test

The tests witnessed by the government, in addition to the overall plant performance test before commencing operation, include:

(1) Reactor shutdown margin test

(2) Functional test of high/low pressure core injection systems

(3) Functional test of emergency power generator, etc.

Q.18 How do you perform maintenance management in such areas as planning, scheduling, staffing, shift coverage, and resource allocation?

A.18 The maintenance management performed by electric power companies covers the planning and practice of the maintenance and inspection work, the planning of the quality control during the work, and budgetary management of the work. 
Q.19 How do you select and train maintenance personnel?

A.19 We prepare and put into practice an education and training program for maintenance personnel based on the safety regulations of the reactor facilities. Basically, on-the-job training is considered to be the most effective training method. In addition, we established a maintenance training center to perform training and education by special instructors. We provide this training for the employees up to about 10 years and, following this training and education, provide seminars by other organizations, including training by the manufacturers.

Q.20 What kind of system do you have to ensure adequate communication between the maintenance organization and other major organizations (for example, operations or engineering) within the unit?

A.20 At each power station we hold regular meetings with related organizations to study and discuss safety measures and maintenance plans so that each member has a better understanding of the status of each organization.

Each organization tries to see that the maintenance personnel fully understand these matters and adjust to the various plans.

Q.21 Do you perform maintenance differently on safety-related versus balance-of-plant equipment?

A.21 Pursuant to the safety regulations, we perform the regular tests on the safety-related equipment during commercial operation to ensure integrity of the facilities and equipment.

With the philosophy of preventive maintenance, the frequency and scope of the inspections are properly determined by using history and inspection experience.

With regard to other equipment under daily operation, the frequency and scope of the inspections are determined by using history and inspection experience. 
APPENDIX B

EUROPEAN MAINTENANCE PRACTICES

B-1/B-2

NUREG-1333 



\section{CONTENTS}

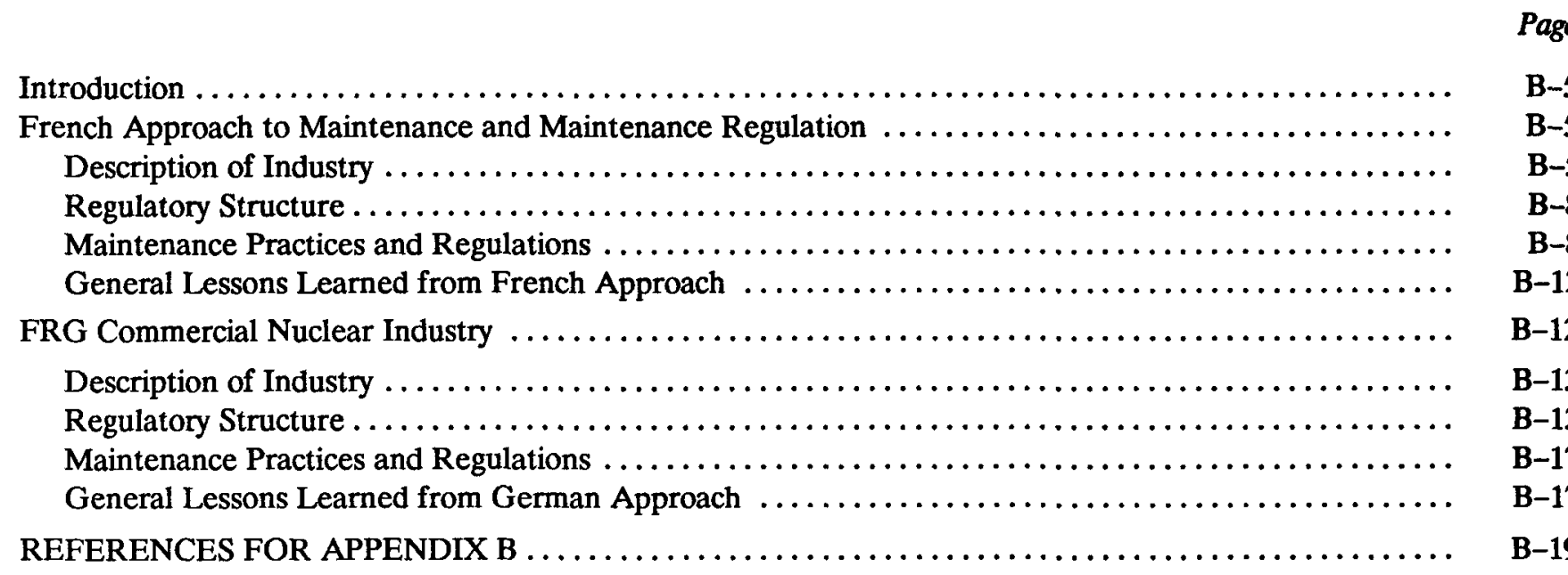

\section{FIGURES}

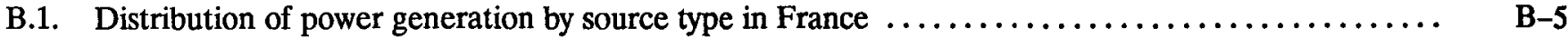

B.2. Overview of French regulatory structure for commercial nuclear power $\ldots \ldots \ldots \ldots \ldots \ldots \ldots \ldots$ B-6

B.3. EDF organization chart. (Adapted from "Maintenance of European Nuclear Power Plants,"

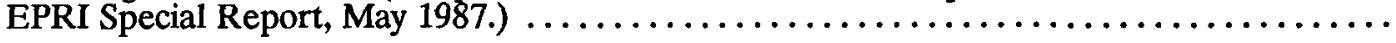

B.4. Typical centrale (Bugey) organization chart. (Adapted from "Maintenance of European Nuclear Power Plants," EPRI Special Report, May 1987.) ............................. B-10

B.5. Distribution of power generation by source type in Federal Republic of Germany ............. B-15

B.6. Overview of Federal Republic of Germany's regulatory structure for commercial nuclear power .... B-16

B.7. Biblis organization chart (Adapted from "Maintenance of European Nuclear Power Plants," EPRI Special Report, May 1987.)

\section{TABLES}

B.1. List of commercial nuclear power plants in Federal Republic of Germany $\ldots \ldots \ldots \ldots \ldots \ldots$. 



\section{INTRODUCTION}

Two countries, France and the Federal Republic of Germany (FRG), are the primary focus of this review. These two countries were selected for several reasons. First, both countries have highly successful nuclear power programs, as indicated by such factors as the continued growth of the industries and the high levels of plant availability. Second, as in the U.S., nuclear power development in both countries has focused on light-water-reactor technologies. This fact makes the experience of these two countries potentially relevant to maintenance regulatory strategies in the U.S. Finally, while there are some substantial differences in the regulatory and industry context between the U.S. and these countries, these differences are not so large as to preclude valuable insights for the U.S.

The discussion to follow is based on a review of published books, articles, and other documents describing the French and German nuclear power industries and, more specifically, maintenance regulation and practice within these industries. While a limited amount of information was available, the literature appears to be consistent on most key points. One main source generated most of the points discussed below (EPRI, 1987). Unless otherwise noted, information presented is from this source. Interviews were also conducted with knowledgeable individuals to corroborate and expand the findings from the literature review.

\section{FRENCH APPROACH TO MAINTENANCE AND MAINTENANCE REGULATION}

This section discusses the French approach to maintenance and maintenance regulation. It starts with a description of the industry. This is followed by a general description of the regulatory context. Next, French practice and regulation are described for the areas listed in the NRC's policy statement on maintenance. Some general lessons learned are also provided.

\section{Description of Industry}

The nuclear power industry in France is a large and growing industry (see Fig. B.1). It currently provides over twothirds of the electric power needs and over half of the total power needs for France. The proportion of electric power production to come from nuclear power is expected to increase to over $75 \%$ in the not too distant future. Thus, nuclear power plays not only an important, but actually a central role in the production of power in France (Vendryes, 1986).

As of the end of 1987, there were 50 units in operation with another 12 under construction. Additional plants are in the planning stage. The current stock of nuclear plants accounts for about $50 \mathrm{GWe}$ of electrical production.

Figure B.2 provides a graphical description of the organization of the industry and the regulatory function in France. Because the producer of nuclear power, Electricite de France (EDF), is a part of the government

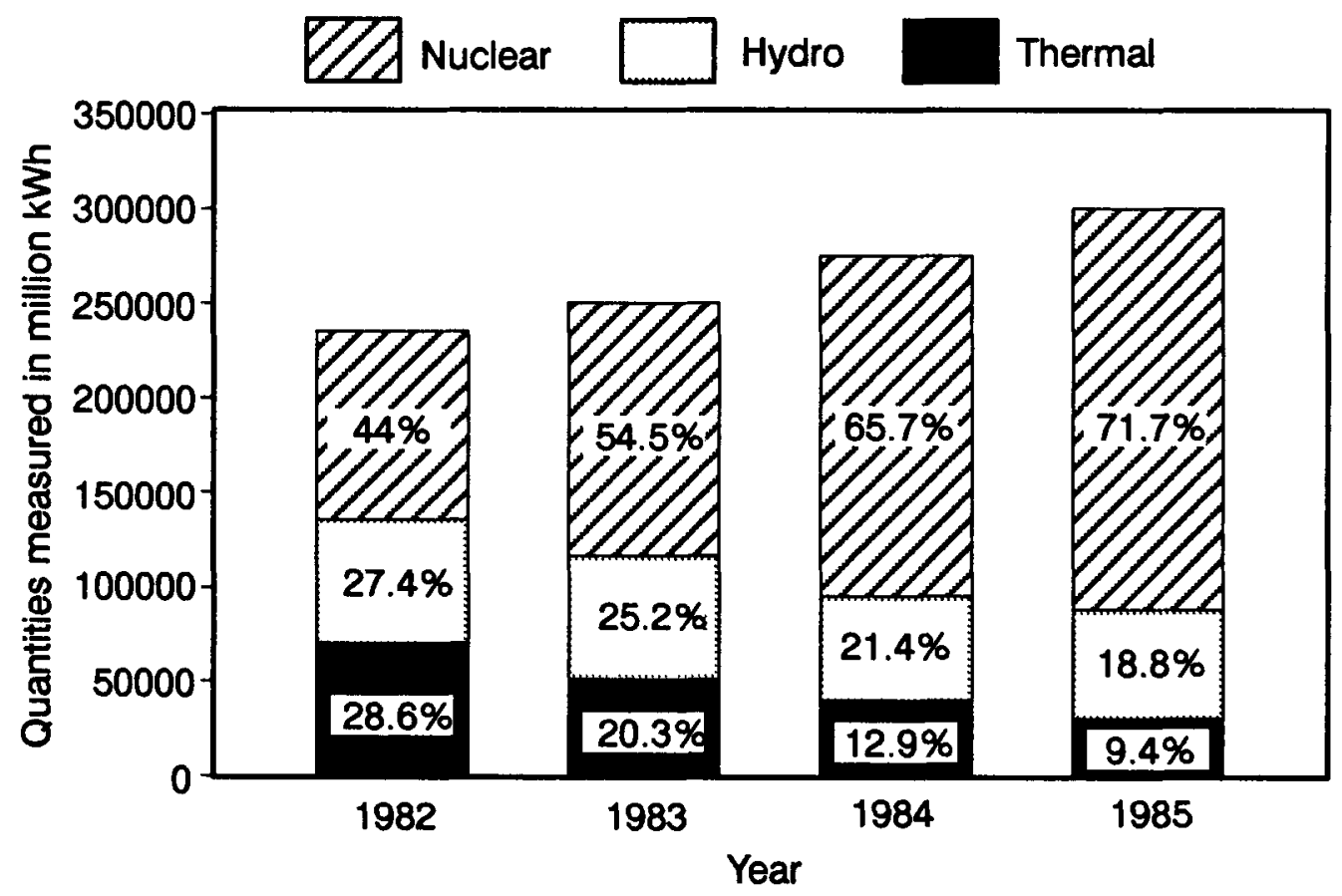

Figure B.1. Distribution of power generation by source type in France. 


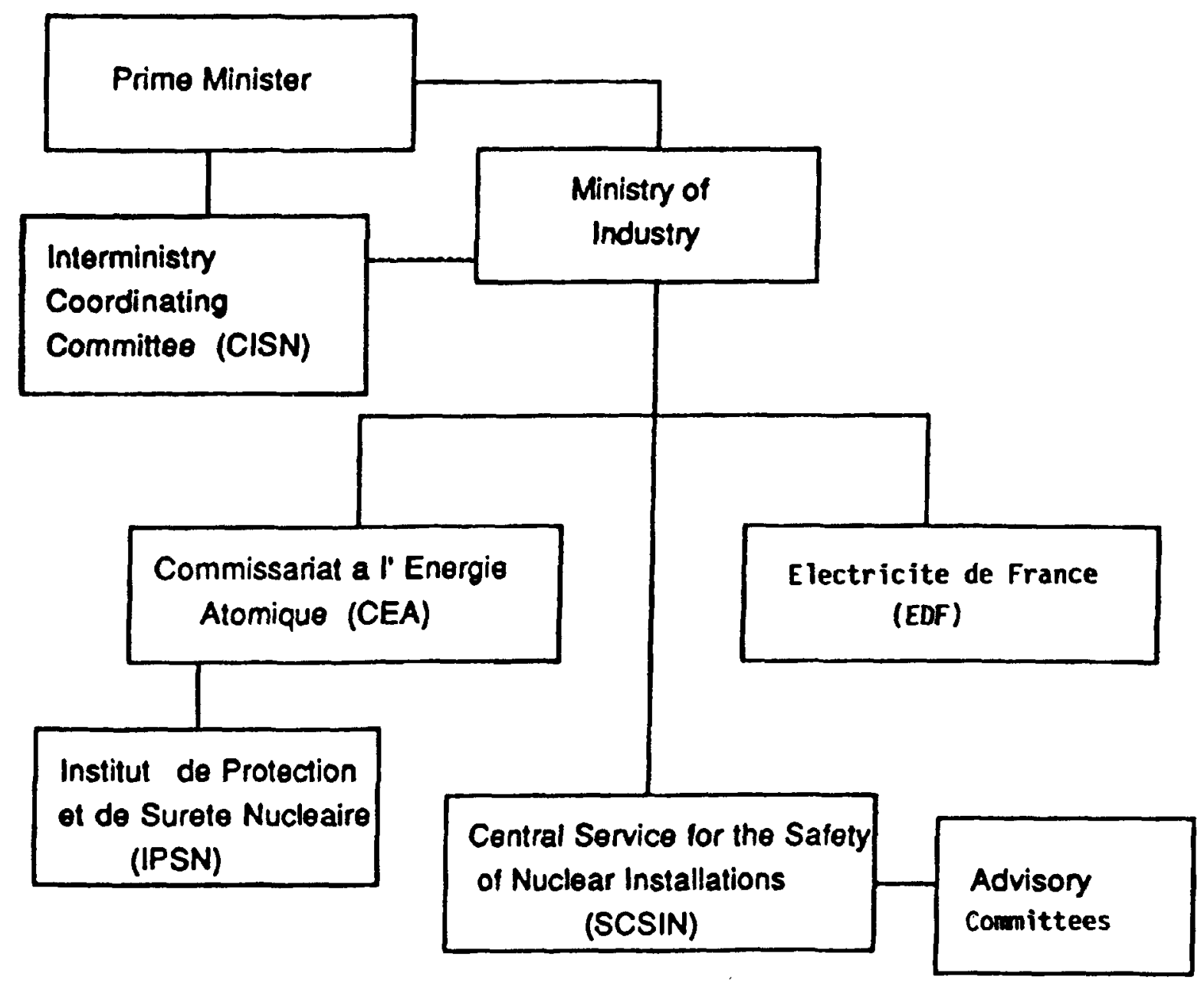

Figure B.2. Overview of French regulatory structure for commercial nuclear power.

structure, this figure describes both the industry and the regulatory structure together.

The French nuclear power industry is much more concentrated than is its U.S. counterpart (EDF, 1982). To begin, there is a single, large nuclear utility, the EDF. The EDF is an agency within the national government, reporting to the Ministry of Industry. EDF maintains a monopoly on electrical power production in France, operating fossil and hydro plants in addition to the large number of nuclear plants. EDF also is responsible for around $80 \%$ of the distribution side of the electrical power system in France. EDF not only operates the plants but also serves as architect/engineer. EDF is a large organization with over 120,000 employees. Figure B.3 provides a general description of the internal structure of EDF.
Another important actor in the French nuclear industry is FRAMATOME, the nuclear steam system supplier for PWRs in France. Almost all reactors in France have been supplied by FRAMATOME. FRAMATOME is $30 \%$ owned by the Commissariat a l'Energie Atomique (CEA). Thus, the French nuclear industry is highly concentrated and, because of this, well integrated and stable.

An important characteristic of the industry is standardization. In 1973, EDF made the decision to pursue rapid expansion of its nuclear component, but to limit the number of basic designs. The first generation of plants following this decision was comprised of 900 MWe PWRs. More recently, a fleet of 1300 MWe PWRs has been added, using much the same design. A third generation of $1450 \mathrm{MWe}$ PWRs is also planned. EDF has also standardized its selection of vendors for the secondary side, resulting in one 


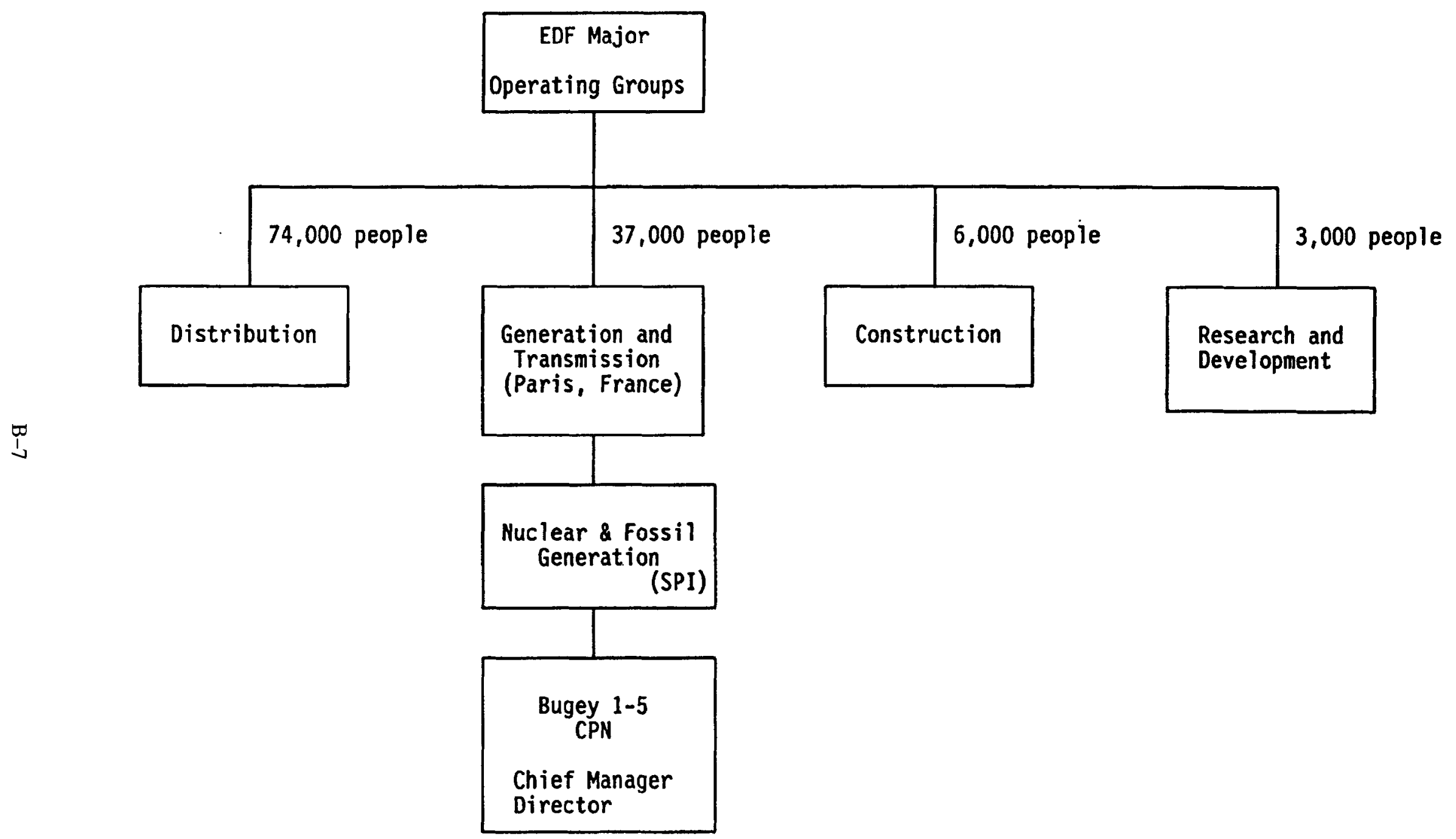

Figure B.3. EDF organization chart. (Adapted from "Maintenance of European Nuclear Power Plants," EPRI Special Report, May 1987.) 
firm, Alsthom Atlantique, supplying the generator-turbine configuration.

The advantages to standardization have been numerous and large (Bemer, 1986; Mercier, 1987; Degot and Lebreton, 1985; Bitsch, 1985). Because of standardization, EDF has been able to develop stable working relationships with a few key vendors. This has allowed for feedback and improvement in design, as well as shared responsibility for maintenance. Licensing schedules and construction costs have been kept under control since each plant is not a custom design. EDF has been able to invest in centralized facilities since they can serve numerous plants at a considerable cost saving. These facilities have allowed for centralized training, the development of industrial robots for maintenance, the maintenance of an effective equipment performance and evaluation data base, and more effective warehousing of spare parts. More importantly, however, standardization has allowed for easier learning from operating experience than seems to be the case in the U.S. The lessons learned at one plant have been easily transferred to the other plants. The result is a high level of availability, in excess of $80 \%$, and reasonable capacity and scram statistics given the load following philosophy applied by EDF to its nuclear plants.

\section{Regulatory Structure}

Figure B.2 also provides information on the regulatory structure in France (Sweet, 1981; Vendryes, 1986). Several ministries are concerned with aspects of nuclear power production. For example, the Ministry of Health has responsibility for radiation exposure regulations. However, the ministry with the major responsibility for nuclear power is the Ministry of Industry. Within the Ministry of Industry is found responsibility for nuclear power promotion (CEA), production (EDF), and safety regulation (CEA and SCSIN).

Until the 1970s, the CEA had primary responsibility for the regulation of nuclear power. Like the Atomic Energy Commission in the U.S., however, concern grew over its joint mission of energy promotion and safety regulation. While the CEA continues to regulate fuel cycle activities and to provide some technical support in the regulation of nuclear power plants, a separate group reporting to the Ministry of Industry has taken over much of the regulatory role. This organization, the Central Safety Department for Nuclear Facilities (SCSIN), develops safety rules and regulations and oversees their application. In addition, the SCSIN develops organization, staffing, and general policies. The SCSIN makes decisions involving safety regulations and typically receives advise from the Institute of Protection and Nuclear Safety (IPSN) on safety issues.

IPSN is a unit in the CEA and is comprised of two departments - the Department of Nuclear Safety (DNS) and the Department of Protection (DP) - and determines the adequacy of applications submitted by the EDF.

The DNS evaluates structural, mechanical, and electrical systems while the DP provides technical assistance to the Ministry of Industry regarding the discharge of radioactive waste.

The French nuclear program is an important part of French national economic policy. Accordingly, there is a higher level of public support for nuclear power in France than in many other countries (Vendryes, 1986). This is due, in part, to the comparative cost saving from nuclear power, but must also be attributed to the high safety and efficiency of operation experienced to date. As in Japan, industry and government work in a much more cooperative mode than in the U.S. This cooperation can be seen in joint planning, government-sponsored $\mathrm{R} \& \mathrm{D}$, and the nonprescriptive approach taken to regulation of the EDF by other government agencies.

\section{Maintenance Practices and Regulations}

This section describes French practice and regulation in the areas listed in the NRC's policy statement on maintenance. For convenience, these areas have been grouped into the following discussion sections:

\section{Maintenance Management and Organization \\ 2. Staffing, Qualifications, and Training \\ 3. Maintenance Philosophy and Strategy \\ 4. Support of Maintenance \\ 5. Work Control and Performance Assessment \\ 6. Radiological Exposure}

\section{Maintenance Management and Organization}

This subsection discusses the French approach to organizing and managing the nuclear power plants.

The organization and management of maintenance within EDF pertains to both centralized functions within the utility and to activities at the plant level (Mercier, 1987). For the utility as a whole, maintenance is the responsibility of the Equipment Division. Three major centralized support organizations for maintenance exist within EDF. The first, a centralized maintenance department, is responsible for collecting equipment design specifications, analyzing significant events and failures, maintaining information on equipment life, helping plants with major maintenance, implementing plant modifications, designing and implementing preventive maintenance programs, feeding back operating experience to vendors, and providing general interface with vendors for maintenance issues.

A second support organization, the Groupe des Laboratories, provides centralized research support concerning knowledge of equipment condition and failure 
mechanisms and for establishing material and chemical specifications.

A third organization, the Technical Support Group (UTO), is a subsidiary of EDF. This organization is responsible for assisting plants in the development of maintenance procedures; the development of robots, mockups, and specialized tools; the maintenance of a centralized, spare parts store; and the promotion and dissemination of planning assistance systems.

In addition to these support organizations, the EDF also provides for centralized maintenance training schools, including a maintenance training simulator, and for regional "hotshops" for the performance of maintenance outside the plant.

The ability of EDF to provide these centralized functions in support of maintenance is due both to the size of the utility and to the fact that it has adopted a standardized design approach that allows for many plants to benefit from the investment in the centralized support activities.

Figure B.4 provides a description of the organization of maintenance at the plant site. The maintenance manager reports directly to the plant manager or his deputy. Of note is the fact that maintenance in French plants is recognized as at least equivalent in importance to operations, as indicated by the fact that plant and utility management personnel generally have maintenance backgrounds (J.P. Mercier, personal communication, June 2,1988 ). This emphasis on maintenance is in contrast to the somewhat greater emphasis on operations in U.S. plants. The management emphasis on maintenance, in turn, is probably helpful to the maintenance department in securing the resources and support necessary to ensure safety and productivity.

Within the maintenance department at the plant, there are four major groups: analogic controls (low-current instrumentation), I\&C/electrical maintenance, mechanical maintenance, and planning and scheduling. Together these groups are responsible for daily maintenance activities. Typically, around 120 staff members are assigned across these groups. Of particular note is the fact that planning and scheduling for routine maintenance is recognized as a significant, separate activity and is staffed accordingly. This allows for care and completeness in the generation of work packages. In some U.S. utilities, this function is left to line management in maintenance or a single, sometimes part-time staff person.

Nonroutine maintenance is planned and executed by an entirely separate department-the Technical Support Subdivision (SUT) reporting directly to the site manager and to the Construction Branch at EDF. This group provides special maintenance support for all the units at the site, including maintenance during outages and outage planning. When required, personnel from this group augment the plant staff for routine maintenance.

As in the U.S., there is a separate quality assurance/quality control (QA/QC) function at the plant. QA/QC is part of the Nuclear Safety Department and reports to the Deputy Site Manager. QA/QC is responsible for independent verification of maintenance work and for the review of maintenance work packages. Plant operations also review work packages and oversee post-maintenance testing.

EDF makes extensive use of subcontractors during scheduled outages. For PWRs, FRAMATOME provides maintenance personnel for the primary system, and Alsthom provides maintenance personnel for the generator/turbine. Other subcontractors are used for nondestructive test and evaluation and for work on large-diameter piping.

At the plant level, considerable emphasis appears to be placed on coordinating the activities of operations, maintenance, and other plant functions. This is reflected in a pattern of review and oversight of one function's activities by another and in the emphasis on planning and scheduling of all activities.

\section{Staffing, Qualifications, and Training}

EDF is not subject to externally imposed standards for staffing, personnel qualifications, and training for maintenance workers. EDF's own practices and policies are described in this section.

A typical plant may have around 270 workers with another 300-400 workers providing support to the several plants at the site. Around 120 maintenance workers are assigned to each plant. Several hundred more are available from the site's Technical Support Subdivision, and around 200 traveling maintenance workers are available for scheduled outages from the central EDF maintenance department. Vendors and other subcontractors are also used during scheduled maintenance.

Excessive overtime for plant maintenance personnel does not appear to be a problem. The normal shift is a 7-hour day shift, with a cadre of maintenance workers "on call" for other shifts. The average workweek for maintenance workers has been reported by one source as 46 hours. It also has been reported that there is a conscious strategy to add more workers rather than increase the work load on an individual to the point that the individual begins to make errors.

Career paths appear to stress promotion from within (Rippon, 1985). Emphasis is placed on long-term employment and the provision of in-house training to allow 


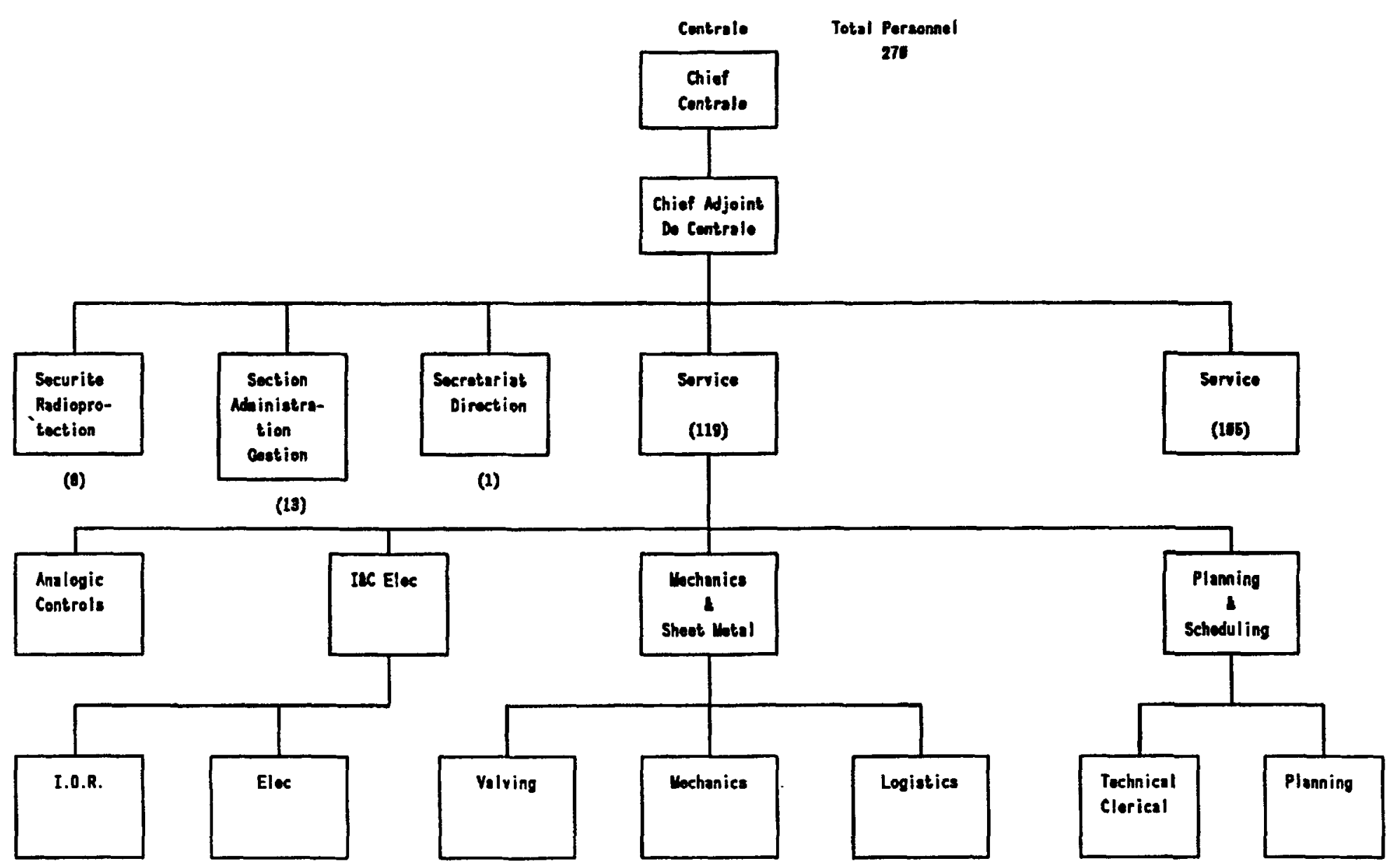

Figure B.4. Typical centrale (Bugey) organization chart.

(Adapted from "Maintenance of European Nuclear Power Plants," EPRI Special Report, May 1987.) 
workers to take advantage of job openings within EDF. One inference that can be drawn from this policy is that the overall experience level is higher (allowing for the expansion of the industry) in EDF than in some U.S. utilities. Another inference is that an EDF employee may be likely to perform several different jobs over the course of his career as opposed to simply one. This pattern may be reinforced by the fact that labor, while unionized, is not unionized along the lines of job specialty (craft). Instead, there is a single, EDF-wide union. Taken together, these employment and personnel practices may encourage rotation of staff within EDF and associated benefits in plant knowledge on the part of workers.

According to one source (EPRI, 1987), entering maintenance workers typically have completed public school through age 16, plus 2 years of technical school. This is followed by either a university education in engineering or a 2-year program at a technical university (see also IAEA, 1980).

EDF conducts a substantial in-house training program for maintenance workers, including a centralized maintenance training center, a maintenance simulator, and various mockups (e.g., steam generator, primary circuit system).

\section{Maintenance Philosophy and Strategy}

This subsection describes the basic maintenance philosophy or strategy employed at French plants. Two themes appear to be most important for understanding the French approach:

a. Finding the right mix of corrective, preventive, and predictive maintenance.

b. Taking steps so that maintenance is proactive rather than exclusively reactive.

In general, the maintenance philosophy adopted by the EDF and at least tacitly endorsed by the regulatory bodies appears to be one that emphasizes the role of maintenance in ensuring plant availability. While not ignoring safety concerns, there is nothing equivalent in the French program to the extended preventive maintenance outage in Japan. The Japanese approach is viewed as wasteful and unnecessary for the French system.

The French approach is to minimize both corrective maintenance and unnecessary preventive maintenance (Mercier, 1987). Corrective maintenance must be minimized because it puts the maintenance program in a reactive mode. It is difficult to plan for and contributes disproportionately to unavailability. Unnecessary preventive maintenance must be avoided because it is costly, it may actually increase the failure probabilities for some types of equipment, and it too contributes to unavailability.
The French strategy for minimizing corrective and preventive maintenance focuses on the use of predictive maintenance within a safety and economic risk model of the plant (Mercier, 1987). There are two primary elements to the predictive maintenance approach. The first is based on the extensive analysis of failure data to determine what are reasonable expectations for failure for each component. This task is made much simpler in the French system because, being a single utility, it is easier to amass failure data for analysis, and because the standardization of design allows for the pooling of information from all the plants. The analysis of failure data informs maintenance as to the likely effects of failure of a certain component on both safety and availability. Again, this activity is made much simpler by the standardization of design in French plants. Using the failure data, maintainers can more accurately target preventive maintenance programs in a cost-effective manner, as well as planning for certain aspects of corrective maintenance.

The second aspect of predictive maintenance, of course, concerns testing to identify degradation in performance of components. For nonredundant systems (e.g., reactor containment, reactor coolant system), a high level of monitoring is suggested, even though failures may be extremely rare. For redundant systems where failure does not jeopardize either safety or availability, little or no preventive maintenance may be performed.

In the attempt to maximize availability, the French approach is to minimize the length of scheduled outages to the length required by refueling and fuel handling. A heavy emphasis is placed on outage planning and adequate staffing for outages so that preventive maintenance and plant modifications do not become the critical path during the scheduled outage.

The strategy of being proactive rather than reactive depends substantially on feedback from operating experience. By analyzing failure information in detail (including causes), EDF constantly changes its maintenance procedures and training so that avoidable failures are not repeated. The heavy emphasis on outage planning also allows the maintenance program to avoid surprises and unreasonable backlogs of work requests.

In general, as long as EDF is successful in achieving adequate availability of safety-related equipment, as specified in the technical specifications, the regulatory bodies in France appear to be satisfied with the EDF approach to maintenance.

\section{Support of Maintenance}

As described in the section under management and organization, th plant maintenance program receives considerable support from both onsite and offsite units (Mercier, 1987). For example, the UTO provides R\&D in the area of specialized tools. The technical support unit 
provides support in the area of outage planning. Corporate headquarters makes available a centralized training program for maintenance workers. In general, the centralized maintenance function in EDF provides the $R \& D$, planning, and engineering expertise to support scheduled maintenance and major plant modifications. The plant maintenance staff, in turn, is responsible only for routine maintenance.

\section{Work Control and Performance Assessment}

This section discusses the French approach to controlling the maintenance process and to evaluating its effectiveness.

The French depend on training, procedures, supervision, and quality assurance to maintain control over the maintenance process-common practice in other countries as well. The French approach to training has already been described. One commenter, however, has pointed out that there is a tradeoff between depending on welltrained and experienced maintainers versus detailed procedures. In cases where craft knowledge can be assumed, therefore, the French are unlikely to write detailed procedures unless operating experience suggests otherwise. In a related sense, independent verification of component position and status is not required within maintenance, since experienced workers are assumed to be able to ensure proper conditions. (Operations perform some independent verification.)

EDF does not typically accept vendor-provided procedures as adequate (Mercier, 1987). Procedures are modified to fit the operating environment of the component in the plant. Failure data are also used to modify procedures. Because of plant standardization, the EDF is able to centralize its procedure development activities and tie them directly to training.

Quality assurance is provided in a manner very similar to that of the U.S. There is a separate QA/QC department that reports to the plant manager. This department is responsible for reviewing work packages and verifying completed work.

A key to the success of the French nuclear program is feedback from operating experience, including activities relevant to maintenance. As described earlier, the EDF maintains an extensive data file on equipment history and maintenance practices that allows for continual adjustment of procedures and maintenance strategy.

\section{Radiological Exposure}

Exposure rates in the French nuclear power industry are less than half the rates for PWRs in the United States. Two main factors have been identified as causes of this disparity. First, the French emphasis on planning and scheduling for maintenance results in less time spent in high radiation areas. Second, EDF and FRAMATOME have been able to develop both specialized tools and maintenance robots that reduce the time or need for exposure.

\section{General Lessons Learned from French Approach}

As mentioned previously, the EDF is part of the French government Ministry of Industry and is responsible for nuclear power production. Safety rules and regulations are developed by the Central Safety Department for $\mathrm{Nu}$ clear Facilities (SCSIN), also part of the Ministry of Industry. Maintenance program development and implementation is the responsibility of EDF. The programs are reviewed by SCSIN to ensure that safety regulations are addressed. The SCSIN has not developed specific regulations or safety rules dealing with maintenance practices. Although the organizational structure of the nuclear power industry in France is quite different from that in the U.S. and there is no current or anticipated regulation of maintenance in the same context under consideration in the U.S., the French experiences and approach to maintenance should provide useful insights. Although more detailed assessments are needed beyond what has been undertaken here to determine the specific degree of applicability to the U.S. situation, several general, but important lessons from the French approach are apparent from this review.

- A highly prescriptive approach to maintenance, or more specifically, preventive maintenance, is not necessarily prerequisite to an effective and safe maintenance program.

- Maintenance success depends on learning from operating experience. While this learning is made easier by the configuration of the industry in France, a high priority should be placed in the U.S. industry on sharing and learning from operating experience.

- Maintenance success is greatly enhanced by having adequate resources to perfect procedures, training, specialized tools, and the like. U.S. utilities need to find ways to combine their resources so that maintainers in the U.S. have access to the same level of support as do maintainers in France.

\section{FRG COMMERCIAL NUCLEAR INDUSTRY}

This section discusses the West German (FRG) approach to maintenance and maintenance regulation. It starts with a description of the industry. This is followed by a general description of the regulatory context. Next, German practice and regulation are described for the areas listed in the NRC's policy statement on maintenance. Some general lessons learned are also provided. 


\section{Description of Industry}

As of 1987, there were 19 nuclear power plants operating in the FRG with approximately seven in the planning or construction phase (see Table B.1). Total net output at this time was in excess of 13,791 MWe. The majority of plants in the FRG are PWRs. However, there are several BWRs and an HRT. In addition, an LMFBR was scheduled for operation sometime in 1988. The plants are divided among 18 state and privately owned utilities. Kraftwerk Union AG (KWU) provides reactors for PWRs and the turbine/generator for most plants (Nuclear News, 1988). Nuclear power plants in the FRG are fully owned by public and private utilities, and construction is carried out by private industrial firms, with indirect guidance from the government.

Nuclear power production, although gradually expanding, is not the sole source of electricity in the FRG and continues to be a controversial issue. The FRG is experiencing a relative degree of success recently in constructing plants and placing them on line, following a series of legal and licensing complications. In 1985, somewhat more than one-third of the electrical power production in the FRG was from nuclear power (see Fig. B.5). This increased success in constructing plants is thought to be related to a standardized licensing procedure started in 1980, referred to as the "convoy" procedure (Rippon, 1986). The convoy procedure is hoped to spur several new projects; however, low projections of growth in the demand for electricity may prevent the projects from coming to fruition. In addition, much like in the United States, there is ongoing public debate in the FRG regarding nuclear power expansion. The accident in Brunsbuttel in 1978 raised awareness of the risks of nuclear energy production and, in addition, caused changes in personnel issues and several regulations. Nuclear energy production is clearly not the central focus, in contrast to France, as government programs are additionally in support of conservation and other means of energy production. More recently, the Transnuclear incident and the accident at Chernobyl have helped stimulate opposition to nuclear power.

The nuclear power capacity in the FRG, nevertheless, has expanded over the past few years. In 1986, the 16 commercial nuclear power plants in operation at the time had an average capacity of approximately $85 \%$ and nuclear electricity production rose from 93 billion $\mathrm{kWh}$ in 1984 to 126 billion $\mathrm{kWh}$ in 1985 (Rippon, 1986).

\section{Regulatory Structure}

The FRG's regulatory system for nuclear power is highly complex due to the federalist structure of the nation (see Fig. B.6). There are 11 separate state governments in the
FRG that license and regulate nuclear power plant operations within their jurisdictions. The Federal Ministry of the Interior (BMI) supervises each of the 11 state ministries and exercises control in a direct fashion, using standardized minimum requirements.

The BMI supplies administrative guidelines or regulations that must be followed by the State Licensing Authorities. The BMI relies, in particular, on two appointed advisory committees for technical and scientific information that the BMI incorporates in its guidelines. These committees are: (1) the Reactor Safety Commission (Reaktor-Sicherheitskommission, or RSK), and (2) the Radiological Protection Commission (Strahlenschutz Kommission, or SSK).

The Reactor Safety Commission advises the BMI on safety issues. The RSK, involved in research and development, is responsible for summarizing the safety requirements or guidelines. These guidelines cover safety aspects of the design, construction, and operation of nuclear power plants. The requirements cover a broad range of areas from control room safety regulations to the handling of nuclear fuels and decommissioning (Franzen, 1982). This 20-member group acts independently, presenting their personal expert opinions.

The Radiological Protection Commission (SSK), also involved in research and development, provides technical information to the BMI on such issues as the hazards of ionizing radiation. The SSK is composed of 15 members who similarly act as independent experts.

A third agency providing information to the BMI for developing guidelines is the Expert Commission for Security Questions of the Nuclear Fuel Cycle (Sachverstandogenkommission fur Fragen der Sicherong des Kernbrennstroffkreislaufes, or SSB). The SSB, playing a less major role, provides recommendations to the BMI as to the protection of nuclear facilities from third party impacts. The recommendations are frequently confidential.

The guidelines set out by the BMI must be fulfilled and verified before a license will be issued. Safety standards act as instructions or steps that can be taken to fulfill the guidelines. In contrast to the regulatory standards, where only legislators and other specified groups are authorized to develop the rules, all interested groups are encouraged to participate in developing safety standards.

The Nuclear Safety Standards Commission (Kerntechnischer Ausschub, or KTA) is responsible for developing safety standards or steps to illustrate whether the guidelines have been fulfilled and to see to their application. The KTA is made up of members from such groups as manufacturers, constructors, owners, and operators, plus 
Table B.1. List of commercial nuclear power plants in Federal Republic of Germany.

\begin{tabular}{|c|c|c|c|c|c|c|}
\hline \multirow{2}{*}{$\frac{\text { Power Plant }}{\text { In Operation }}$} & \multirow[t]{2}{*}{ Operator } & \multirow[t]{2}{*}{$\begin{array}{c}\text { Pesetor } \\
\text { Tree }\end{array}$} & \multirow[t]{2}{*}{$\begin{array}{l}\text { Capealty } \\
\text { awe: Nes) }\end{array}$} & \multirow[t]{2}{*}{$\begin{array}{l}\text { noacter } \\
\text { suppller }\end{array}$} & \multirow[t]{2}{*}{$\begin{array}{l}\text { Oenerater } \\
\text { eupeller }\end{array}$} & \multirow[t]{2}{*}{$\begin{array}{l}\text { Start of } \\
\text { Operaflon }\end{array}$} \\
\hline & & & & & & \\
\hline $\begin{array}{l}\text { Grefenthindeld KKSO } \\
\text { (Gralenrheinield) }\end{array}$ & Bayermuark 10 & PWR & 1236 & kws & mW & Jun-e2 \\
\hline CNK 1 (Nockanwedhoim) & $\begin{array}{l}\text { Comoinechuftakomikrati wert } \\
\text { Necker (GKN) }\end{array}$ & PWR & 785 & kns & kwu & Dec-76 \\
\hline $\begin{array}{l}\text { Kruemmal KKX } \\
\text { (Geesthecht-Knuemmed } \\
\text { Elbe) }\end{array}$ & $\begin{array}{l}\text { Kemkrattwerk Kruemmol } \\
\text { CmbH (KKK) }\end{array}$ & BWR & 1260 & $\operatorname{mos}$ & kWu & Mar-84 \\
\hline $\begin{array}{l}\text { THTA } 300 \\
\text { (Hamm-Uentrop) }\end{array}$ & $\begin{array}{l}\text { Hochtemperalur-Kornkraft- } \\
\text { work GmbH (KKa) }\end{array}$ & HIR & 286 & hos & Eac & Jun-87 \\
\hline KBA (Brokdont) & $\begin{array}{l}\text { Komkrnattwerk Brokdort } \\
\text { Crith }\end{array}$ & PWA & 1307 & kWu & kwu & Dec-86 \\
\hline $\begin{array}{l}\text { Bruncbuenel } \\
\text { (Brunubuettolesbo) }\end{array}$ & $\begin{array}{l}\text { Komknatiwork Brunabubtiel } \\
\text { GmbH (KKB) }\end{array}$ & BWA & 771 & $\mathbf{m}$ & ans & Fob- $n$ \\
\hline KKI I (Esembench) & Kermkraftwork lear (KKI) & BWR & 807 & kns & KWv & Mer-79 \\
\hline - KKI 2 (Easentach) & Kornkratiwerk lsar (KKI) & PWR & 1285 & knus & kWv & May-80 \\
\hline $\begin{array}{l}\text { Obrighaim Kwo } \\
\text { (Obrigheim) }\end{array}$ & $\begin{array}{l}\text { Kernknetiwork Obrighalm } \\
\text { OmbH (KWO) }\end{array}$ & PWR & 340 & Simoneste & Shemen & Mar-60 \\
\hline KKP I (Phillppoburg) & $\begin{array}{l}\text { Kemkrattwerk Phllippeburg } \\
\text { (KKP) }\end{array}$ & BWR & 864 & $\mathrm{mun}$ & KWU & $F=b-80$ \\
\hline KKP 2 (Phillippsburg) & $\begin{array}{l}\text { Kornkofifwerk Philippaburg } \\
\text { (KKP) }\end{array}$ & PWR & 1268 & $\mathrm{~km}$ & kwu & Apr-85 \\
\hline $\begin{array}{l}\text { KPB II Block B } \\
\text { (Gundremmingen) }\end{array}$ & $\begin{array}{l}\text { Kemkraftwork RWE-Bayerr } \\
\text { work GmbH (KRB) }\end{array}$ & BWR & 1244 & $\mathbf{k n}$ & kno & Jul-84 \\
\hline $\begin{array}{l}\text { KRB } \| \text { Bbock C } \\
\text { (Gundremmingen) }\end{array}$ & $\begin{array}{l}\text { Kornkrntlwerk RWE-Bayerm- } \\
\text { work Gmbt (KRB) }\end{array}$ & BWA & 1244 & $\mathbf{m m s}$ & $\mathbf{k n} \mathbf{v}$ & Jan-85 \\
\hline Sindo IOKS (SIado) & $\begin{array}{l}\text { Kambermmert stade GmbH } \\
\text { (KKS) }\end{array}$ & PWR & 630 & Sinmane & sinmen: & May-72 \\
\hline KurW (Wuerpesesen) & ProusenenElecidra AG & BWR & 640 & man & AECAMMU & Mar-72 \\
\hline KKU (Esensham) & $\begin{array}{l}\text { Kernkraftwerk Unterweser } \\
\text { CmbtH (KKU) }\end{array}$ & PWR & 1230 & kwu & mms & Oct-70 \\
\hline KWO (Grahnde) & $\begin{array}{l}\text { Comolinschaltskemteraftwerk } \\
\text { Grohnis Conbli (KWG) }\end{array}$ & PWR & 1300 & mw & KWU & Fob-es \\
\hline Bibls A (Worma/Amain) & $\begin{array}{l}\text { Rhelnisch-Wostlälieches } \\
\text { Elokdrizithlowork } A Q \text { (RWE) }\end{array}$ & PWR & 1146 & Shemenese & kWU & Mar.75 \\
\hline Biblis B (Worma/Rhain) & 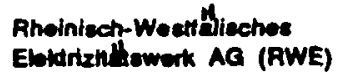 & PWR & 1240 & Slomens: & $\mathbf{k m}$ & $\operatorname{Jan}-77$ \\
\hline $\begin{array}{l}\text { Mulhoim-Keorilich } \\
\text { (Mulheim-Keoritich) }\end{array}$ & 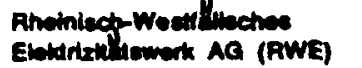 & PWR & 1227 & ean & Ex & Oct-87 \\
\hline
\end{tabular}


Table B.1. (Contınued)

\begin{tabular}{|c|c|c|c|c|c|c|}
\hline \multirow{2}{*}{$\begin{array}{l}\text { Powee Mant } \\
\text { In Oparatlon } \\
\text { - Kalker ENR-300 } \\
\text { (Kalkar) }\end{array}$} & Operator & $\begin{array}{l}\text { Reneter } \\
\text { Type }\end{array}$ & $\begin{array}{c}\text { Capeoly } \\
\text { cure: Nell }\end{array}$ & $\begin{array}{l}\text { Ronoter } \\
\text { guppller }\end{array}$ & $\begin{array}{r}\text { Oonorator } \\
\text { Suppller }\end{array}$ & $\begin{array}{l}\text { surt of } \\
\text { Operatien }\end{array}$ \\
\hline & Behnell-Eruter-Kornkraft- & UMFEA & 298 & Int/Bn/Nere & $k w \mathbf{s}$ & 2188 \\
\hline Subtofn (20 unite) & & & 13701 & & & \\
\hline \multicolumn{7}{|l|}{ Under Construetton } \\
\hline CKN 2 (Noctanweetheim) & $\begin{array}{l}\text { Comoinecheftikemikraftwerk } \\
\text { Necker (CNK) }\end{array}$ & PWR & 1228 & mus & $\mathbf{k n v}$ & Mav-8s \\
\hline Emoland (Lingen) & $\begin{array}{l}\text { Kornkrattwork Llppo-ems } \\
\text { ConbH (KLE) }\end{array}$ & PWA & 1242 & kmo & kns & Aug-88 \\
\hline Subtotal (2 unlte) & & & 2467 & & & \\
\hline \multicolumn{7}{|l|}{ Planned } \\
\hline KWS (Wyhl/Ahein) & $\begin{array}{l}\text { Kenluatmonk stdd } \mathrm{CmbH} \\
\text { (KWs) }\end{array}$ & PWA & 1284 & nans & knus & 79 Indal \\
\hline Blblis C (Womma/Rholn) & 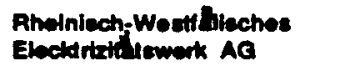 & PWR & 1237 & kwv & kws & Be1 indef. \\
\hline 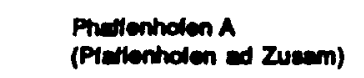 & 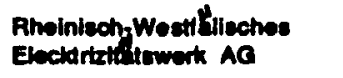 & PWR & 1258 & kWU & kWv & 190 indel. \\
\hline Subtotal $(3$ units) & & & 3770 & & & \\
\hline
\end{tabular}

*Plant has been fully constructed but is not yet operatıng

(Adapted from "World List of Nuclear Power Plants," Nuclear News, February 1988, Vol 31, No 2 )

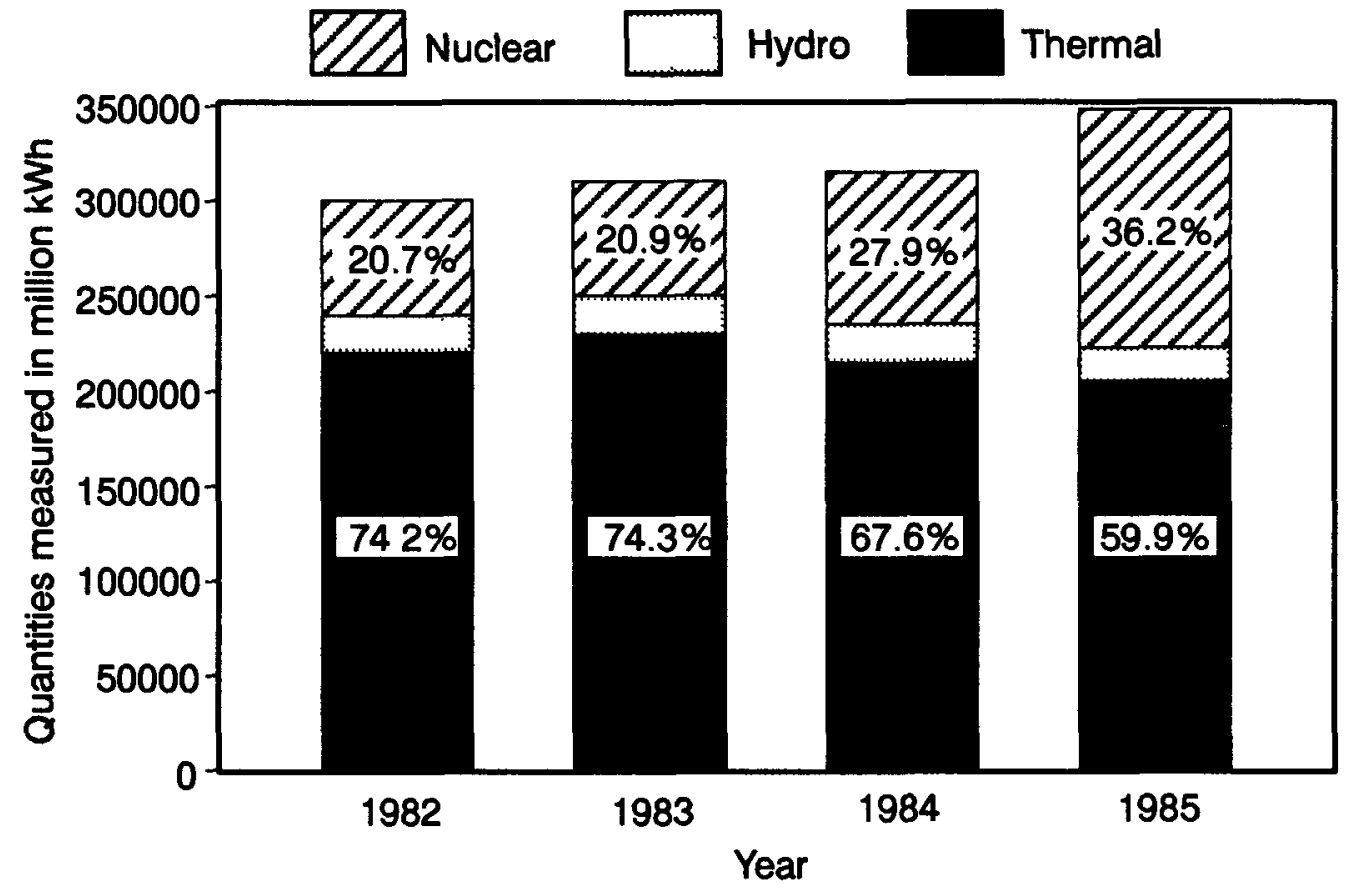

Figure B 5 Distribution of power generation by source type in Federal Republic of Germany 


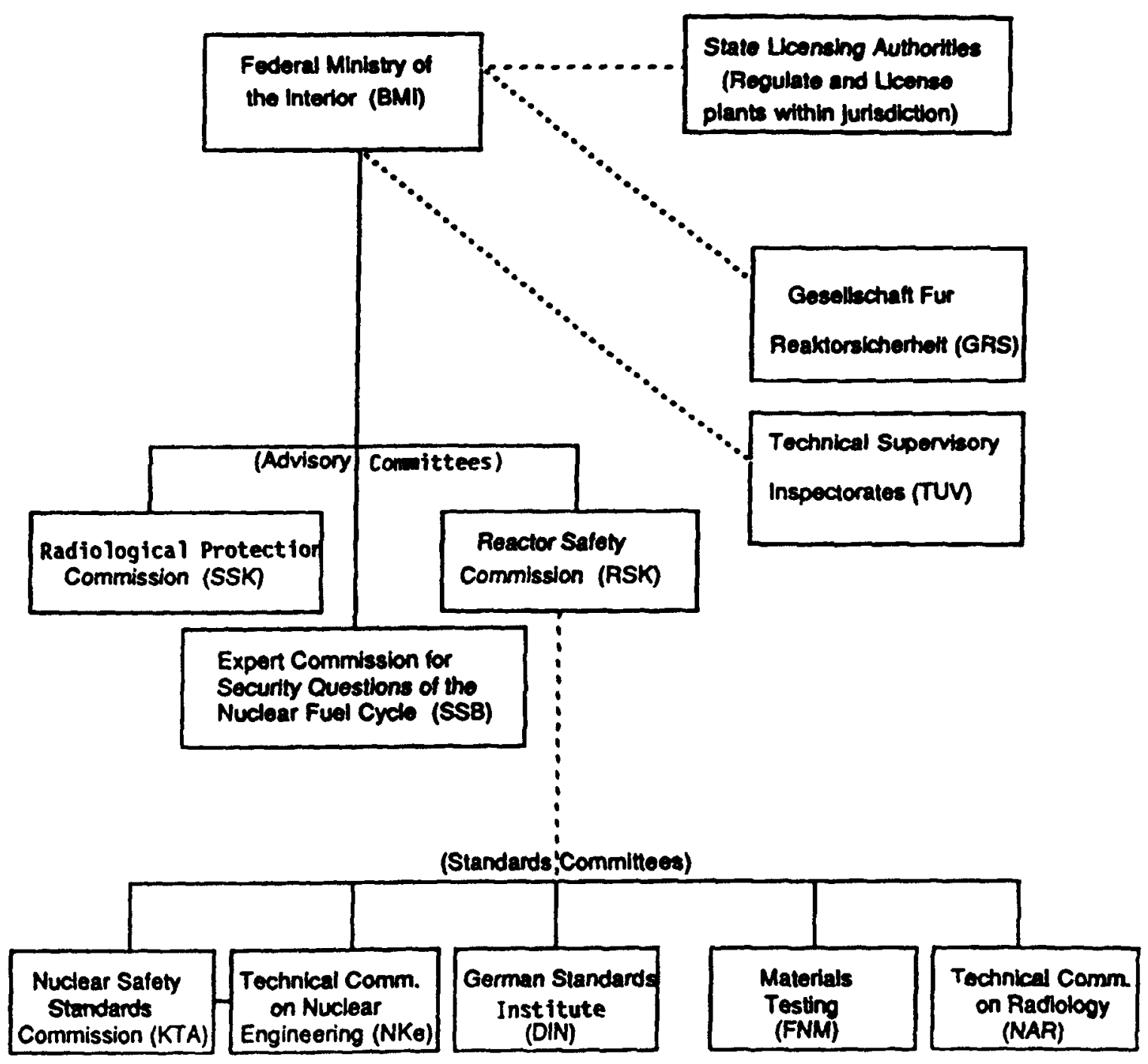

Figure B.6. Overview of Federal Republic of Germany's regulatory structure for commercial nuclear power.

10 other members from technically oriented organizations. A complex process is used to develop the standards. The first draft of standards is developed by task groups, reviewed by the public, and passed through a series of steps until a final draft is passed and published by the KTA. The KTA makes decisions, based on a 5/6 majority, concerning the placement of orders for upcoming projects, draft standards, and the final standards developed. The German Standards Institute (Deutsches Institut fur Normung, or DIN) plays a similar role as the KTA, but, instead of developing safety standards, focuses on the development of technical standards. The DIN has a more simplified approach to developing the standards, avoiding the use of task groups. The Technical Committee on $\mathrm{Nu}$ clear Engineering (Normenausschub Kerntechnik, or
NKe), similar to the KTA, is comprised of "all interested groups" and is also involved in developing technical standards. The NKe comes up with standards and coordinates with the KTA by passing them by KTA's ratifying procedures. Other standards committees useful in radiological protection are Technical Committee on Radiology (Normenausschub Radiologie, or NAR) and Materials Testing (Fachnormenausschub Metrialprufung, or FNM).

The licensing authorities must ensure that the safety and technical standards have been met and, therefore, consult the BMI, Technical Inspection Agencies (Technische Uberwachungs Vereine, or TUV), and the Reactor Safety Company (Gesellschaft fur Reaktorsicherheit, or GRS) for additional information regarding safety issues. 
Although Figure B.6 shows the standards committees as directly communicating with the RSK, other lines of communication take place such as the standards committees and the BMI or the TUV and GRS.

The TUV is a group of nonprofit organizations supervised by the government that inspects safety measures for industries. These agencies are important for maintenance activities as they determine the quality of the safety tests in use. There are 11 TUVs of which seven have special nuclear departments. Since each TUV is independent, a group was formed that would allow for uniformity in decisionmaking. The Nuclear Steering Committee of the Technical Inspection Agencies (TUV-Leitstelle Kerntechnik) is comprised of members from those TUVs with the nuclear departments and members from the GRS. The Nuclear Steering Committee of the TUVs is responsible for ensuring homogeneous examination, assessment of similar technical contents, control task groups, and coordination of certain committee members (e.g., KTA, NKe).

The GRS, an advisory body to the government, is financed by the federal government and conducts studies on the safety of nuclear facilities and of radiological protection by order of the BMI. However, it maintains a quasiprivate status with nuclear licensing, and supervisory authorities suggest that GRS assesses special safetyrelated questions, contributes to the preparation of safety-related standards, and coordinates international and national activities.

Each state licensing authority, responsible for coordinating public advisory groups and state and regional agencies and for authorizing the licensure of plants, must adhere to those regulations as determined by the Atomic Energy Act, the Reactor Safety Commission, and the technical rules as developed by several of the mentioned agencies in order to promote a safe approach to nuclear power production (Franzen, 1982).

\section{Maintenance Practices and Regulations}

Information was available on some aspects of the management and organization of maintenance for the Biblis nuclear power station. Figure B.7 provides an organizational chart from Biblis. Maintenance is one of four major departments. It is further divided into five sections:

1. Work preparation

2. Mechanical installations

3. Electrical installations

4. Service and transport

5. Maintenance technology

Instrumentation and control is part of the engineering department. Except for fuel handling and major modifica- tions, the onsite maintenance team performs all required maintenance. At the Biblis plant, the inservice inspection program has been held to be equivalent to U.S. practices.

\section{General Lessons Learned from German Approach}

The Federal Republic of Germany has a complex, yet effective, approach toward regulating the nuclear power industry. The decentralized system allows for a degree of variation among states, in that each state is responsible for regulating and licensing plants in their territory. A framework of minimum requirements or standards is supplied by the Federal Ministry of the Interior, however, to maintain quality and some homogeneity in approach across the states. The safety standards incorporate input from a large body of experts, pooling information from a great many sources (e.g., RSK, SSK, TUV, GRS). The system being based on the exchange of information across many areas of technical expertise reduces the chance of overlooking important safety-related details.

Further contributing to FRG's success is the serious approach taken to nuclear power plant training. Training is extensive and conducted "in-house" by the respective utility, following the completion of up to 12 years of school, plus an apprenticeship.

The FRG recognizes the importance of good maintenance procedures. The Biblis plant spends $50 \%$ of maintenance time on corrective activities and $50 \%$ on preventive measures. Periodic inspections are conducted of plant systems and components. A catalog of inspections are developed in cooperation with the manufacturer KWU, the operator of the plant, and the official expert.In addition, there are a number of preventive maintenance measures that are used to aid plant availability. The following are used in particular by the Gemeinschaftskernkraftwerk (GKN), a nuclear power plant in the FRG: (1) recurrent tests; (2) special tests; (3) upkeep; and (4) repair, modification, and deviation. Recurrent tests are used to ensure that the instrument is functioning properly to perform its job. The frequency of this type of test is made in accordance with the needs of the whole plant, the requirements of the system, and the component and licensing standards. In addition, systems, components, and system parts are typically tested during recurrent tests. The testing includes such things as visual inspection; surface, internal, and leakage tests; and chemical analysis and measurement. A QA unit keeps a list of recurrent maintenance, specifying the maintenance work for a particular component and for a particular interval. Units are assigned to individual systems and must develop updated maintenance procedures. In addition, a test manual lists the tests, and a test schedule will provide the dates on which they should take place. Also, a test procedure manual is available that describes the details of 


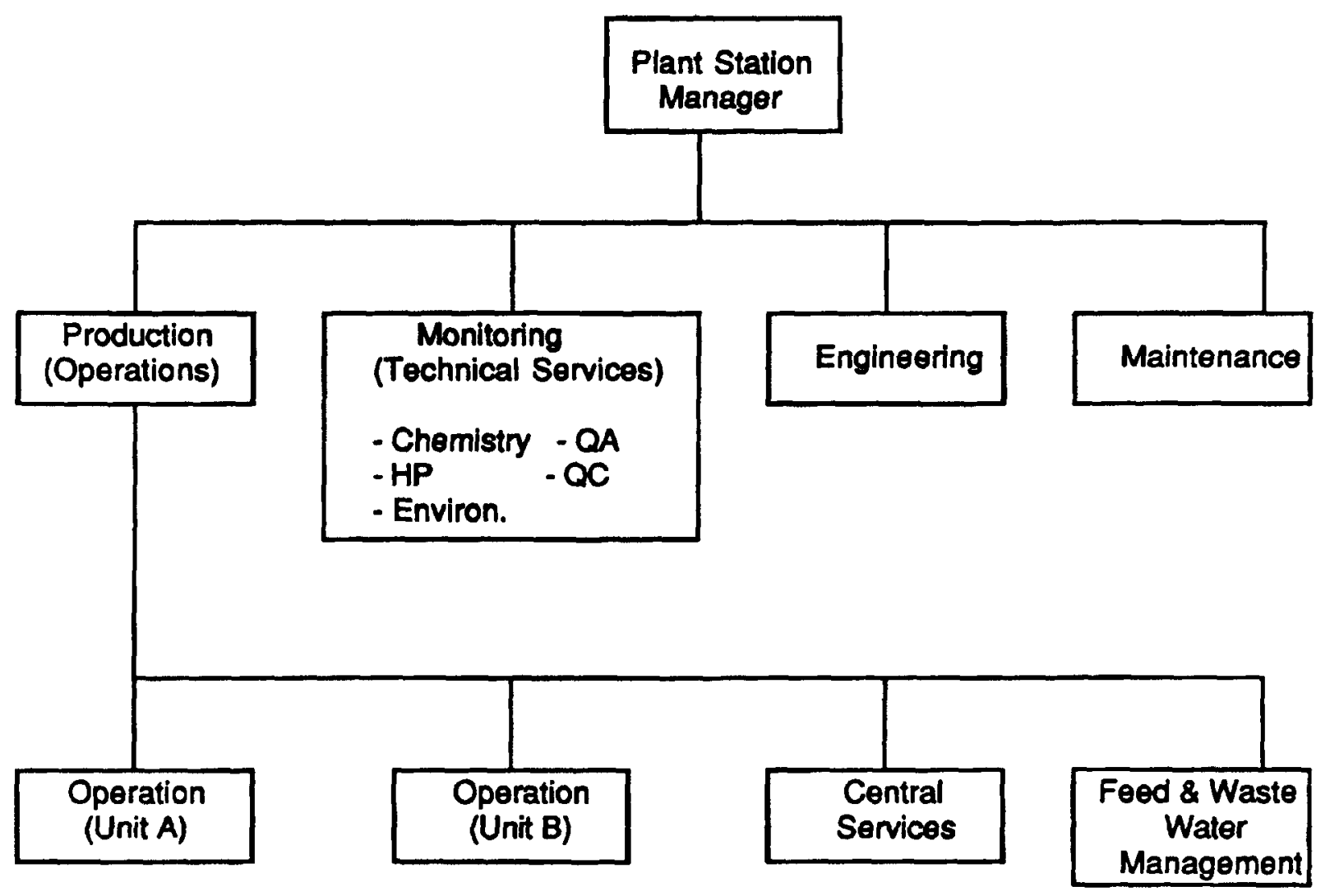

Figure B.7. Biblis organization chart.

(Adapted from "Maintenance of European Nuclear Power Plants," EPRI Special Report, May 1987.)

the operation. These are all used for internal organizational documentation.

Contributing to successful maintenance is the process by which the FRG monitors spare parts. The FRG has a complex data processing system to keep track of inventory, referred to as the Kraftwerk-Kennzeichensystem (KKS) (Schegk, 1986). This system aids in maintenance practices since one may assess when parts need to be replaced.

The serious approach taken toward maintenance and training, in addition to meeting quality safety standards, have contributed to FRG's recent success. While additional information is needed, several lessons from the FRG approach can be anticipated.

- An approach to maintenance that includes considerable corrective maintenance is not necessarily antithetical to safe maintenance programs, so long as equipment availability can be ensured.

- Maintenance programs can be successful, even in a decentralized industry and regulatory structure. 


\section{REFERENCES FOR APPENDIX B}

Bemer, J. P. 1986. "Maintenance Success in Availability Trends," Nuclear Power Plant Maintenance, Proceedings from an International Meeting, March 23-27, 1986, Utah.

Bitsch, D. 1985. "Continuous Improvement of Operation and Maintenance Conditions of French PWR Nuclear Islands," Nuclear Power Plant Availability, Maintenance and Operation, International Atomic Energy Agency, Vienna, pp. 209-216.

Degot, D., and G. Lebreton. 1985. "Standardization of Nuclear Power Plants," American Nuclear Society Transactions, May 19-23, 1985, 49:103-112.

Electricite de France (EDF), Construction Division. 1982. The French Nuclear Electricity Programme, France.

Electric Power Research Institute (EPRI). 1987. "Maintenance of European Nuclear Power Plants," Special Report, EPRI-NP-5185-SR, May 1987. Palo Alto, CA: Electric Power Research Institute.

Franzen, L.F. 1982. "The Nuclear Licensing and Supervisory Procedures for Nuclear Facilities in the Federal Republic of Germany," GRS-43, February 1982.
International Atomic Energy Agency (IAEA). 1980 "France," Manpower Development for Nuclear Power. Technical Report Series No. 200, Vienna.

Mercier, J. P. 1987. "Nuclear Power Plant Maintenance the EDF Way," Presented at the International Executive Conference for NPP Maintenance, December 1987, Orlando.

Nuclear News, 1988, 31(2):63-82.

Rippon, S. 1985. "Training at Electricite de France," $\mathrm{Nu}$ clear News, 28(15):55-59.

Rippon, S. 1986. “The Nuclear Scene in Europe,” Nuclear News, 29(7):86-100.

Schegk, J. R. R. 1986. “Maintenance Program, Organization, and Procedures," Presented at IAEA-Interregional Training Course, September 15-October 23, 1986, Essen.

Sweet, C. 1981. "A Study of Nuclear Power in France," Energy Paper No. 2, Polytechnic of the South Bank, London, England.

Vendryes, G. 1986. "Observations from France," $L A E A$ Bulletin, Autumn, pp. 52-54. 
APPENDIX C

U.S. COMMERCIAL AVIATION INDUSTRY

$c-1 / c-2$ 



\section{CONTENTS}

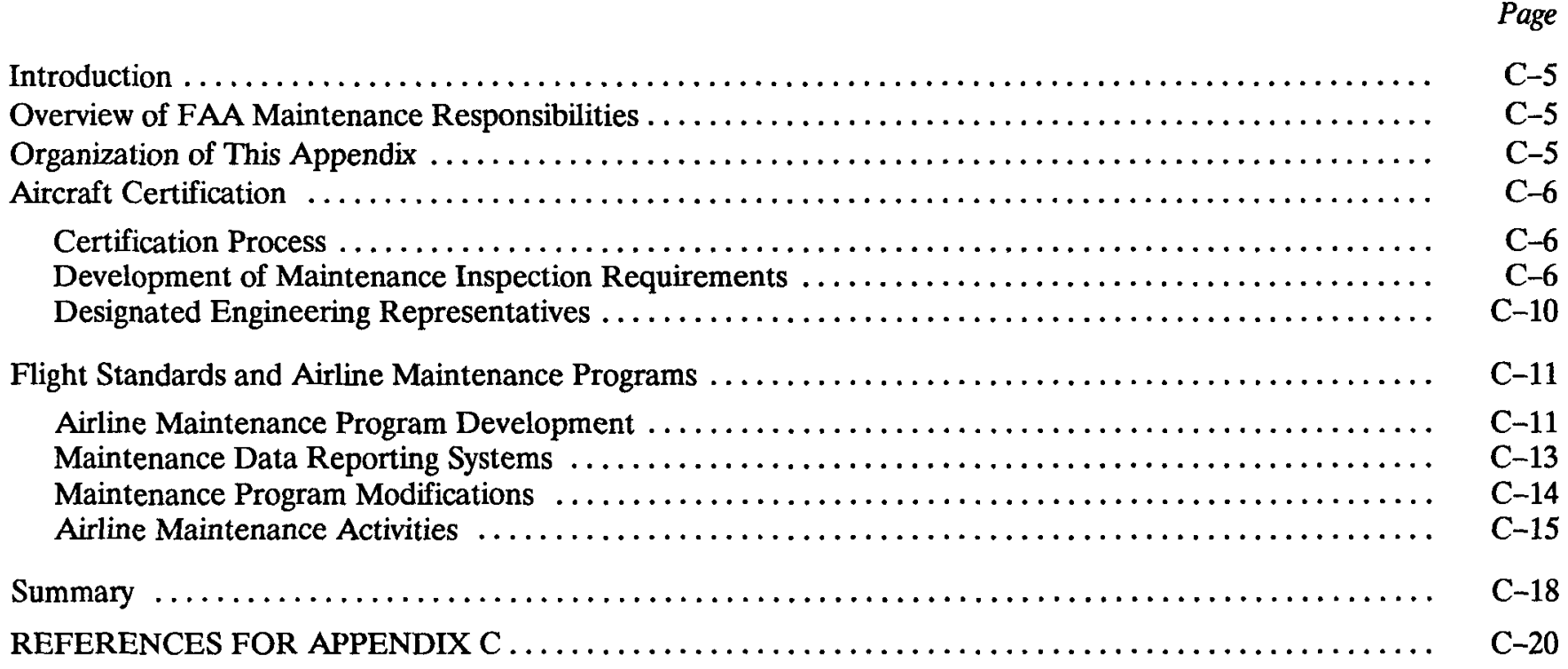

\section{FIGURES}

C.1. Simplified MSG-3 logic diagram $\ldots \ldots \ldots \ldots \ldots \ldots \ldots \ldots \ldots \ldots \ldots \ldots \ldots \ldots \ldots \ldots \ldots \ldots, \quad$ C -8

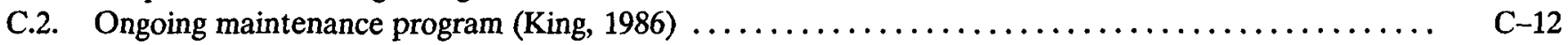





\section{Introduction}

This appendix presents an examination of the role that the Federal Aviation Administration (FAA) plays in the maintenance of U.S. commercial aviation aircraft. The purpose is to assess the approach that the FAA takes in the regulation of aircraft maintenance in order to identify activities that could potentially be adapted in the development of a maintenance rule for the nuclear industry.

The NRC and FAA have a number of important similarities and differences that make such an examination valuable. The NRC and FAA are both responsible for the regulation of the safe operation of complex technologies that have the potential for catastrophic accidents. New aircraft must be certified by the FAA, just as new plants must be licensed by the NRC. Unlike the NRC, though, the FAA is responsible for both the promotion and regulation of civil aviation to ensure safe and orderly growth. Also, the FAA has adopted and applied a system of qualitative safety goals and numerical guidelines for the certification and monitoring of aircraft maintenance inspection programs.

It is the system for the certification and monitoring of aircraft maintenance programs that is the focus of this report. The approach consisted of both an extensive literature search and interviews with representatives of the Boeing Commercial Airplane Company, the FAA Seattle Aircraft Certification Office, and the Flight Standards District Office located in the NW Mountain Regional Office.

\section{Overview of FAA Maintenance Responsibilities}

The FAA was established in 1958 from the Civil Aeronautics Board. In 1967, it became part of the Department of Transportation. Over the years the principal mission of the agency has remained the promotion and regulation of civil aviation to ensure its safe and orderly growth. To achieve this objective, the FAA is involved in such activities as the operation of the air traffic control network, flight service stations, air traffic route control centers, and aids for navigation. The agency also issues and enforces rules, regulations, and standards for the manufacture, operation, and maintenance of aircraft. The focus of this report is the examination of these rules, regulations, and standards for maintenance and their applicability for the NRC.

There are currently over 223,000 active general aviation aircraft and 4,600 air carrier aircraft in the United States (FAA, 1987). Each aircraft must be certified as airworthy by the FAA. Both the original design and the aircraft developed from the original design require FAA approval. The certification process is important in an assessment of maintenance regulation because it is during the certifica- tion period that the scheduled maintenance program requirements are developed for an aircraft.

The FAA becomes involved when the aircraft is still in the blueprint stage. Throughout the entire design and construction phase, the FAA engineers monitor the progress of numerous components and systems to ensure quality of workmanship and conformity to FAA requirements and the approved design. This oversight is also conducted for the design and manufacture of aircraft engines, propellers, and instruments.

When an aircraft prototype has been demonstrated to meet FAA's standards for construction and performance, it is issued a Type Certificate. It is during the later phase of this certification process that the initial requirements for a maintenance program are developed. The manufacturer and prospective aircraft operators establish the times for periodic inspections and overhauls of various aircraft components such as engines, instruments, communications, and flight systems. After review and analysis by the FAA, this information becomes the approved scheduled maintenance program for that specific aircraft type and forms the framework for each operator's maintenance program.

Once an aircraft leaves the manufacturer and begins flying, the responsibility of ensuring that it remains airworthy is assigned to the FAA flight standards division. The agency approves each operator's maintenance program (Operation Specifications-Maintenance) and also licenses the repair stations that perform the required maintenance checks and repairs and alterations to the aircraft. Inspectors are assigned to verify that the operators continue to maintain the aircraft as required by their maintenance program.

Since the key element in the proper maintenance of an aircraft is the individual responsible for the maintenance, the FAA requires that each aviation mechanic have a valid certificate from the agency with the appropriate ratings. The FAA also certifies the mechanic schools and instructors who teach in these institutions. Currently, there are over 280,000 certified mechanics in the U.S. (FAA, 1987).

\section{Organization of This Appendix}

The following sections examine the FAA's involvement in the civil aviation maintenance programs. The first section addresses the development of the initial maintenance requirements during the certification process. An overview of the activities of the FAA and the operators to ensure that the aircraft is properly maintained (referred to as flight standards activities) is presented. A summary description of those aspects of the FAA program that could be potentially applicable for the NRC maintenance rule is also presented. Included in this section is a description of the specific FAA activities that address the aspects of an 
adequate nuclear plant maintenance program as outlined in the final Commission Policy Statement on Maintenance of Nuclear Power Plants.

\section{AIRCRAFT CERTIFICATION}

As mentioned above, it is during the aircraft certification process that the initial requirements for an approved maintenance program are generated. This section discusses the approach used by a large aircraft manufacturer (Boeing) to develop these requirements. Also examined is the role the FAA plays in this process.

After a brief review of the aircraft certification process, the following three principal features of the maintenance program development operation are examined:

- Airline/Manufacturer Maintenance Program Planning Document, MSG-3 (Air Transport Association, 1980)

- Maintenance Steering Committee, and

- Maintenance Review Board.

Also discussed in this section is the use of designated engineering representatives by the FAA during the certification process. Although these representatives are not directly involved in the development of the maintenance program, their activities provide a number of possible lessons for the NRC to consider in the development of a maintenance rule.

\section{Certification Process}

The aircraft certification process is the method by which the FAA ensures that a new design for a specific type of aircraft, engine, or instrument complies with all the applicable rules and standards. In the case of an aircraft, the FAA issues three certificates during the process. The first is the Type Certificate that is issued once the plane has passed an extensive series of ground and flight tests. The Type Certificate describes the conditions and limits for the operation of the particular aircraft type. A Product Certificate is issued when the manufacturer has demonstrated the ability to duplicate the type design. The Product Certificate gives the manufacturer the authority to produce an aircraft type. The third certificate, the Airworthiness Certificate, accompanies each aircraft that leaves the manufacturing facility. This certificate attests to the fact that the aircraft conforms to the Type Certificate and is safe to fly. Such a certification process can, for new large transport aircraft, take a number of years to complete.

As the aircraft design is finalized and the first plane is being prepared for its initial flight test, the manufacturer begins to assemble a committee of representatives from its own organization, the airlines that will be potential operators of the aircraft, and the regulatory agencies (the FAA and foreign aviation regulatory bodies). The purpose of this committee (the Maintenance Steering Committee) is first to identify those systems on the aircraft that require scheduled maintenance and then to prepare a document describing the necessary minimum inspection and replacement periods for these items. The approach that is used in the development of this document is the result of 20 years of effort on the part of the Air Transport Association (ATA). The process uses a task-oriented logic and is based on reliability-centered maintenance to identify the inspection schedules.

The results of this committee activity are submitted to the FAA Maintenance Review Board for its review and analysis. Upon approval, these scheduled maintenance requirements become the foundation for each operator's maintenance program.

\section{Development of Maintenance Inspection Requirements}

There are three primary components in the development of maintenance inspection requirements for new commercial aircraft types. These are the MSG-3, the Maintenance Steering Committee, and the Maintenance Review Board. As can be noted in the following sections, certain aspects of these three components, or operations, could be potentially applicable to the nuclear maintenance field.

\section{Airline/Manufacturer Maintenance Program Planning Document, $M S G-3$}

The Maintenance Steering Group process is one that has been developed and refined over the last two decades to assist the airlines and aircraft manufacturers in developing a preventive maintenance inspection schedule. Although not required by the FAA, the MSG process has been approved as an acceptable method to comply with the FAA requirements. The current version of the MSG (MSG-3) is considered to be representative of the stateof-the-art in aircraft maintenance program design.

In 1968, the ATA initiated the Maintenance Steering Group concept to develop a structured process for the Boeing 747 scheduled maintenance program. Because of the complex nature of the 747 compared to previous aircraft, it was felt that such a process was necessary. The initial maintenance program planning document was the MSG-1. An MSG-2 was produced for the Douglas DC-10 and Lockheed L-1011 based on the MSG-1. A number of factors influenced the industry to make the considerable effort to revise MSG-2. These included the expanded use of reliability-centered maintenance, new structural analysis rules (CFR, 1988, 14:25.571), and the experience gained from the use of MSG-2. The current version, used for the Boeing 757 and 767 aircraft, is the 
MSG-3. At the present time, MSG-3 is being revised. The future version, MSG-3 Revision 1, will be more generic in nature than previous versions and more useful to a wider range of manufacturers.

An important feature of the MSG-3 is the approach taken to identify scheduled maintenance and inspection periods. The MSG-3 involves a top down, or consequences of system failure, approach. The focus is on systems and not on components. Instead of looking at each component and determining how each will fail, the emphasis is on determining which systems and which components within each system are critical to safety. Also, the MSG-3 identifies maintenance tasks rather than processes, as was the case in MSG-2.

There are currently several processes being used by aircraft manufacturers to determine the required maintenance inspection schedule for significant items on an aircraft. Previously, under MSG-2, the three processes were labeled on-condition, hard-time, and condition monitoring. On-condition is defined as repetitive inspections or tests that are used to determine the condition of units and the corrective action to be taken when a part requires action. Hard-time refers to when a part is required to be removed at or before a pre-set time. Condition monitoring is the process in which the total population of parts is monitored for future problem identification (i.e., parts are allowed to fail) (Matteson et al., 1984).

Difficulties were encountered when attempting to determine what maintenance was to be accomplished on an item under these process labels. The MSG-3 taskoriented approach allows the Maintenance Review Board Report to present the entire maintenance program for a specific item in a unified format.

Tasks in the MSG-3 that may be included in the scheduled maintenance program are:

- Lubrication/servicing

- Operating crew monitoring and operational check

- Inspection/functional check

- Restoration

- Discard

Initially each system or subsystem on the aircraft that may require preventive maintenance is identified by the Maintenance Steering Committee. Any failures and the consequences of failures to that system are then determined. Based on this information, the maintenance-significant items (MSIs) are then identified using a top-down approach. The committee examines the aircraft design and partitions it into major divisions. A system breakdown is then developed within each division category. The "maintenance significance" of a system or part within the system is determined based on the safety, economic, and hidden consequences of a failure. The eventual inspection requirements identified for the MSIs are based on both operational and testing information and the expert judgment of the committee members.

After all MSIs have been identified, the MSG-3 decision logic diagram is used to assist in the development of a specific maintenance inspection requirement for each MSI. A simplified version of the MSG-3 logic diagram is presented in Figure C.1. The diagram displays questions connected by flowlines to aid one through the decision process. The responses to the "Level 1" questions determine the category of an MSI failure in terms of its visibility and safety and economic consequences. Based on the category of the MSI failure, responses to the "Level 2" questions determine which maintenance tasks are applicable and effective in preventing failure.

As shown in Figure C.1, the first question deals with whether or not the occurrence of a functional failure is evident to the operating crew. If an MSI is determined to be hidden, it is necessary to identify maintenance procedures in which the condition of the given item can be operationally checked. Thus, hidden functions require maintenance fundamentally different from the maintenance required of nonhidden functions. It is because of this difference that the logic diagram separates hidden and nonhidden items in the first step of the decision process. An example of a hidden MSI is windshield wipers. Unless checking of windshield wipers is included in the maintenance program, their failure will only be evident when they are needed.

The second question in the logic diagram asks why either failure of the MSI has safety or economic consequences. As can be seen in Figure C.1, a safety-related item requires much more extensive maintenance task analysis. If there is no maintenance task that is applicable and effective in maintaining a safe aircraft, then redesign, a potentially costly alternative, is the only option.

The last question in Level 1 specifically relates to evident nonsafety MSI failures. At this stage, it is determined whether or not the MSI failure will affect operating capability. For example, the malfunction of an engine would not be considered safety-related for multi-engine aircraft, because redundancy (i.e., additional engines) is built into the system. The malfunction of an engine would, however, require a change in operation.

Once the MSI has been categorized as evident or hidden, safety or economic, and operational or nonoperational, specific maintenance tasks are identified to address the MSI within Level 2 of the diagram. The emphasis within the airline industry is on preventive maintenance. As can be seen from the diagram, the first maintenance task is lubrication/servicing, followed by operating crew 


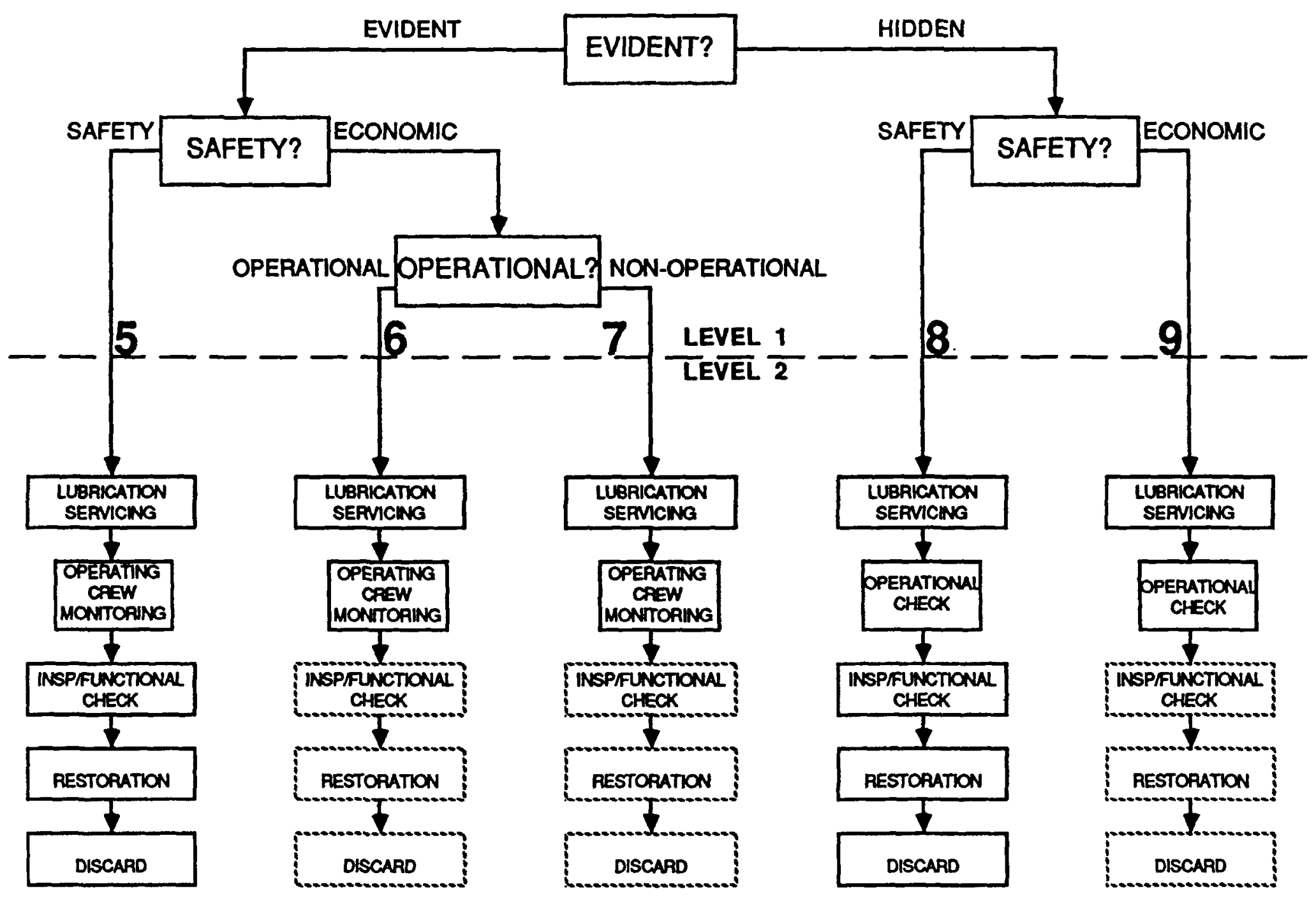

Figure C.1. Simplified MSG-3 logic diagram. 
monitoring (for an evident MSI), or operational check (for a hidden MSI). If neither of the first two maintenance tasks is applicable and effective for a nonsafety MSI, the remaining tasks-inspection/functional check, restoration, and discard - are examined in order until an applicable and effective task is found. If a maintenance task is not found, based on cost-effectiveness, either the item is redesigned or no maintenance is scheduled. For safety items, all maintenance tasks must be examined for applicability and effectiveness until at least one is found or redesign is required.

From discussion with aircraft manufacturer representatives, it became apparent that the airline industry has a slightly different definition of a safety system than is used by the NRC. One of the first questions the MSG-3 process poses concerning a functional failure is whether it, or any secondary damage resulting from the failure, has a direct adverse effect on operating safety. The definition used by the airlines and FAA is that to be direct, the failure must achieve its effect by itself with no existing redundancy. To have an adverse effect on operating safety implies that the consequences will cause the loss of the aircraft or injury to the occupants during the period that the airplane moves under its own power for the purpose of flight.

The result of this MSG-3 process is the identification of specific maintenance-significant items and their required frequency of inspection. This information forms the basis of the industry input to the FAA for a proposed scheduled maintenance program.

\section{Maintenance Steering Committee}

The Maintenance Steering Committee is the organizational unit that implements the MSG-3 process and develops the recommended maintenance requirements. The management of the maintenance program development activities is conducted by a Steering Committee that is convened about the time the aircraft is prepared for its first flight (Matteson et al., 1984). Participants include representatives from the manufacturers of the airframe and power plant, the airlines purchasing the plane, and the FAA (and foreign regulators). The FAA and foreign regulators attend the meetings as observers. The committee is chaired by one of the airline representatives and cochaired by a manufacturer representative. This committee is then broken up into five or six working groups-each addressing a major system, such as structures or avionics. There are three or four FAA observers for each working group.

The first step performed by the individual working groups is the identification of the systems or subsystems that may require preventive maintenance. For each aircraft operating system, a physical and functional description of the system is required and drafted by the task group. Design engineers from the manufacturing organizations are brought in to assist the task groups in their understanding of any new designs or features associated with the aircraft systems. Also identified at this stage are any redundancy features that will ensure that the system remains functional in the event of a subsystem failure.

The second step is for the task group to identify failure mechanisms associated with each system or subsystem and the consequences of such a failure. This allows the task group to produce a list of MSIs and Structurally Significant Items (SSIs). This step involves the use of the MSG-3 structured decision approach (see Fig. C.1). Based on this approach, about $5 \%$ of the aircraft systems can be eliminated from further analysis. With the 757 and 767, about 400 MSIs were identified for each of the aircraft types.

After the relevant MSIs have been identified, the task group uses the MSG-3 logic diagram to identify proper preventive maintenance tasks. Once all MSIs and their maintenance tasks have been identified by each of the task groups, they are compiled in the Maintenance Steering Committee Proposal Document, which is submitted to the FAA Maintenance Review Board for review and approval. It should be noted that, up to this point, the FAA has had representation on each of the task groups and thus has done most of the review throughout the process. After FAA acceptance, this document, now referred to as the Maintenance Review Board Report, becomes the cornerstone for the airline maintenance.

\section{Maintenance Review Board}

The Maintenance Review Board (MRB) is the committee of FAA personnel responsible for the approval of the proposed maintenance requirements submitted by the industry Maintenance Steering Committee. The Maintenance Review Board Report for the specific aircraft type is developed by the FAA based on its review, analysis, and revision of the MSC Proposal Document. The MRB is chaired by an FAA Airworthiness Specialist in the controlling region. MRB members are FAA Principal Maintenance/Avionics Inspectors that are assigned to various airlines and thus have experience with maintenance regulations and requirements.

Members of the FAA Maintenance Review Board are the FAA representatives who observed the task groups that developed the Maintenance Steering Committee Proposal Document. MRB members, while observing the task groups, are responsible for providing the MRB chairmen with regular progress reports, thereby prompting early awareness of potentially controversial items.

Because of this early involvement of the FAA in the development of the MSC Proposal Document, the approval 
process is much faster for both the manufacturers and the FAA.

The document generated by the MRB entitled "Maintenance Review Board Report; Requirements-Scheduled Maintenance Program" outlines the initial maintenance requirements as approved by the FAA for systems, power plant, structures, and zones for a specific type of aircraft operated by U.S.-certificated operators. It is the intent that each operator develop a complete maintenance program within the framework of the requirements that is compatible with their own basic maintenance philosophy. The FAA does not require any specific form of maintenance program.

The MRB report provides both guidance to the air carrier in the preparation of the original Operations Specifications relating to maintenance and guidance to the FAA inspector in the approval of those Operations Specifications. Based on operating experience, each operator can negotiate with the FAA Certificating Region for any alteration of or deviation from the requirements in the MRB report.

In addition to the MRB report, the aircraft operators also receive a Maintenance Planning Data (MPD) document from the manufacturer that includes the MRB report requirements as well as other nonmandatory maintenance items. Recommendations on certain lubrication activities and other nonscheduled activities are detailed in this document.

\section{Designated Engineering Representatives}

While the aircraft is in the design phase, one of the key positions used by the FAA is that of the Designated Engineering Representative (DER). The Designated Engineering Representative is an example of the cooperative approach between the FAA and the manufacturer. In this case, the FAA uses a senior engineer, employed by the manufacturer, to certify that the new airline design meets FAA regulatory standards. The DERs are responsible for ensuring that all regulations (CFR, 1988, 14:25) applicable during the design of a new aircraft are satisfied. DERs are required to have 8 years of experience, 4 of which may be engineering school or other educational time. Some DERs have up to 15 or 20 years of experience. Few DERs are above the level of first line supervisory management. The exception to this is the "Master DER" who performs administrative functions for projects allocated entirely to DERs. With the design of any new aircraft, a number of DERs are used by the FAA, specializing in areas such as hydraulics and avionics. Individuals are nominated by the manufacturer but must be appointed by the FAA regional director based on their professional qualifications and experience.
The DER system has a number of obvious advantages for the FAA. It allows the agency to substantially increase the number of examining engineers with a high level of expertise. DERs have a state-of-the-art knowledge of the field and day-to-day familiarity with the particular systems that are unlikely to be found in the FAA. The FAA does not have the resources or the manpower to accomplish such an extensive review without the use of Designated Engineering Representatives.

In the design of a large commercial aircraft such as the 757 or 767 , several hundred thousand engineering drawings and reports are developed. It is the responsibility of the appropriate DER to review and approve the final assembly drawings. The DER, though, can delegate review responsibilities to other persons in his specialty area.

The principal benefit the manufacturer realizes from the DER system is the flexibility of maintaining the aircraft design schedule. As an employee of the manufacturer, the DER is available to review the design as the schedule requires. Without such a system there could be potentially costly delays awaiting FAA review.

The FAA makes use of the dual role concept in other places. For example, after the FAA has awarded the Product Certificate for a given aircraft, Designated Manufacturing Inspection Representatives (DMIRs), under the supervision of the FAA, are responsible for ensuring that ongoing quality control is present during the manufacture of the aircraft (Matteson et al., 1984). The DMIRs work full time as representatives of the FAA ensuring that the aircraft are being constructed according to FAA regulations.

The "dual" role that the DERs play has raised concerns on numerous occasions when it has been suggested that the use of DERs does not foster objectivity and there is a conflict of interest for the DER. In a review of the FAA certification process prepared for the Secretary of Transportation after the American Airlines DC-10 crash in Chicago in 1979, the committee concluded that the DER position should continue to be used (NAS, 1980). In the report a number of checks and balances were cited for objectivity throughout the DER process:

- All three segments of the air transportation system-the manufacturer, the airlines, and the FAA-are concerned with safety.

- Engineers are motivated to maintain their reputation for technical integrity and professionalism.

- Because of the great concern of the manufacturer in producing a safe plane, the design review function would be performed by the manufacturer even without the DERs. 
- The DER is under supervision of FAA staff.

- The FAA assigns to its own staff the most critical design decisions and approvals (e.g., all fault-type safety analyses, the witnessing of all major tests, all major flight testing, and the aircraft flight manual).

\section{FLIGHT STANDARDS AND AIRLINE MAINTENANCE PROGRAMS}

After an operator begins to fly an aircraft, the responsibility for the verification that the aircraft is operated and maintained in a safe and airworthy manner becomes the responsibility of the FAA Flight Standards Branch. As shown in Figure C.2, the FAA and the aircraft manufacturer play major roles in the continual revision and improvement of an airline's maintenance program.

Maintenance programs are continually being changed. From the moment the program is developed, the airline, FAA, and manufacturer are involved in improving the program. This modification process and the interactions among the three organizations are depicted in Figure C.2. The airlines, in addition to continually assessing their own operational experience with the aircraft, also receive information from the manufacturer and FAA concerning recommended and required changes to their maintenance programs. As can be noted in Figure C.2, there is considerable interaction and information transfer among the three organizations. The following sections examine these interactions and the activities associated with ensuring that a commercial aircraft is maintained in a safe, economical, and airworthy condition.

The first section describes the development of airline maintenance programs. The maintenance data reporting systems that have been developed to assist in the identification of any necessary program modifications are reviewed in the second section. The third section provides information on the principal activities associated with the implementation and improvement of the maintenance program. The fourth section highlights the major activities associated with airline maintenance programs. The specific activities examined are:

1. FAA Inspections

2. Airline Maintenance Personnel Activities

3. Maintenance Management

4. Engineering Support

\section{Airline Maintenance Program Development}

The regulatory basis for approval of airline maintenance programs is contained in Federal Aviation Regulations
(FAR), Part 121 (CFR, 1988, 14:121). The regulations describe general rules governing the certification and operations of air carriers. Advisory Circular 121-1A (FAA, 1978 ) is based on these regulations and prescribes maintenance practices and methods that can be used to determine initial overhaul time limits and periodic inspection frequencies for individual airlines. These practices and methods are used to establish inspection intervals and overhaul times and to formulate an airline's approved maintenance program. They are referred to as Operations Specifications-Maintenance. Operations Specifications-Maintenance "are issued to supplement air carrier and air taxi rules by listing authorizations and limitations that are not specifically prescribed by the regulations" (FAA, 1985). Operations SpecificationsMaintenance are usually used to develop individual airline maintenance programs. The maintenance program may be developed in accordance with the Operations Specifications-Maintenance detailed in Advisory Circular 120-17A, Maintenance Control by Reliability Methods, or an airline may choose to use the conventional form of operations specifications described in Advisory Circular 121-1A (King, 1986).

Three maintenance processes, overhaul time limit or part-life limit, on-condition maintenance, and condition monitoring, have traditionally formed the basis for analyzing operational and maintenance requirements of aircraft (King, 1986). The MSG-3 that employs a consequence of failure approach and is based on reliabilitycentered maintenance has been used in the development of inspection schedules for large commercial aircraft such as the 757 and 767 .

The FAA requires the airlines to perform aircraft corrective maintenance, preventive maintenance, inspections, and repairs. It also requires the airlines to develop or adopt a continuous airworthiness maintenance program. That program and related practices and procedures can be adjusted to best suit the airlines' needs (King, 1986).

Certification of an airline's maintenance program requires FAA approval of the airline's maintenance manuals and materials. Regulations pertaining to the establishment of maintenance manuals for commercial air carriers are contained in FAR Parts 91, 121, and 135 (CFR, 1988, $14: 91,121,135)$. The maintenance, preventive maintenance, and alterations program requirements are provided in FAR Part 121. FAR Part 121.367 states that:

Each certificate holder shall have an inspection program and a program covering other maintenance, preventive maintenance, and alterations that ensures that- 


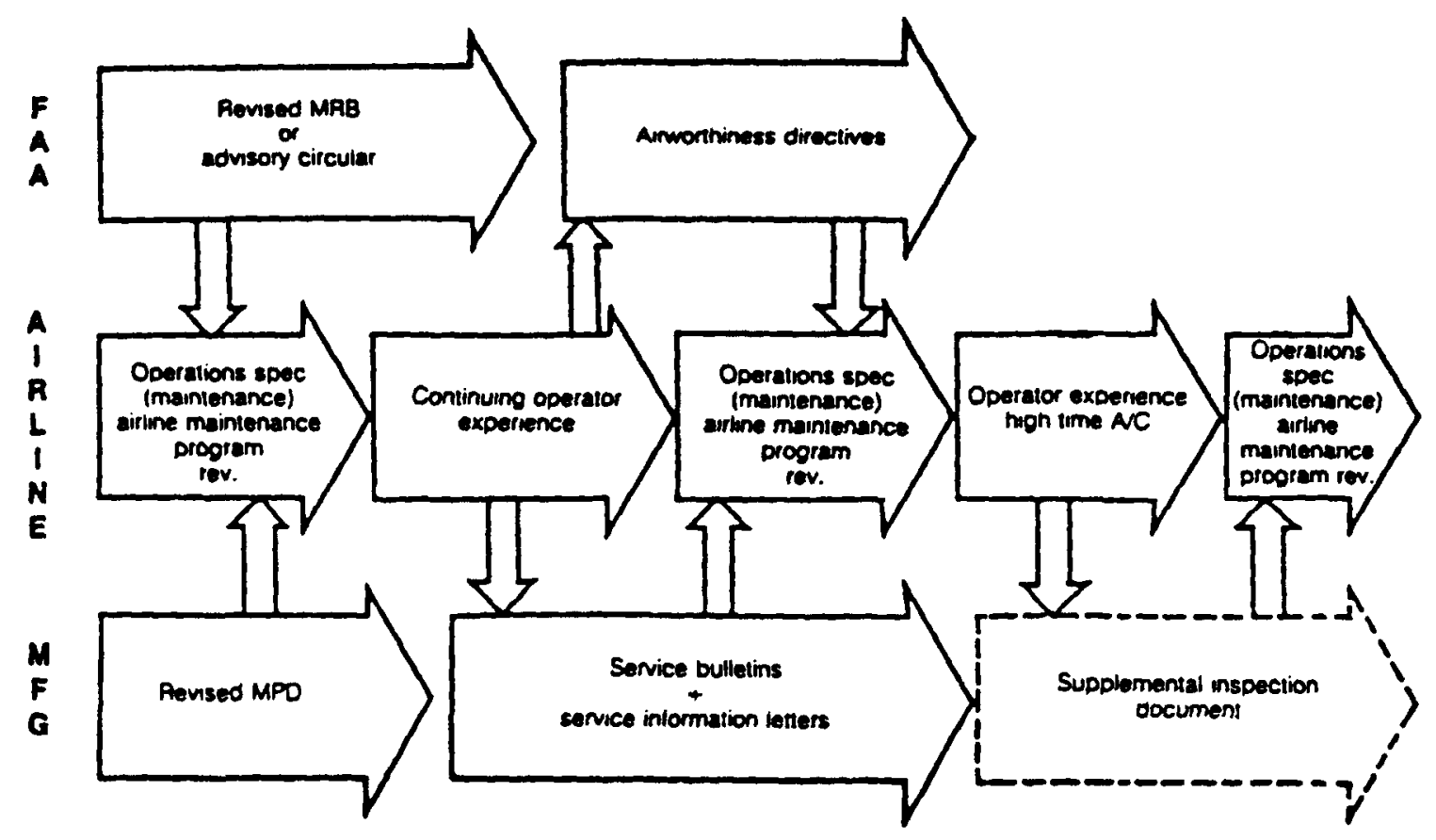

Figure C.2. Ongoing maintenance program (King, 1986).

(a) Maintenance, preventive maintenance, and alterations performed by it, or by other persons, are performed in accordance with the certificate holder's manual;

(b) Competent personnel and adequate facilities and equipment are provided for the proper performance of maintenance, preventive maintenance, and alterations; and

(c) Each aircraft released to service is airworthy and has been properly maintained for operation under this part (CFR, 1988, 14:121.367).

The maintenance manual requirements are specified in FAR Parts 121.369 and 135.427 for commercial aircraft with more than 10 passenger seats (CFR, 1988, 14:121.369, 135.427). In general: “The operator's maintenance manual should provide policies, procedures and technical criteria in sufficient detail to assure that the requirement of the FARs are fully met" (FAA, 1985). This includes the following:

- A total explanation of the maintenance manual system as well as general policies and administrative procedures.
- A section describing the inspection program in detail. This includes the following:

- Procedures for program scheduling,

- Recording accountability for continuing accomplishment and for program revision,

- Copies of the work forms and schedule of maintenance/inspection intervals, and

- Reference instructions for methods, techniques, and practices and for standards, tools, and equipment for accomplishment of the maintenance/inspection tasks.

- A chart or description of the operator's organization and points of contact within the organization.

- Clear references for the entire manual system.

In addition to the airline maintenance program itself, other related maintenance program requirements are evaluated by the FAA prior to maintenance program certification, as outlined in FAR Part 121 (CFR, 1988, 14:121). This includes FAA evaluation of the specific needs of the operator in terms of its operating philosophy, 
organizational structure, recordkeeping practices, statistical and data processing measures, and the airline's program for corrective action (FAA, 1978).

Approved reliability programs are also required by FAR Part 121 (CFR, 1988, 14:121). The reliability programs provide a set of rules and practices for managing maintenance processes throughout the operator's maintenance organization. Some of these processes are specifically designed to accommodate an airline's management needs (King, 1986).

Airlines are required by FAR Parts 121 and 135 to implement a continuing analysis and surveillance program. Sections (a) and (b) of FAR Part 121.373 state that (CFR, 1988, 14:121.373):

(a) Each certificate holder shall establish and maintain a system for the continuing analysis and surveillance of the performance and effectiveness of its inspection program and the program covering other maintenance, preventive maintenance, and alterations and for the correction of any deficiency in those programs, regardless of whether those programs are carried out by the certificate holder or by another person.

(b) Whenever the Administrator finds that either or both of the programs described in paragraph (a) of this section does not contain adequate procedures and standards to meet the requirements of this part, the certificate holder shall, after notification by the Administrator, make any changes in those programs that are necessary to meet those requirements.

The purpose of such a program is to establish a quality assurance or internal audit function. Airlines collect data on maintenance and reliability characteristics from various formal and informal in-house reporting systems such as unusual flight incident reports, malfunction reports, maintenance information systems, flight logs, shop cost, operations reports, and other measures (NAS, 1980).

According to the National Aviation Safety Inspection Program (NASIP), an acceptable continuing analysis and surveillance program should do the following (National Transportation Safety Board, 1987):

1. Audit the frequency of unscheduled parts replacement or need of unscheduled maintenance.

2. Audit the degree and frequency of adjustment and calibration of equipment.

3. Audit all publications and work forms for currency and ready availability to the user.
4. Ensure that maintenance is in fact performed in accordance with methods, standards, and techniques specified in the operator's manual.

5. Ensure that maintenance forms are screened for completeness and proper entries, including Required Inspection Item (RII) identification.

6. Ensure that records pertaining to tracked components are cross-referenced to stock issue records in order to minimize errors.

7. Audit all training program requirements.

8. Ensure that the quality of fuel is in accordance with carrier's manual.

9. Ensure compliance with all Airworthiness Directives.

10. Audit all repair agencies and vendors.

11. Ensure compliance with carrier's reliability program.

12. Ensure compliance with requirements of approved operations specifications.

The airline is also required by the FAA to establish minimum equipment lists (MELs) as part of its maintenance reliability program. MELs stipulate the components that are not required to be functioning when an aircraft departs until the aircraft may make repairs at a maintenance base (Wallich, 1986). MELs are similar to nuclear power plant technical specifications that refer to operability requirements on essential equipment (Matteson et al., 1984). The levels and types of criteria for continued flight with faulty or inoperable equipment vary because of differences among airline maintenance programs and operational requirements such as scheduled maintenance overhauls and the location and availability of maintenance facilities wherever the aircraft is located along its route.

Airlines are required to submit reliability and significant event reports to the FAA on a regular basis. Reporting requirements of the FAA-approved maintenance reliability program include daily Mechanical Reliability Reports (MRRs), which are sent to their assigned FAA maintenance inspectors. These reports cover 16 types of aircraft failure, malfunction, or defect (NAS, 1980). Airlines are also required to submit Mechanical Interruption Summaries (MISs), listing the causes of all mechanical difficulties that result in flight delay or cancellation (NAS, 1980).

\section{Maintenance Data Reporting Systems}

The proper collection, storage, and analysis of maintenance-related plant information is essential in any 
complex technological environment. Most airline maintenance information systems separate the reporting of critical events from the reporting of routine statistics. Proper design of these systems also ensures that critical events that require individual attention are directed immediately to someone who can take responsive action (Matteson et al., 1984). This design includes "real-time" discussion between pilots and station mechanics, if necessary. Analysis of data collected on a frequent industrywide basis, such as daily airline Maintenance Reliability Reports and Maintenance Interruption Summaries, contributes to quick responsiveness within the industry (NAS, 1980).

Information systems within the airlines and the manufacturers are fairly comprehensive. This is attributed to reliability and maintenance data collection methods developed primarily during the last 25 years, FAR criteria for maintenance program development, and the transfer of information between manufacturers and the airlines.

Inservice reliability management is mandated by FAR Part 121 and requires that each airline maintenance program develop an in-house reliability management program that audits and surveys its quality control through the use of internal and external reporting services and information systems. Inservice reliability management permits each airline to develop and operate a program suited to its particular needs. The program is monitored by the FAA (CFR, 1988, 14:121). This regulatory flexibility facilitates unique operational requirements while maintaining industry standards.

Once the aircraft is in use, the airlines, the manufacturer, and the FAA track equipment performance to justify changes to the maintenance program. The airline industry uses the following methods to track aircraft fleet reliability (Robertson, 1986):

1. Service history and operating experience based on information provided from the airlines and repair shops to the manufacturer and the FAA.

2. Onsite presence of manufacturer field representatives and FAA inspectors.

3. Use of reliability statistics-shop visit, removal, and in-flight shutdown rates.

4. Engineering analyses of parts used in service.

Several processes are used to notify the airlines and take corrective action when problems are encountered in service by the above reliability tracking methods. These are (Robertson, 1986):

- All-operator correspondence-advisories and recommendations. Telegrams, facsimile, telephone, or letters are used to alert operators to the problem area. These communications are then followed with recommended action.

- Service Bulletins-specific recommendations by manufacturer on maintenance procedures or hardware improvements. For example, if there is a service problem that requires a new periodic inspection technique, the service bulletin will tell the operator when and how to do it.

- Airworthiness Directives (ADs)-mandatory changes issued by the FAA on maintenance procedures or hardware improvements. These are usually based on service bulletins as service difficulties develop, or they are based on accidents or incidents that pose fleetwide safety implications.

- Revisions to manuals-the manufacturer will regularly send updated pages to add to their official maintenance manuals.

- Industry meetings-convened to address specific problems and update procedures.

Based on discussions with Boeing representatives, four data reporting systems were identified as in use by Boeing to track and assess aircraft reliability factors. These include the Structural Significant Inspection Program, the Significant Item Reporting System, the Engine Data System, and the Component Removal Data System.

The ability of the FAA to achieve full access to in-house airline maintenance data bases and information provided by the airlines to the manufacturer are limited by proprietary rights, confidentiality between the airline and the aircraft manufacturer, and their concerns regarding the disclosure of information. Thus maintenance information systems are well developed within the industry, but their distribution throughout industry is relatively limited. The FAA is currently developing an automated informationgathering and data base system. This would include access to airline and manufacturer records (Voelcker, 1986).

\section{Maintenance Program Modifications}

As a new aircraft is used and experience is gained, the FAA-approved scheduled maintenance requirements are subject to change. These changes can come from the manufacturer, the FAA, or the airlines. Maintenance programs establish the time limitations or standards for determining overhauls, inspections, and checks of airplanes, engines, and appliances. These limitations and standards have been subject to continued change as technological advances in airframe, engine, and equipment design occur and knowledge about the effectiveness of preventive maintenance is gained (King, 1986). 


\section{Airline Modifications to Maintenance Program}

Airlines can initiate changes in their maintenance inspection schedules through negotiations with the FAA. These are based on specific operating experience data or engineering studies. Subject to FAA approval, a change applies specifically to the airline requesting it. Changes to an airline's maintenance program are not generalizable to other airlines since each operates in a different environment (i.e., unique environmental and operating conditions and aircraft characteristics).

In order to change a program from the minimum maintenance requirements described in the MRB document, an airline must show, based on its own operational performance reliability records, that such a change is warranted. Performance records typically include the following: engine shutdown and removals; component removals and verified failures; system level delays and cancellations; chronic aircraft systems (repeated corrective maintenance actions on a system or system component in a specific airplane); and engine performance (in-flight operation performance determined from readings of engine instruments) (Matteson et al., 1984).

\section{Manufacturer Modifications to Maintenance Program}

As shown in Figure C.2, the manufacturer provides the airline operator with information concerning modifications to the recommended maintenance activities described in the Maintenance Planning Document. The airline provides the manufacturer with reliability and maintenance findings on its aircraft. When a problem arises (for example, structural damage is detected that requires changes in maintenance procedures), the manufacturer will issue a fleetwide Alert Service Bulletin if the problem has fleetwide implications for safety. The Alert Service Bulletin is also routinely sent to the FAA regional office (NAS, 1980). Airlines usually respond immediately to Alert Service Bulletins. However, they are not legally required to do so, nor are they required to report the completion of work to the manufacturer or to the FAA (NAS, 1980).

\section{FAA Oversight}

The FAA makes a substantial effort to accommodate the economic and operational requirements of airlines in light of maintenance requirements at all stages of the aircraft's life cycle. FAA inspectors generally work closely with the airlines to establish workable and viable solutions to problems related to manufacturing standards, flight certification, the development of a maintenance program, and flight standards. Onsite presence of FAA inspectors allows continued monitoring and response.

When a condition has been verified as a safety-significant problem, the FAA develops an Airworthiness Directive
(AD). The $\mathrm{AD}$ is designed to correct unsafe conditions revealed by service experience. $A D$ material is prepared by the FAA engineering and manufacturing offices directly in charge of the technical data file on the particular aircraft model. The Aircraft Certification Division or Office coordinates the proposed $\mathrm{AD}$ with the manufacturer (FAA, 1985). Proposed ADs are coordinated with the appropriate regional office maintenance personnel.

The $\mathrm{AD}$ is the primary vehicle by which the FAA mandates fleetwide inspection and repair changes. For example, Airworthiness Directive 84-21-06 was issued by the FAA in 1984 to require operators with high-cycle aircraft to modify their examinations of significant structural items by adjusting the frequency and method of structural fatigue and corrosion inspection. The $\mathrm{AD}$ required aircraft that have exceeded 37,500 flight cycles by April 30, 1983 , to be included in the significant structural items inspection program (Haueter, 1988). This program supplements the operator's existing approved continuous structural inspection maintenance program to identify cracks, corrosion, and other forms of structural damage.

\section{Airline Maintenance Activities}

The following sections highlight the major activities associated with airline maintenance programs.

\section{FAA Inspections}

To ensure that aircraft are maintained and operated in an airworthy condition, the FAA has three types of inspectors. These are the Principal Maintenance Inspectors (PMIs), the Principal Avionics Inspectors (PAIs), and the Principal Operations Inspectors (POIs). The FAA surveys airline maintenance programs through the use of Principal Maintenance Inspectors and Principal Avionics Inspectors. Their primary maintenance inspection duty is to determine the adequacy of personnel and facilities at any base, terminal, or intermediate stop along routes flown by an airline at which maintenance is to be performed on its aircraft (King, 1986).

Inspectors are assigned to one or more airlines; the number of inspectors depends on the size and specific operations of the airline and its fleet. For example, there may be one PMI assigned to several small airlines or several PMIs assigned to a major airline.

Maintenance spot checks and aircraft ramp inspections are used to determine the quality of an airline's maintenance program and degree of compliance with established maintenance standards and procedures. Maintenance spot checks are the primary inspection activity. These involve observations and analyses of a maintenance program's compliance with specified methods, including techniques, practices, personnel procedures, and facility operations. Inspection of an airline maintenance program pursues the following questions: 
- Are publications and work forms current and available for use?

- Is maintenance performed in accordance with the methods, standards, and techniques specified in the operator's manual?

- Are maintenance forms screened for completeness and proper entries?

- Are records pertaining to tracked components crossreferenced to stock-issue records, etc., to minimize errors?

- Are there indications of inadequate training?

- Are airworthiness releases executed by designated persons and in accordance with the procedures specified in the operator's manual?

- Are carryover items and deferred maintenance items properly handled?

Reviewing an airline's maintenance system also includes review of maintenance job records. Conducting reviews or spot-checking actual work in progress depends upon methods and procedures determined by the respective inspectors (NAS, 1980). Maintenance spot checks should be performed for scheduled aircraft, shop activities, and contractors and subcontractors who perform related work, including a determination of their respective accountability and responsibilities (King, 1986).

The inspectors are supported by the use of other surveillance activities. First, FAA inspectors at airports along the airline route perform ramp (in-service) inspections of the aircraft to evaluate its apparent condition and routine servicing. Second, audit-type inspections (situation monitorings) are conducted in limited cases, notably where the regional office becomes aware of specific safety problems. Third, the FAA uses a formal system for reporting and reviewing accidents, incidents, and service difficulties (NAS, 1980).

FAA inspectors analyze data that the airlines provide daily, such as Maintenance Reliability Reports and Mechanical Interruption Summaries. If problems in maintenance or operations are detected, the information is converted to Service Difficulty Reports (SDRs) and forwarded to the FAA Maintenance Analysis Center in Oklahoma City, where it is included in an industrywide analysis (NAS, 1980).

There are differences in the practices of FAA inspectors, especially regarding the frequency and amount of direct observation of aircraft maintenance activities. In a review of five district offices, inspectors spent about 80 percent of their time doing something other than inspections.
Manpower shortages contribute to this problem (Golich, 1988). However, the FAA has implemented a plan to increase the inspector workforce and support personnel by a total of 500 over FYs 1986, 1987, and 1988 (U.S. Congress, 1986).

The duties of the FAA inspector depend somewhat on the nature of the airline and its routine maintenance operations. For instance, reports from mechanics may show inspection documents apparently in order that do not reflect the true state of the aircraft (Wallich, 1986). Thus hands-on inspection is a vital characteristic of enforcing flight standards.

Inspectors should have firsthand familiarity with maintenance activities around the clock. This requires that inspectors are provided with sufficient tools and knowledge to perform their work, such as access to airline service computers and their own computer systems, ongoing training on new aircraft, attendance at annual conferences on issues of concern, trend analysis through the use of maintenance-related information both onsite and fleetwide, and access to statistical data (NAS, 1980).

\section{Airline Maintenance Personnel Activities}

Airline maintenance personnel are an especially critical link in the flight standard process. Accordingly, their skills and training should be appropriate to the highly complex nature of aircraft maintenance. FAR Part 65 describes specific skill, experience, and inspection requirements for maintenance and other air industry personnel (CFR, 1988, 14:65).

The training and experience requirements of airline maintenance personnel are usually fulfilled by completion of a certificated aviation maintenance technician program. The training should be equally divided between classroom and hands-on instruction. Experience requirements are satisfied through completion of courses at certificated aviation maintenance technician schools, or satisfactory evidence of practical experience in the construction, maintenance, or alteration of aircraft or power plants. This includes oral and practical skill tests to determine the applicant's suitability based on experience (Richardson and Rodwell, 1985).

The FAA certifies aircraft mechanics with airframe and/ or power plant $(\mathrm{A} \& \mathrm{P})$ licenses after the individual has passed written, oral, and practical tests for the appropriate area and rating. After review of supporting documents such as proof of training and satisfactory skill demonstration, the FAA will issue a certificate with the appropriate rating. All maintenance work must be signed by an individual with an appropriate license. Mechanics currently obtain ratings and remain perpetually licensed regardless of subsequent work experience, training, or changes in their qualifications (NAS, 1980). In general, certified aircraft mechanics must satisfy the following requirements for FAA: 
- Perform work with demonstrated proficiency to the FAA, or accomplish the work under supervision of certified mechanic.

- Understand current instructions of the manufacturer and the maintenance manuals for specific operations.

- Have experience within previous 24 months that demonstrates task proficiency, or within previous 6 months that demonstrates the mechanic has supervised, in executive capacity, the maintenance or alteration of aircraft.

Inspection authorizations are issued to aviation mechanics who demonstrate experience and responsibility for approving finished work. The following requirements cited in FAR Part 65.91 hold that an applicant in order to gain an inspection certification rating must:

- Hold current mechanic certificate with both an airframe and power plant (A\&P) rating, effective for at least 3 years.

- Have been actively engaged for at least 2 years before application in maintaining certificated aircraft.

- Have a fixed base of operations, not necessarily located where inspections will be conducted.

- Have necessary equipment, facilities, and inspection data to inspect airframes, power plants, propellers, or related parts and appliances.

- $\quad$ Pass a written test on ability to inspect according to safety standards for returning aircraft to service after major repairs, alterations, annual inspections, and progressive inspections (CFR, 1988, 14:65.91).

Inspection authorizations are renewed annually. They are renewed when the inspector demonstrates that during each 90 days of his term at least one annual aircraft inspection was performed; that inspections were performed of major repairs or alterations; and that the inspector performed or supervised and approved at least one progressive inspection in accordance with prescribed standards (Richardson and Rodwell, 1985).

Airline maintenance mechanics and inspectors are assisted by certified repairmen. Certified repairmen perform or supervise the maintenance, preventive maintenance, or alterations of aircraft and aircraft components appropriate to their qualifications and certification rating. Eligibility for certification requires employer recommendation, formal training, and 18 months of practical experience. Certified repairmen may perform condition inspections in accordance with the operating limitations of the aircraft.
Advances in airplane technology have the greatest individual impact on maintenance activities. For example, the rapid change in cockpit display design from analog to digital instruments has been a mixed blessing for operations and maintenance; the instruments are far more reliable than their analog counterparts. However, they require entirely different maintenance and troubleshooting procedures and are usually more complex and demanding analytically (Wallich, 1986). Thus training orientation, methods, and subject area are driven by technological change.

Responsibility for training in a particular airline maintenance program resides with the airline. United Airline's program, for example, has a comprehensive training program commensurate with its fleet size and diversity of operations. Maintenance training programs vary substantially in the airline industry. Training programs within the industry are derived from specific Operations Specifications-Maintenance requirements within each airline. However, every airline maintenance training program must adhere to training and certification requirements outlined in FAR Part 65 (CFR, 1988, 14:65).

One example of a substantive maintenance training program in the airline industry is United Airlines (United Airlines Maintenance Operations Training, 1986). The maintenance training organization identifies and analyzes training needs; plans, develops, schedules, and provides cost-effective formal classroom and practical training for personnel in aircraft maintenance, ground equipment maintenance, and aircraft-related station operations; and evaluates and assesses the quality and effectiveness of the training product.

Because of the variety of airline flight and maintenance operations, training programs also vary substantially in organizational structure, operations, and quality. The FAA is currently addressing airline maintenance training program requirements industrywide.

\section{Maintenance Management}

The organization of maintenance within commercial airlines can take a variety of forms based on the size and regional distribution of the airline (King, 1986). There are several parallels to the nuclear industry, however, that are worthy of note.

First, maintenance, as a function, is essential to the successful operation of the airline both in terms of business and regulatory considerations. Accordingly, maintenance is at the center of a successful airline organization. For example, the Senior Vice President for Maintenance at United Airlines ranks as high in the organization as the heads of the other business functions (e.g., marketing/ sales).

The maintenance organization can be dispersed geographically with line maintenance (at the terminal), han- 
gar maintenance (at selected airports), or centralized fleet maintenance (at one or more maintenance centers). More extensive maintenance and modifications may also require involvement of the manufacturer.

Within the maintenance organization, there typically reside units responsible for aircraft and engine maintenance, maintenance planning, supply, training, ground support equipment, document control, and maintenance facilities (King, 1986). In some airlines, engineering is integrated into the maintenance department. In others, it constitutes a separate department. Quality control is a highly developed function and, as in nuclear power plants, is separated in the organization from the actual conduct of maintenance.

\section{Engineering Support}

The relationship between the manufacturer and the airline is an important aspect of the continued improvement of maintenance programs. Boeing, McDonnell-Douglas, and Lockheed have product support departments that monitor the use of their equipment and provide assistance to the owners regardless of how often the equipment changes hands. The underlying rationale is that the performance of one aircraft reflects on all others from that manufacturer (NAS, 1980). Manufacturer representatives are assigned to an airline prior to delivery of the aircraft. They assist the airline with engineering and maintenance advice, provide training when necessary, serve as a point of contact with the manufacturer, and report to their parent company on matters of technical significance (NAS, 1980). Product support from the manufacturer is ensured through the use of guarantees and warranties provided to the airlines. These allow for the correction of design deficiencies in a timely fashion and provide spare assemblies when pre-established limits are surpassed (such as mean time between unscheduled removal).

Guarantees support the airline's economic requirements. In turn, airlines return defective assemblies and collect data concerning product improvement. Guarantees ultimately enhance and refine the airline's maintenance program. For example, Boeing has developed an inspection program to check its aircraft fleet for structural fatigue. The program includes development of supplemental inspection documents (SIDs). In this instance, Boeing acts as a clearinghouse for statistical data, inspection requirements, and information about problems with hightime aircraft. Inspection intervals of aging aircraft are negotiated by the airlines and the regulatory agencies of individual countries (Ott and O'Lone, 1988).

\section{SUMMARY}

This report examined the principal activities and regulations associated with the development and implementa- tion of civil aviation maintenance programs. The NRC, in the final Commission Policy Statement on Maintenance of Nuclear Power Plants (53 FR 9430), identified a number of areas considered as necessary parts of a nuclear power plant maintenance program. The following is a summary of the maintenance-related activities conducted by the airlines and the FAA related to these areas.

- Technology in the areas of corrective, preventive, and predictive maintenance. A Maintenance Review Board Report is created for each new type of aircraft released. A scheduled preventive maintenance program is presented in this report and becomes the FAA-required basis for the airlines maintenance program. The document lists what specific maintenance inspections are required and is based on a number of reliability studies conducted by the manufacturer. The goal is to locate and correct problems before they occur.

- Engineering support and plant modifications. Designated Engineering Representatives (DERs), employed by the manufacturer and approved by the FAA, are used throughout the aircraft design process to ensure that the aircraft satisfies FAA engineering standards.

- Quality assurance and quality control. Quality is ensured, in part, by DER and DER-type positions where the FAA relies on manufacturing personnel with state-of-the-art knowledge to help in regulation. The FAA requires airlines to have internal quality control and audit functions that are monitored by the FAA. The FAA inspectors also provide a QA role to ensure that the aircraft is maintained in a safe and airworthy manner.

- Equipment history and trending. Regular reports are required from the airlines on function failures, other aircraft problems and delays, or incidents during operations. In addition, for a change of the maintenance inspection intervals contained in the MRB report to be accepted by the FAA, the airlines must show reliability and trending records for which the change is requested. Service history of aircraft is a critical aspect of aviation reliability and maintenance practices.

- Maintenance records. The generation and proper accounting and recording of maintenance records have a regulatory basis for formulation and use. These are used internally by manufacturer and airlines. The FAA inspects documents as part of a general inspection program.

- Procedures. The minimum maintenance requirements, as they are listed in the MRB document, must be included in a maintenance program that each airline drafts and submits to the FAA for ap- 
proval. Procedures for airline maintenance programs are developed by the FAA and the airlines based on Operations Specifications-Maintenance. Procedure development includes maintenance procedures, organizational reporting, inventory, and cost-accounting procedures.

- Post-maintenance testing and return-to-service activities. If a function is infrequently used or hidden from the operator, failure-finding tasks must be developed to detect problems. Minimum Equipment Lists (MELs) are used by the airlines and inspected by the FAA. MELs are similar to nuclear power plant technical specifications that refer to operability requirements on essential equipment. They are used to determine airworthiness of aircraft due to inoperable or out-of-service equipment. Return to service is approved by signoff on work by maintenance inspectors (airline) and FAA inspectors.

- Maintenance management and organization in the areas of planning, scheduling, staffing, and shift coverage. Maintenance generally holds an important and central position within the organization. The maintenance organization can be central or dispersed across the country depending on the individual airline. Within the maintenance organization there typically reside units responsible for maintenance planning, maintenance activities, training, support, and document control.

- Personnel qualification and training. All maintenance personnel are required to be trained and certified for duties. This includes aircraft mechanics, repairmen, and airline maintenance inspectors.

Based on analyses of the FAA's role in civil aviation maintenance programs, the following six points were considered as potentially useful factors to consider for the development of an NRC maintenance rule for nuclear power plants.

1. Maintenance Steering Group (MSG) process. The MSG process may represent a potentially viable method for the nuclear industry in the development of scheduled maintenance inspection requirements. The MSG is a process that lends itself to a variety of tasks. For example, in the airline industry, it has been used to develop maintenance requirements for both plane structures and engines and has been used by a number of different manufacturers.

2. Maintenance Review Board (MRB). A board similar to the FAA MRB provides a method for a regulatory agency to become involved in the creation of scheduled maintenance requirements early in the process.
The board is composed of FAA inspectors who are involved as observers in the MSG process where initial maintenance requirements are drafted. The MRB has final approval of the scheduled maintenance requirements. The board promotes early interaction with industry working groups leading to more timely decisions with input from all affected parties.

3. Designated Engineering Representative (DER). A DER-type position might be considered by the NRC to assist in the evaluation of maintenance regulatory compliance. The DERs are senior engineers employed by the manufacturer who report to the FAA. Their primary duty is to certify that manufacturing designs for the airframe, power plant, and avionics meet FAA regulatory standards. DERs make possible the timely review of documents, and they have increased the FAA's ability to monitor day-to-day operations during the design of new aircraft.

4. Maintenance program modifications. Airline maintenance programs are continually being reviewed and modified. The initial maintenance requirements for an aircraft are subject to change as new reliability data, fleetwide maintenance trends, and information from specific incidents become available.

5. Engineering support shared responsibilities. Modifications to maintenance programs involve interaction among the airlines, the FAA, and the manufacturers. The FAA accommodates unique airline maintenance program development based on specific operational requirements. The airlines work closely with the aircraft and parts manufacturers to provide reliability data on existing equipment. In turn, the manufacturers continue to make improvements in the equipment and the maintenance program, subject to FAA approval. This also reduces costs by reducing maintenance service requirements and increasing component reliability. Encouraging industry participation through onsite presence and exchange of information may be applicable to the nuclear industry.

6. Maintenance performance information systems. Data on fleetwide reliability, equipment maintenance techniques, and specific problems are well developed in the commercial aviation industry. Airlines, manufacturers, and the FAA use a variety of in-house and industrywide data analysis and reporting systems to enhance aircraft system reliability and safety through maintenance. Similar use of data in the nuclear industry may be useful to track maintenance reliability and performance. 


\section{REFERENCES FOR APPENDIX C}

Air Transport Association. 1980. Airline/Manufacturer Maintenance Program Planning Document, MSG-3.

Code of Federal Regulations (CFR). 1988. 14:25.

Code of Federal Regulations (CFR). 1988. 14:65.

Code of Federal Regulations (CFR). 1988. 14:91.

Code of Federal Regulations (CFR). 1988. 14:121.

Code of Federal Regulations (CFR). 1988. 14:135.

Federal Aviation Administration (FAA). 1978. "Aircraft Maintenance Handbook," Advisory Circular 121-1A, Washington, D.C.: U.S. Department of Transportation.

FAA. 1985. "Airworthiness Inspector's Handbook," U.S. Department of Transportation. Initiated by: AWS-300.

FAA. 1987. This is the FAA, Washington, D.C.: U.S. Department of Transportation.

Federal Register. March 23, 1988. 53:9430.

Golich, V. L. 1988. “Airline Deregulation: Economic Boom or Bust? Flight Safety Foundation," FSF Flight Safety Digest, 7(1):1-14.

Haueter, Thomas E. 1988. Maintenance Records Group Chairman's Factual Report, Washington, D.C.: National Transportation Safety Board.

King, F. H. 1986. Aviation Maintenance Management, Southern Illinois University Press.

Matteson, T. D., J. F. McDonald, and A. M. Smith. 1984."Commercial Aviation Experience of Value to the Nuclear Industry," Prepared by Los Alamos Technical Associates, Inc., for Electric Power Research Institute, NP-3364, Final Report, January 1984.
National Academy of Sciences (NAS). 1980. Improving Aircraft Safety-FAA Certification of Commercial Passenger Aircraft, Washington, D.C.: National Academy of Sciences.

National Transportation Safety Board. 1987. National Aviation Safety Inspection Program (NASIP) Airworthiness Findings, Washington, D.C.: National Transportation Safety Board, December 21, 1987.

Ott, J., and R. G. O'Lone. 1988. "737 Fuselage Separation Spurs Review of Safeguards," Aviation Week and Space Technology, pp. 92-95.

Richardson, J. D., and J. F. Rodwell. 1985. Essentials of Aviation Management, Dubuque, Iowa: Kendall/Hunt, 464 pp.

Robertson, W. 1986. Statement of William G. Robertson, Pratt and Whitney, United Technologies Corp., in Aging Commercial Airline Fleet, Hearing before the Subcommittee on Aviation of the Committee on Commerce, Science and Transportation, U.S. Senate, April 15, 1986.

United Airlines Maintenance Operations Training. 1986."Maintenance Operations Training," Information Sheet 355, October 1986.

U.S. Congress, House Subcommittee on Transportation, Aviation and Materials of the Committee on Science and Technology. 1986. Hearings, "Geriatric Aircraft: Aircraft Maintenance During an Era of Aging Commercial Fleets," 99th Cong., 2nd Sess. [No. 109].

Voelcker, J. 1986. "Gold-Plated Design," IEEE Spectrum, 23(11):56-66.

Wallich, P. 1986. "Keeping Them Flying," IEEE Spectrum, 23(11):69-75. 


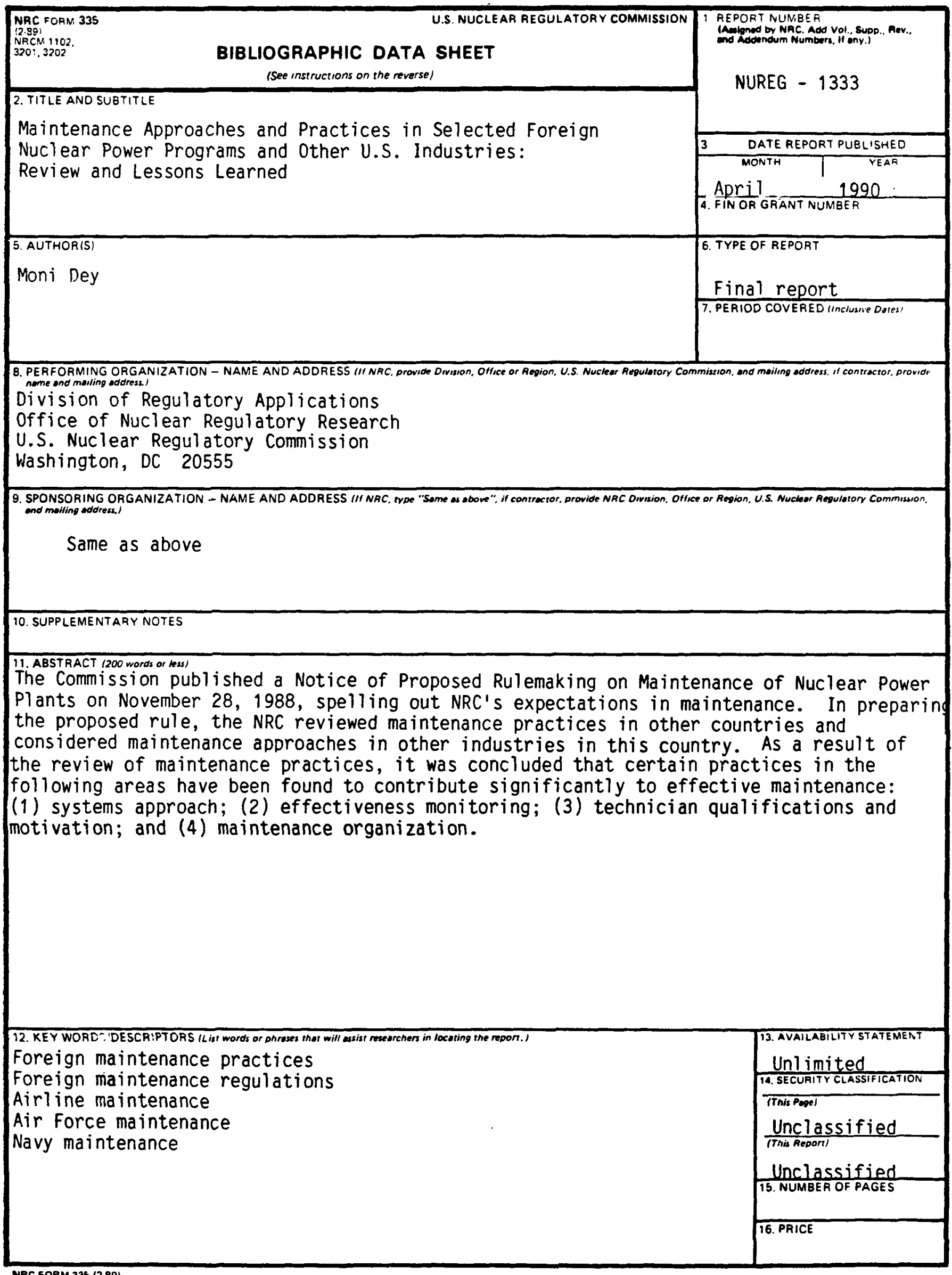

